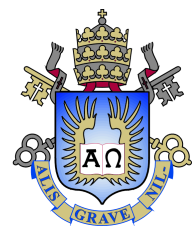

Renato Silveira Feitoza

\title{
Sensor RFID sem Chip Utilizando Estruturas Baseadas em Grafeno
}

Dissertação apresentada como requisito parcial para obtenção do grau de Mestre pelo Programa de Pós-graduação em Engenharia Elétrica do Centro Técnico Científico da PUC-Rio.

Orientador : Prof. Glaucio Lima Siqueira Coorientador: Prof. Marbey Manhães Mosso 

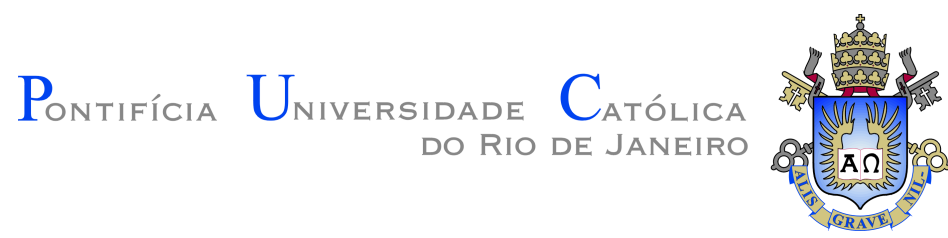

Renato Silveira Feitoza

\title{
Sensor RFID sem Chip Utilizando Estruturas Baseadas em Grafeno
}

Dissertação apresentada como requisito parcial para obtenção do grau de Mestre pelo Programa de Pós-graduação em Engenharia Elétrica da PUC-Rio. Aprovada pela Comissão Examinadora abaixo assinada.

\author{
Prof. Glaucio Lima Siqueira \\ Orientador \\ Centro de Estudos em Telecomunicações - PUC-Rio
}

Prof. Marbey Manhães Mosso

Coorientador

Centro de Estudos em Telecomunicações PUC-Rio

Profa. Úrsula do Carmo Resende Centro Federal de Educação Tecnológica de Minas Gerais

Profa. Maria Cristina Ribeiro Carvalho

Centro de Estudos em Telecomunicações - PUC-Rio

Dra. Gelza de Moura Barbosa

Marinha do Brasil

Prof. Márcio da Silveira Carvalho

Coordenador Setorial do Centro Técnico Científico- PUC-Rio 
Todos os direitos reservados. É proibida a reprodução total ou parcial do trabalho sem autorização da universidade, do autor e do orientador.

\section{Renato Silveira Feitoza}

Received his Bachelor Degree in Electronic Engineering (EE) in 2014, at the Federal University of Santa Catarina (UFSC). During undergraduate years, worked at the Integrated Circuits Laboratory (LCI/UFSC) and Radio-Frequency Research Group (GRF/UFSC). Took part in research projects related to printed antennas and radio-frequency circuits, with applications on energy harvesting and wireless sensors. Now, is a Master's Degree student in Applied Electromagnetics at the Pontical Catholic University of Rio de Janeiro (PUC-Rio), working at the Microcircuits and Microwaves Laboratory at CETUC (PUC's Center for Telecommunications Studies).

Ficha Catalográfica

Silveira Feitoza, Renato

Sensor RFID sem Chip Utilizando Estruturas Baseadas em Grafeno / Renato Silveira Feitoza; orientador: Glaucio Lima Siqueira; co-orientador: Marbey Manhães Mosso. - 2017.

v., 97 f: il. ; $30 \mathrm{~cm}$

Dissertação (mestrado) - Pontifícia Universidade Católica do Rio de Janeiro, Departamento de Engenharia Elétrica.

Inclui bibliografia

1. Sensores RFID sem Chip;. 2. Óxido de Grafeno Reduzido;. 3. Antenas baseadas em Guias de Onda Integradas em Substrato;. 4. Metamateriais.. I. Lima Siqueira, Gláucio. II. Manhães Mosso, Marbey. III. Pontifícia Universidade Católica do Rio de Janeiro. Departamento de Engenharia Elétrica. IV. Título. 


\section{Agradecimentos}

Dedico esta dissertação à minha companheira Bárbara Cristina Abrahão da Silva, pela paciência, apoio, e por todos os filmes do Oscar assistidos sozinha ao longo do desenvolvimento desta; e aos meus pais Kateucia Silveira e Adenilson Huller Feitoza, por todo o suporte e confiança de sempre.

Gostaria de aproveitar para agradecer ao meu orientador Gláucio Lima Siqueira por todo apoio ao longo do desenvolvimento desta dissertação, por toda a motivação fornecida pela sua fascinação pela teoria eletromagnética e áreas afins, e principalmente por ter acolhido a mim e a meus colegas quando da aposentadoria do meu primeiro orientador e atual coorientador. Gostaria de agradecer também a este mesmo coorientador, Marbey Manhães Mosso, por ter me recebido e orientado desde os primeiros dias na PUC-Rio, e por toda a imensa sabedoria e experiência compartilhada ao longo destes dois últimos anos.

Ao aluno de pós-doutorado do laboratório Van de Graaff (VDG) Eric Romani Cardona pela enorme contribuição dada a este trabalho, por ter acreditado em mim e nesta empreitada desde o início e por ter se empenhado lado a lado de forma a proporcionar todas as condições para que os resultados aqui obtidos pudessem ser alcançados. Também pelas espectroscopias Raman e de efeito fotoelétrico de raio x realizadas de forma a auxiliar na caracterização das amostras aqui fabricadas.

À professora Cecília Vilani do departamento de engenharia de materiais da PUC-Rio pelo apoio, pelo empréstimo das câmaras utilizadas para medição de vapor de álcool - fundamentais para realização dos testes de sensor - e pelas dicas relacionadas à preparação de óxido de grafeno e de polímeros em geral.

À aluna de pós-doutorado do VDG Stefania Nardecchia pela preparação das amostras de óxido de grafite, posteriormente diluídos em óxido de grafeno, e pela paciência em continuamente dividir conosco a estufa utilizada para redução das amostras.

Ao professor Lázaro Freire Jr., coordenador do VDG, pelo suporte e por colocar o laboratório à disposição para realização dos experimentos.

Aos colegas do Laboratório de Microcircuitos e Micro-ondas Juliana Carvalho, por ter me auxiliado sempre que precisei, antes de eu sequer ter colocado meus pés no Rio de Janeiro; Jorge Virgílio de Almeida, pelas conversas edificantes, inspiração e cumplicidade; Gidy Carolina Florez, pelas trocas de informação e conhecimento sobre antenas e eletromagnetismo em geral e pelo suporte na utilização do Lab-Volt; Jorge Mitrione, por todos o suporte fornecido em licenças de software e modelagem de vias no HFSS. 
Aos colegas do CETUC em geral, em especial ao Kinko Linden pela camaradagem nas madrugadas viradas resolvendo problemas de teoria eletromagnética, ao Marcelo Balisteri pelo suporte na confecção das placas, e ao seu Chiquinho, por toda a cafeína.

Ao professor Marco Cremona do Laboratório de Filmes Finos da PUCRio pelo empréstimo do medidor de resistência de filmes finos e seu aluno Harold Camargo pelo suporte na sua utilização.

Às doutoras Úrsula do Carmo Resende, Maria Cristina Ribeiro Carvalho e Gelza de Moura Barbosa por terem aceitado participar da banca de defesa de forma tão solícita e por suas contribuições ao trabalho.

Finalmente à FAPERJ que, apesar de todas as dificuldades, concedeu a mim a bolsa de fomento no programa mestrado nota 10 . 


\section{Resumo}

Silveira Feitoza, Renato; Lima Siqueira, Gláucio; Manhães Mosso, Marbey. Sensor RFID sem Chip Utilizando Estruturas Baseadas em Grafeno. Rio de Janeiro, 2017. 97p. Dissertação de Mestrado - Departamento de Engenharia Elétrica, Pontifícia Universidade Católica do Rio de Janeiro.

Estruturas baseadas em grafeno como óxido de grafeno (OG) e óxido de grafeno reduzido (OGr) vêm sendo amplamente utilizadas em aplicações de sensoriamento resistivo de gás. Entretanto, poucos projetos são efetuados utilizando métodos pervasivos e não intrusivos, que são importantes para aplicações onde intervenções podem ser problemáticas. Este trabalho apresenta a implementação de protótipos de sensores sem fio de baixo custo baseados na tecnologia de RFID sem chip, para sensoriamento de vapor de álcool, utilizando uma topologia de antena miniaturizada baseada em Metamateriais (MTMs) carregada com OGr. Simulações utilizando o método dos elementos finitos são efetuadas de forma a encontrar o melhor local para deposição das estruturas sensíveis ao vapor de álcool. É observado que a estrutura responde a variações de resistividade de OGr apenas para uma determinada faixa de valores. O tempo de redução térmica de OG necessário para atingir este espectro de valores é experimentalmente determinado, estando entre 60 e 90 min à $200^{\circ} \mathrm{C}$. Amostras de GO são fabricadas utilizando o método de Hummer modificado, e são depositadas nos gaps das antenas. Posteriormente, são reduzidas por 60, 75 e 90 minutos. O setup de medição consistiu em medições do coeficiente de reflexão em banda X. Após um determinado tempo para estabilização, álcool isopropílico e também etanol são colocados em contato com a amostra em um recipiente fechado por 1 h30, e a resposta foi observada. Resultados com sensibilidade de até $11,5 \%$ foram obtidos.

\section{Palavras-chave}

Sensores RFID sem Chip; Óxido de Grafeno Reduzido; Antenas baseadas em Guias de Onda Integradas em Substrato; Metamateriais. 


\section{Abstract}

Silveira Feitoza, Renato; Lima Siqueira, Gláucio (Advisor); Manhães Mosso, Marbey (Co-Advisor). Chipless RFID Sensor Using Graphene Based Structures. Rio de Janeiro, 2017. 97p. MSc. Dissertation - Departamento de Engenharia Elétrica, Pontifícia Universidade Católica do Rio de Janeiro.

Graphene oxide (GO) and reduced graphene oxide (rGO) based structures have been widely applied for resistive gas sensing applications. However, few projects are developed using pervasive and non-intrusive methods, which are important for applications where intervention can be an issue. This work presents the implementation of low-cost wireless sensor prototypes based on chipless RFID technology, for alcohol vapor sensing, by using a metamaterial (MTM) based miniaturized antenna loaded with rGO. Simulations are performed using finite element method in order to find the best place to deposit the alcohol vapor sensitive structures. It is observed that the structure responds to resistivity variations only for a determined range of values. The GO reduction time necessary to reach this spectrum of values is experimentally determined, and it is found to be between 60 and 90 min at $200^{\circ} \mathrm{C}$. GO samples are synthesized using a modified Hummer's method, and deposited in the gaps of the antenna structures. Later, they are reduced for 60, 75 and $90 \mathrm{~min}$. The measurement setup consists in reflection coefficient characterization at X band frequencies. After a stabilization time, isopropyl alcohol and ethanol are put in contact with the samples in a closed container for $1 \mathrm{~h} 30$, and the response is observed. Sensitivities up to $11,5 \%$ are obtained.

\section{Keywords}

Chipless RFID Sensors; Reduced Graphene Oxide; Substrate Integrated Waveguide Antennas; Metamaterials. 


\section{Sumário}

1 Introdução 18

2 Fundamentação Teórica $\quad 23$

2.1 Parâmetros Básicos de uma Antena 23

2.1.1 Impedância de Entrada 23

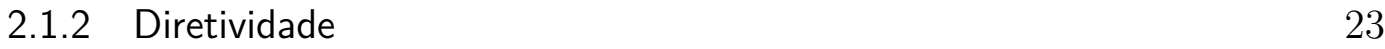

2.1.3 Eficiência e Ganho 24

2.1.4 Diagrama de Irradiação 25

2.1.5 Abertura Efetiva 25

2.2 Espalhamento de Antenas 26

2.2.1 Relação entre RCS e Ganho de uma Antena 26

2.2.2 Modo Estrutural e Modo Antena 27

2.2.3 Estimativa do alcance de uma Etiqueta sem chip 29

2.3 Metamateriais e Linhas de Transmissão CED 30

2.3.1 Metamateriais 30

2.3.2 Linhas de Transmissão Puramente à Esquerda 32

2.3.3 Linhas de Transmissão Compostas à Esquerda e à Direita 34

2.4 Componentes e Antenas Baseados em Guias de Onda Integrados em Substrato $\quad 36$

2.4.1 Componentes GIS 37

2.4.2 Antenas baseadas em GIS 38

2.5 Estruturas baseadas em Grafeno 40

2.5.1 Introdução e Propriedades do Grafeno 40

2.5.2 Óxido de Grafeno e Óxido de Grafeno Reduzido 42

2.5.3 Síntese de OG e OGr 42

2.5.4 Espectroscopia Raman 43

2.6 Considerações finais do Capítulo 2

3 Projeto Sensores GIS: Abordagem Paramétrica 46

3.1 Sensor de Gás sem Fio em Substrato Rogers RT5880 46

3.1.1 Condição de Contorno de Circuito Aberto 46

3.1.2 Condição de Contorno Curto-Circuito 51

3.2 Sensor de Gás sem Fio em Substrato FR4 Utilizando OG e OGr 54

3.3 Simulações Antena + OG/OGr 60

3.4 Resultados Experimentais 64

3.4.1 Ensaio para caracterização do sensor de vapor 68

3.5 Considerações finais Capítulo $3 \quad 71$

4 Projeto Sensores GIS em FR4 utilizando OGr $\quad 72$

4.1 Projeto da Guia de Onda Integrada em Substrato 72

4.2 Projeto das Antenas GIS Condição de Contorno Aberta 77

4.3 Antenas GIS com Condição de Contorno Curto-Circuito 78

4.4 Simulação e Caracterização Experimental das Estruturas como Sensor 83

4.5 Caracterizações Sensor de Vapor 88 
5 Conclusão e Trabalhos Futuros

Referências bibliográficas 


\section{Lista de figuras}

2.1 Definição do sistema de coordenadas utilizado como referência neste trabalho.

2.2 Exemplo de diagrama de irradiação direcional. 25

2.3 Diagrama $\epsilon$ - $\mu$ ilustrando as classificações dos materiais. 31

2.4 Células unitárias básicas de metamateriais (a) dipolos de fio e (b) ressonadores de anel cortado (RACs). 32

$2.4(\mathrm{a}) \quad 32$

2.4(b) 32

2.5 Células unitárias complementares de metamateriais (a) dipolos de fendas e (b) ressonadores de anel cortado complementar (RACCs). $\quad 32$

$2.5(\mathrm{a}) \quad 32$

2.5(b) 32

2.6 Célula unitária de uma linha de transmissão orientada à esquerda. 33

2.7 Os efeitos inerentes aos fenômenos clássicos, incluídos ao modelo da linha orientada à esquerda, formam a LTCED homogênea. 34

2.8 Exemplo de um diagrama de dispersão de uma LTCED [28]. 35

2.9 Linha de transmissão LTCED artificial. 36

2.10 Geometria de uma guia de onda integrada em substrato (GIS). $\quad 37$

2.11 Exemplos de antenas baseadas em GIS utilizadas neste trabalho, condições de contorno (a) aberta e (b) curto. 39

2.11(a) 39

2.11(b) 39

2.12 Modelo $\pi$ de uma linha de transmissão LTCED para modelo das antenas baseadas em guias de onda integradas em substrato. $\quad 39$

2.13 Estrutura de OG e suas ligações.

2.14 Produção de OG e OGr.

2.15 Espectro Raman de grafeno e suas respectivas interpretações para caracterização de grafeno monocamada, bicamada, multicamada e grafite.

2.16 Exemplo de Espectro Raman de OG e OGr.

3.1 Simulação impedância de entrada para antena GIS RT5880, condição de contorno aberta.

3.2 Simulação coeficiente de reflexão para antena GIS RT5880 casada com transformador quarto de onda, condição de contorno aberta:

(a) layout e (b) otimização diâmetro das vias. 48

$3.2(\mathrm{a}) \quad 48$

3.2(b) 48

3.3 Simulação diagrama de irradiação para antena GIS RT5880, condição de contorno aberta: (a) $\phi=0$ e (b) $\phi=\pi / 2$. 49

3.3(a) $\quad 49$

3.3(b) 49

3.4 Protótipo da antena GIS com condição de contorno aberta em substrato RT5880. 
3.5 Medidas coeficiente de reflexão da antena GIS em RT5880 condição de contorno aberta para as três diferentes implementações (vermelho protótipo 1, azul 2, preto 3).

3.6 Medidas diagrama de irradiação das antenas de condição de contorno aberta (a) protótipos 1, (b) 2 e (c) 3.

$3.6(\mathrm{a})$

$3.6(\mathrm{~b})$

$3.6(\mathrm{c})$

3.7 Simulação coeficiente de reflexão para antena GIS RT5880 condição de contorno curto-circuito: (a) layout e (b) otimização diâmetro das vias.

$3.7(\mathrm{a})$

$3.7(b)$

3.8 Simulação diagrama de irradiação da antena GIS RT5880 condição de contorno curto-circuito: (a) $\phi=0$ e (b) $\phi=\pi / 2$.

3.9 Protótipo antena GIS RT5880 com condição de contorno curtocircuito em substrato RT5880.

3.10 Medidas coeficiente de reflexão condição de contorno curto-circuito em substrato RT5880 (vermelho protótipo 1, azul 2, preto 3).

3.11 Medidas diagrama de irradiação das antenas de condição de contorno curto-circuito (a) 1, (b) 2 e (c) 3.

$3.11(\mathrm{a})$

3.11(b)

$3.11(\mathrm{c})$

3.12 Simulação do coeficiente de reflexão das novas amostras projetadas em substrato FR4 (Preto aberto, vermelho curto.)

3.13 Protótipos das antenas GIS em FR4, condições de contorno (a) aberta e (b) curto-circuitada.

3.13(b)

3.14 Resultados experimentais dos coeficientes de reflexão das antenas GIS em FR4 (as linhas verdes correspondem à simulação), condições de contorno (a) aberta e (b) curto-circuito.

$3.14(\mathrm{~b})$

3.15 Imagens de microscopia óptica da antena aberta em FR4 (a) referência e (b) amostra com OG.

3.16 Simulação da intensidade do campo elétrico ao longo da estrutura da antena GIS em FR4, destacando a sua grande intensidade no capacitor interdigital, para condições de contorno (a) aberta e (b) curto-circuito.

3.17 Setup medição antena/OG $+\mathrm{CO}_{2}$. 
3.18 Definição de substrato no ADS utilizando a camada "resi"para simulação de OG/OGr.

3.19 Simulação comparando os coeficientes de reflexão da antena GIS FR4 curto-circuito para o caso sem filme e com OG.

3.20 Simulação diagrama de irradiação GIS FR4 condição de contorno aberta com OG (a) $\phi=0$ e (b) $\phi=\pi / 2$.

3.20 (a)

3.20 (b)

3.21 Simulação variação do coeficiente de reflexão da antena GIS FR4 em função da resistividade OGr.

3.22 Simulação diagrama de irradiação da antena GIS FR4 condição de contorno aberta com resistividade na faixa de interesse (a) $\phi=0$ e (b) $\phi=\pi / 2$.

$3.22(\mathrm{~b})$

3.23 Simulação da eficiência de irradiação da antena GIS FR4 em função da resistividade da folha de OGr.

3.24 Variação da resistência de entrada da antena GIS FR4 em função da resistividade.

3.25 Esquemático do método de Van der Pauw para caracterização da resistência de folha.

3.26 Aparato para caracterização da resistência de folha das amostras de OGr, utilizando método Van der Pauw.

3.27 Protótipos da segunda versão das antenas GIS em substrato FR4. $3.27(\mathrm{a})$ $3.27(\mathrm{~b})$

3.28 Novo setup de medição para prova de conceito do sensor de álcool.

3.29 Sensibilidade medida versus tempo dos quatro sensores implementados.

4.1 Simulação do GIS em FR4: (a) layout e (b) Coeficiente de transmissão $S_{21}$.

$4.1(\mathrm{a})$

4.1(b)

4.2 Simulação GIS com fenda em FR4: (a) layout e (b) Coeficiente de transmissão $S_{21}$, linha contínua para a GIS pura e tracejada para o caso com fenda.

4.3 Simulação coeficiente de transmissão $S_{21}$ GIS com fenda em FR4 para $f_{c}=11 \mathrm{GHz}$. Linha contínua: guia de onda pura; linha tracejada: estrutura com fenda.

4.4 Simulação GIS com fenda estendida em FR4: (a) layout e (b) Coeficiente de transmissão $S_{21}$, linha contínua para a GIS pura e tracejada para o caso com fenda estendida, ilustrando a ressonância de ordem -1 . 
4.5 Simulação coeficiente de transmissão $S_{21}$ GIS com fenda modificada em FR4. Linha contínua: estrutura da Figura 4.4(a); linha tracejada: guia de onda com fenda modificada (margem do gráfico). 77

4.6 Simulação antena GIS: (a) Comparação entre coeficiente de reflexão das estruturas de 1 e 2 portas; e (b) Parte real da impedância de entrada.

$4.6(\mathrm{a})$

$4.6(\mathrm{~b})$

4.7 Simulação antena GIS com alimentação microfita e plano de terra:

(a) Layout e (b) Comparação entre coeficiente de reflexão das duas estruturas.

$4.7(\mathrm{a})$

$4.7(\mathrm{~b})$

4.8 Simulação diagrama de irradiação antena GIS com alimentação microfita e plano de terra: (a) 3D e (b) Corte planos $\phi=0$ e $\phi=\pi / 2$

$4.8(\mathrm{~b})$

4.9 Layout da cavidade ressonante integrada em substrato utilizada para projeto da antena GIS com condição de contorno curtocircuitada.

4.10 Simulação cavidade ressonante integrada em substrato: (a) Coeficiente de Reflexão e (b) Parte real da impedância de entrada.

$4.10(\mathrm{a})$

$4.10(\mathrm{~b})$

4.11 Layout da antena GIS com condição de contorno curto-circuitada.

4.12 Simulação antena GIS com condição de contorno curto-circuitada: (a) Coeficiente de Reflexão e (b) Parte real da impedância de entrada, comparação entre condição de contorno curto-circuito e circuito aberto (linha contínua: curto-circuito; linha tracejada: circuito aberto).

$4.12(\mathrm{a})$

$4.12(\mathrm{~b})$

4.13 Simulação antena GIS com condição de contorno curto-circuitada, plano de terra e alimentação via linha de microfita de $50 \Omega$ : (a) Layout e (b) Coeficiente de reflexão (linha contínua: antena da Figura 4.12(a); linha tracejada: esta topologia).

4.13(a)

$4.13(\mathrm{~b})$

4.14 Simulação diagrama de irradiação versão final antena GIS com condição de contorno curto-circuitada: (a) 3D e (b) Cortes nos planos $\phi=0$ e $\phi=\pi / 2$.

4.15 Simulação coeficiente de reflexão GIS condição de contorno aberta para diferentes valores de resistividade na faixa de interesse. 
4.16 Simulação diagrama de irradiação GIS condição de contorno aberta para diferentes valores de resistividade na faixa de interesse: (a) plano $\phi=0$ e (b) $\phi=\pi / 2$.

4.16(a)

$4.16(\mathrm{~b})$

4.17 Simulação eficiência de irradiação GIS condição de contorno aberta para diferentes valores de resistividade na faixa de interesse.

4.18 Amostras OG em silício para caracterização via XPS.

4.19 Caracterização via XPS para OG e OGr em silício (a) OG e (b) OGr 60 min.

$4.19(\mathrm{a})$

4.19(b)

4.20 Espectroscopia Raman das três amostras preparadas para sensoriamento de vapor de álcool.

4.21 Medidas sensibilidade versus tempo dos sensores de condição de contorno aberta para álcool isopropílico.

4.22 Medidas sensibilidade versus tempo dos sensores de condição de contorno aberta para etanol.

4.23 Medidas sensibilidade versus tempo dos sensores de condição de contorno curto-circuito para álcool isopropílico.

4.24 Medidas sensibilidade versus tempo dos sensores de condição de contorno curto para etanol. 


\section{Lista de tabelas}

3.1 Medidas Antenas GIS: Aberta 50

3.2 Medidas Antenas GIS: Curto-Circuito 53

3.3 Medidas iniciais de resistividade OG/OGr 67

3.4 Medidas resistividade $\mathrm{OG} / \mathrm{OGr}$ à $200^{\circ} \mathrm{C} . \quad 68$

3.5 Resultados Medidas Sensores GIS 70

4.1 Medidas XPS OG e OGr $\quad 87$

4.2 Resultados Medidas GIS aberto $\quad 89$

4.3 Resultados Medidas GIS curto-circuito 90

4.4 Medidas de resistividade OGr 91 


\section{Lista de Abreviaturas}

ARE - Analisador de rede escalar

CCP - Comunicação por Campo Próximo

DQV - Deposição química por vapor

GIS - Guia de onda integrada em substrato

LFMP - Largura de feixe de meia potência

LTCED - Linha de transmissão composta à esquerda e à direita

LTMD - Linha de transmissão de mão direita

LTMD - Linha de transmissão de mão esquerda

LTPME - Linha de transmissão puramente mão esquerda

ME - Mão esquerda

OG - Óxido de grafeno

OGr - Óxido de grafeno reduzido

PAB - Passivas assistidas por bateria

RAC - Ressonador de anel cortado

RACC - Ressonador de anel cortado complementar

RCS - Seção transversal equivalente de radar

RFID - Identificação por radiofrequência

RSSF - Redes de Sensores sem Fio

TE - Transversal elétrico

TM - Transversal magnético

UAF - Ultra-Alta Frequência 
If you love something, let it go.

If you don't love something, definitely let it go.

Basically just drop everything, who cares.

BJ Novak. 


\section{Introdução}

A tecnologia de identificação por radiofrequência (RFID) é amplamente consolidada e utilizada nos dias de hoje, principalmente para catalogação e monitoramento de bens. Baseada no paradigma leitor-etiqueta, encontra também aplicações mais avançadas em setores como logística, gestão de inventário, sistemas para pessoas portadoras de deficiência física, defesa, assistência médica [1], entre outras, e possui potencial para uma enorme gama de outras aplicações. Apresentando características atrativas como baixo custo, alcance de vários metros, autonomia em relação à energia, capacidade de integração com sensores e com agentes químicos, esta tecnologia é uma das favoritas em conjunto com redes de sensores sem fio (RSSF) no que diz respeito à implementação de sistemas de sensoriamento ubíquo em soluções de quinta geração de celular (5G) e de internet das coisas (IoT) [2].

Etiquetas RFID clássicas são classificadas de diferentes maneiras considerando diferentes aspectos do seu funcionamento. Por exemplo, em relação ao alcance, são divididas entre curto-alcance, longo-alcance, e comunicação por campo próximo (CCP). No que diz respeito à funcionalidade, podem ser divididas entre identificação, sensoriamento, autenticação e localização [3]. Quanto à forma de alimentação do chip, etiquetas são classificadas em passivas, semi-passivas e ativas. O funcionamento de uma etiqueta passiva de ultra-alta frequência (UAF) - operadas em campos distantes, ao contrário das etiquetas CCP, que utilizam o acoplamento indutivo - é baseada na codificação da informação (ID) através de modulação (ou seja, variação da amplitude ou fase) da onda que é re-irradiada de volta para o leitor. Usualmente, apresentam distância de leituras de aproximadamente $10 \mathrm{~m}$, e utilizam um conversor DC-DC para retificação da onda incidente de forma a aproveitar esta energia para retransmissão dos dados. A não utilização de uma bateria é conveniente para redução de custos e miniaturização da etiqueta, porém em alguns casos onde a aplicação demanda um maior alcance ela se faz necessária em conjunto com um transceptor integrado, e estas etiquetas são classificadas como ativas. O alcance deste tipo de etiqueta pode atingir distâncias superiores a $100 \mathrm{~m}$. Além disso, um meio termo interessante são as etiquetas semi-passivas, também conhecidas como PAB (passivas assistidas por bateria), que utilizam uma 
bateria para alimentação dos circuitos da etiqueta, porém continuam utilizando comunicação por re-irradiação no uplink etiqueta-leitor.

Embora consolidada, a tecnologia RFID continua permeando novos mercados, e as previsões econômicas para sua aplicação na próxima década são impressionantes. De acordo com o relatório da IDTechEx 2014 [4], etiquetas RFID passivas vêm dobrando suas vendas em diversos anos, e é esperado que esta progressão se mantenha nas próximas décadas. De acordo com o relatório, espera-se um crescimento exponencial, de um mercado estimado de 9 bilhões de dólares em 2014 (ou 7 bilhões de etiquetas vendidas) para mais de 30 bilhões de dólares em 2024. Contudo, para que soluções baseadas em RFID sejam amplamente adotadas em contextos como os prospectos para os próximos anos, o custo de uma etiqueta continua sendo proibitivo para diversas aplicações devido ao custo do chip. Portanto, novas soluções e abordagens baseadas em etiquetas RFID sem chip foram propostas para identificação [5] e sensoriamento [6]. Embora ainda em estágio de pesquisa (a fatia de mercado ainda é desprezível, sendo de 0,1\% em 2012) devido aos diversos aspectos que devem ser levados em consideração para esta nova tecnologia [5], as previsões são de que a proporção de etiquetas sem chip no mercado seja de $31 \%$ já no ano de 2019 [4].

Sensores baseados em etiquetas RFID sem chip dependem do tipo de princípio de transferência de dados utilizado pelo interrogador, que pode ser classificado em tempo ou frequência [5]. A interrogação no domínio da frequência torna o projeto da etiqueta mais simples, deixando a maior parte da complexidade e do processamento de dados para o leitor. Neste modo, a informação carregada pela antena-sensor pode ser extraída através da fase, amplitude ou assinatura de frequência dentro de uma determinada largura de banda. Isto é geralmente alcançado através de materiais químicos, usualmente condutores ou isolantes polímeros que interagem com a amostra a ser medida de forma a modificar características da onda eletromagnética re-irradiada, permitindo desta forma a medição das propriedades desejadas [7].

Para implementação dos protótipos das antenas-sensor, uma potencial abordagem é a de metamateriais (MTMs). MTMs são estruturas artificiais projetadas de forma a manipular efeitos eletromagnéticos, mecânicos, acústicos, entre outros fenômenos físicos. Com uma gama enorme de aplicações em áreas diversas, as origens dos MTMs remetem à teoria eletromagnética e à teoria de micro-ondas, tendo revolucionado ambas as áreas. As aplicações na área de antenas também são numerosas [8], sendo que MTMs são usualmente empregados de forma a controlar características de irradiação da antena, como ganho e diretividade, para miniaturização, entre outras. Além disso, alguns 
trabalhos na literatura sugerem que a performance de sensores baseados em MTMs são geralmente superiores quando comparadas às de sensores clássicos [9]. Tendo em vista estas duas vantagens da utilização de MTMs, estas estruturas são potenciais candidatas para utilização no projeto de um sensor sem fio eficiente.

O primeiro aspecto do projeto do sensor sem fio é o dispositivo irradiador - no caso, a antena - , e o segundo é o material químico que de fato interage com o objeto de sensoriamento (gás, temperatura, umidade, DNA, etc). Neste contexto é que se considera para elaboração deste trabalho estruturas baseadas em grafeno, devido às suas características promissoras para diversas áreas de pesquisa. Grafeno é uma estrutura bidimensional alótropa do carbono, onde os átomos são ligados entre si por meio de ligações $\mathrm{sp}^{2}$ [10]. Estruturas baseadas em grafeno vêm sendo amplamente exploradas na literatura, devido às suas excepcionais propriedades físicas e químicas. Formado por uma rede bidimensional de átomos de carbono arranjados hexagonalmente, grafeno é o material mais fino, com as condutividades elétricas e térmicas mais altas, além de ser flexível, transparente e excepcionalmente resistente [11]. Além disso, as propriedades condutoras deste material são facilmente modificadas por agentes externos $[12,13,14]$, especialmente pela adsorção de espécimes na sua superfície, viabilizando assim a sua aplicação como sensor de gás ou vapor. Como exemplo de sua importância nos próximos anos, grafeno foi considerado um dos materiais estratégicos chave por uma das diretrizes tecnológicas mais relevantes do mundo, o décimo terceiro plano de cinco anos da China (20162020) [15].

Diversos métodos podem ser utilizados para obtenção de grafeno, sendo a deposição química por vapor (DQV) a mais utilizada, devido à alta qualidade das folhas e em grandes áreas obtidas através desse método. Entretanto, uma desvantagem desta abordagem são as altas temperaturas necessárias para deposição, em torno de $1000^{\circ} \mathrm{C}$, inviabilizando algumas aplicações onde temperaturas tão críticas se tornam proibitivas. Uma alternativa é a esfoliação na fase líquida para obtenção de óxido de grafeno (OG). OG é definido como um material de uma ou poucas camadas formado de carbono, hidrogênio, e moléculas de oxigênio pela oxidação de cristais de grafite. Esses cristais são abundantes e de baixo custo, dispersáveis em água e relativamente fáceis de processar. Além disso, o OG pode ser parcialmente reduzido para folhas similares ao grafeno através da remoção dos grupos de oxigênio. As folhas de OG reduzido (OGr) são usualmente consideradas um tipo de grafeno derivado quimicamente. Duas características fazem com que o OG seja tão amplamente estudado e utilizado: ele pode ser produzido utilizando grafite como matéria-prima, que apresenta 
um custo consideravelmente baixo, juntamente com métodos químicos de alto rendimento; e é altamente hidrofílico (tem a tendência de se misturar com ou se dissolver em água) e pode assim formar coloides aquosos estáveis, facilitando a montagem de estruturas macroscópicas via processos simples e de baixo custo. Além disso, a grande densidade de defeitos ao longo da sua estrutura faz com que ele seja um sensor com desempenho ainda melhor que grafeno primitivo. Apesar do OG apresentar comportamento isolante, estruturas baseadas em OGr podem apresentar condutividades quase tão altas quanto a do grafeno pristino, além de apresentar excelentes propriedades eletromecânicas [16].

Embora uma gama grande de aplicações de grafeno, OG e OGr em sensores sejam reportadas na literatura [17], pouco foi feito utilizando a abordagem sem fio, o que é crucial em aplicações onde intervenção pode ser um problema. O objetivo principal deste trabalho é o estudo de viabilidade da aplicação sem fio, inspirada no que foi efetuado em termos de sensores baseados em grafeno de forma resistiva ou em frequências ópticas. Ou seja, a proposta consiste em projetar os sensores no contexto de sensoriamento via RFID sem chip, utilizando células unitárias baseadas em MTMs. Além disso, outro aspecto relevante que vem sendo amplamente considerado é a utilização do espectro eletromagnético. Grande parte das aplicações se concentra em uma parcela relativamente pequena do espectro, principalmente nas faixas de UAF e nas bandas próximas a 2,4 GHz. Por esta razão, vemse estudando extensivamente a utilização de ondas milimétricas, que por definição se encontram na faixa de 30 a $300 \mathrm{GHz}$. Por estar subutilizada, esta faixa apresenta grande potencial para utilização de bandas largas e consequentemente de potenciais velocidades muito mais rápidas do que as disponíveis nos dias de hoje. As provas de conceito implementadas neste trabalho foram projetadas para operação em banda X (8-12 GHz).

Esta dissertação é organizada da seguinte maneira: o Capítulo 2 tem como objetivo sumarizar os conceitos teóricos multidisciplinares que fundamentam os capítulos subsequentes do trabalho, de forma a facilitar sua compreensão. O Capítulo 3 ilustra as simulações e implementação de uma primeira versão dos protótipos das antenas-sensor, com uma abordagem mais experimental que teórica, cujo objetivo principal é angariar uma intuição sobre o projeto em desenvolvimento, de forma a simplificar o trabalho posterior. A principal contribuição é a demonstração por simulação e experimental que o sensor responde apenas para uma determinada faixa de valores de resistividade do OGr. No Capítulo 4 é ilustrada a contribuição mais importante deste trabalho, uma metodologia completa para projeto do sensor aqui proposto. Neste último, a teoria apresentada no Capítulo 2 é aprofundada e aplicada a antenas baseadas 
em guias de onda integradas em substrato, ilustrando a intersecção que há entre essa teoria e a de MTMs. Tanto o Capítulo 3 quanto o 4 apresentam provas de conceito de antenas-sensor de álcool. O Capítulo 5 discute os resultados obtidos e apresenta os passos subsequentes do projeto. 


\section{2}

\section{Fundamentação Teórica}

Alguns parâmetros são fundamentais para análise e compreensão dos dados apresentados neste trabalho, e por conseguinte serão brevemente introduzidos nas seções subsequentes.

\section{1}

\section{Parâmetros Básicos de uma Antena}

A maioria das definições e conceitos abordados nesta subseção são clássicos na teoria de antenas e linhas de transmissão, e foram retiradas majoritariamente das referências [18] e [19].

\subsection{1}

\section{Impedância de Entrada}

A impedância de entrada de uma antena é definida como a relação entre a tensão e a corrente em seus terminais. De forma geral, ela é escrita como $Z_{A}=R_{A}+j X_{A}$, onde $R_{A}$ e $X_{A}$ são respectivamente a resistência e reatância de entrada. A componente resistiva pode ser dividida em duas partes $R_{A}=R_{r}+R_{l}$, onde $R_{r}$ representa a resistência de irradiação, uma resistência "fictícia" cujo valor de potência dissipada é o mesmo que o da potência irradiada pela antena, e $R_{l}$ contabiliza as perdas ôhmicas na estrutura.

\subsection{2}

\section{Diretividade}

Primeiramente, para a definição da diretividade, é importante apresentar a intensidade de radiação, que é definida como "a potência irradiada por uma antena por unidade de ângulo sólido". A intensidade de irradiação é um parâmetro de campo distante, e pode ser obtido multiplicando a densidade de potência pelo quadrado da distância. É expresso matematicamente como:

$$
U(\theta, \phi)=r^{2} S(\theta, \phi),
$$

onde $\theta$ é o ângulo de elevação e $\phi$ é o ângulo de azimute, conforme definidos no sistema de coordenadas esféricas ilustrado na Figura 2.1, e $S(\theta, \phi)$ é a densidade de potência em $\mathrm{W} / \mathrm{m}^{2}$. 


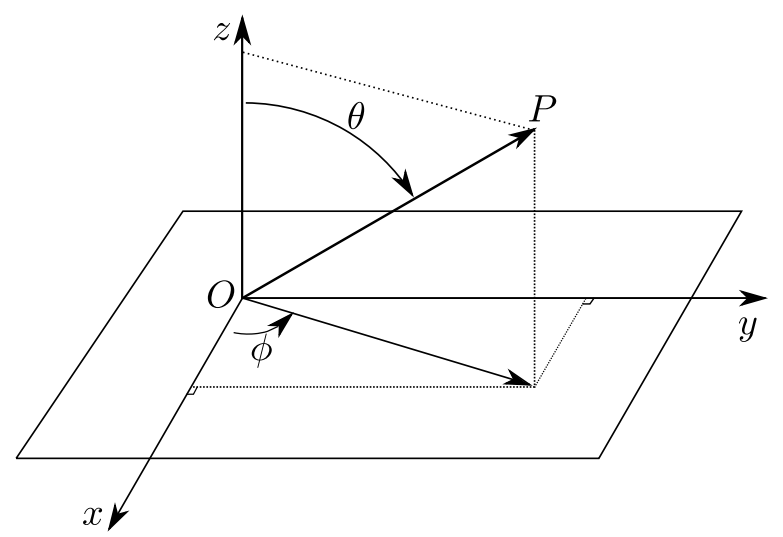

Figura 2.1: Definição do sistema de coordenadas utilizado como referência neste trabalho.

Desta forma, o ganho diretivo de uma antena é dado por:

$$
D(\theta, \phi)=\frac{S(\theta, \phi)}{\frac{P_{r a d}}{4 \pi r^{2}}}=\frac{4 \pi U(\theta, \phi)}{P_{r a d}},
$$

onde $P_{\text {rad }}$ é a potência irradiada. A expressão acima representa uma medida do quão diretiva é uma antena individual em relação à antena isotrópica (antena idealizada que irradia potência igualmente em todas as direções) irradiando a mesma potência total. A diretividade é definida como o valor do ganho diretivo na região de máxima concentração, ou seja, $D=\left.D(\theta, \phi)\right|_{\max }$. Em outras palavras, a diretividade quantifica a capacidade da antena concentrar o feixe em uma determinada direção. Pelo fato de ser uma medida relativa, é comumente especificada em decibel isotrópico (dBi), definido como:

$$
D_{\mathrm{dBi}}=10 \log \left(\frac{D}{D_{i}}\right)=10 \log (D),
$$

sendo que $D_{i}=1$ é a diretividade da antena isotrópica.

\subsection{3}

\section{Eficiência e Ganho}

A diretividade pode ser vista como o ganho direcional que a antena teria se toda potência na entrada aparecesse como potência irradiada. Como potência pode ser perdida nos arredores da estrutura em forma de calor, definese a eficiência de radiação como:

$$
e=\frac{P_{r a d}}{P_{i n}}=\frac{R_{r}}{R_{r}+R_{l}}=\frac{R_{r}}{R_{A}},
$$

onde $P_{\text {in }}$ é a potência disponível fornecida à antena. A partir desta, define-se outro parâmetro importante para descrição da performance de uma antena, o ganho:

$$
G=e D
$$


Também é muito comum encontrar o ganho especificado em dBi. Apesar da semelhança com a diretividade, este parâmetro considera também as perdas, e portanto não depende apenas de características diretivas de irradiação e é uma medida mais consistente da capacidade da antena de focalizar a energia em uma determinada direção.

\subsection{4}

\section{Diagrama de Irradiação}

O diagrama de irradiação de uma antena é uma representação gráfica tridimensional da distribuição de potência irradiada em função das coordenadas espaciais. Usualmente é normalizado em relação ao seu valor máximo, e plotado em decibel $(\mathrm{dB})$. Um exemplo de diagrama de irradiação direcional é ilustrado na Figura 2.2.

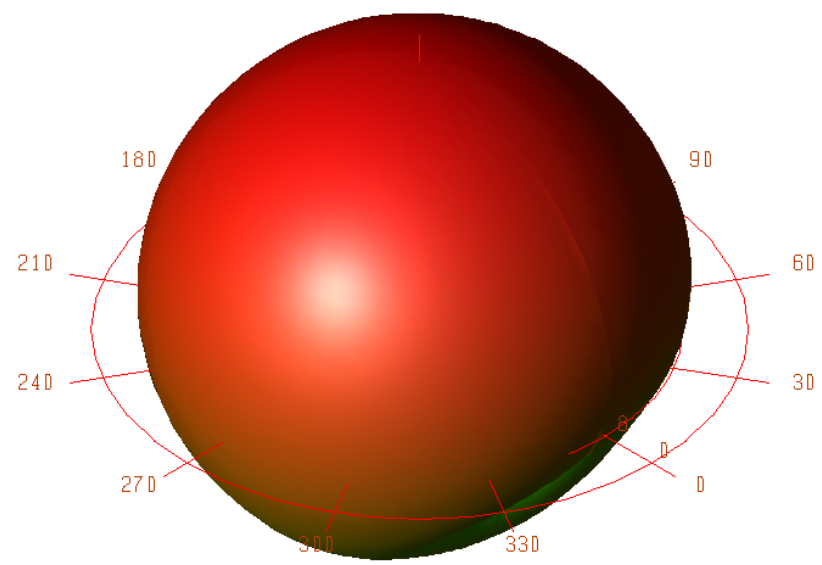

Figura 2.2: Exemplo de diagrama de irradiação direcional.

Apesar de serem representações 3D, é comum apresentá-las em planos de corte bidimensionais. Para finalidades práticas, algumas plotagens do diagrama em função de $\theta$ para alguns valores particulares de $\phi$, mais algumas plotagens em função de $\phi$ para alguns valores particulares de $\theta$ contêm toda a informação necessária sobre as características de irradiação da antena.

\subsection{5}

\section{Abertura Efetiva}

Pode-se associar a uma antena receptora uma abertura efetiva $\left(A_{e}\right)$ em $\mathrm{m}^{2}$, de forma que dada uma onda eletromagnética plana incidente com 
densidade de potência $S$, a antena absorve uma potência $P=A_{e} S$. Demonstrase que para qualquer antena, a abertura efetiva pode ser obtida através de [18]:

$$
A_{e}=\frac{\lambda_{0}^{2}}{4 \pi} G
$$

onde $\lambda_{0}=c / f$ é o comprimento de onda no espaço livre, $c \approx 3 \times 10^{8} \mathrm{~m} / \mathrm{s}$ é a velocidade de propagação da luz no vácuo, e $f$ a frequência da onda incidente.

\section{2}

\section{Espalhamento de Antenas}

O conceito de espalhamento é fundamental para a operação de sistemas de sensores sem fio e RFID, portanto esta seção apresenta um tratamento da teoria. Essencialmente, foca-se no fato de que se pode relacionar os parâmetros de espalhamento com parâmetros elétricos e eletromagnéticos de uma determinada antena. Primeiro, é feito um tratamento idealizado onde considera-se que todo o espalhamento é devido à operação do sistema como antena; posteriormente, são incluídas também as contribuições estruturais, ou seja, os modos referentes ao espalhamento causado pelas correntes geradas na superfície de forma a satisfazer as condições de campos elétricos tangenciais nulos no metal.

\subsection{1}

\section{Relação entre RCS e Ganho de uma Antena}

Primeiramente, será demonstrada a relação entre ganho e seção transversal de radar equivalente (RCS) de uma antena simplificada e irrealizável, na qual todo espalhamento é devido à energia coletada na abertura e re-irradiada devido às reflexões na carga. A potência recebida na região da antena é dada por [20]:

$$
P=S A_{e},
$$

onde $S$ é a densidade de potência na região da antena. Seja $G$ o ganho da antena e $\Gamma$ o coeficiente de reflexão, a densidade de potência re-irradiada é dada por:

sendo que

$$
S_{r}=\frac{P G|\Gamma|^{2}}{4 \pi r^{2}}=\frac{S A_{e} G|\Gamma|^{2}}{4 \pi r^{2}}
$$

$$
\Gamma=\frac{Z_{L}-Z_{A}^{*}}{Z_{L}+Z_{A}}
$$

$\mathrm{Na}$ teoria de radares, para modelagem da potência refletida por objetos reais, é definida a seção transversal de radar $(\sigma)$, dada $\mathrm{em}^{2}$. Ela é definida como a área equivalente que intercepta uma quantidade de potência que, quando re-irradiada isotropicamente, produz no receptor a mesma densidade de potência que o objeto original [21]. Por exemplo, um pássaro tem uma 
seção transversal de radar de $0,01 \mathrm{~m}^{2}$, enquanto um avião grande tem uma seção transversal de $100 \mathrm{~m}^{2}$. Toda antena receptora pode ser modelada como uma RCS equivalente. Substituindo a definição original em termos dos campos espalhado e incidente pelas densidades de potência, já que $S \propto|E|^{2}$, pode-se escrever a RCS da antena como [20]:

$$
\sigma=\lim _{r \rightarrow \infty}\left(4 \pi r^{2}\right) \frac{\left|E^{S}\right|^{2}}{\left|E^{i}\right|^{2}}=\lim _{r \rightarrow \infty}\left(4 \pi r^{2}\right)\left(\frac{S_{r}}{S}\right) .
$$

Assim, é fácil chegar a

$$
\sigma=A_{e} G|\Gamma|^{2}
$$

Utilizando a relação entre abertura efetiva e ganho dada em (2-6), finalmente demonstra-se a relação entre RCS equivalente e ganho da antena:

$$
\sigma=\frac{\lambda_{0}^{2} G^{2}}{4 \pi}|\Gamma|^{2}
$$

Pode-se reescrever a equação acima como [22]:

$$
\sigma=\frac{\lambda_{0}^{2} G^{2} R_{A}^{2}}{\pi\left|Z_{A}+Z_{L}\right|^{2}}=\frac{\lambda_{0}^{2} G^{2} R_{A}^{2}}{\pi\left|Z_{A}+Z_{\text {mod }}\right|^{2}}
$$

ou seja, é possível modular informação através da variação de $Z_{L}=Z_{\text {mod }}$.

\subsection{2}

\section{Modo Estrutural e Modo Antena}

O campo elétrico espalhado por uma antena conectada a uma impedância de carga $Z_{L}$ pode ser expresso por [18]:

$$
\vec{E}^{s}\left(Z_{L}\right)=\vec{E}^{s}(0)-\frac{I_{s}}{I_{t}} \frac{Z_{L}}{Z_{L}+Z_{A}} \vec{E}^{t}
$$

onde $\vec{E}^{s}\left(Z_{L}\right)$ é o campo elétrico espalhado por uma antena cuja carga é $Z_{L}$; $\vec{E}^{s}(0)$ é o campo elétrico espalhado por uma antena cuja carga é um curtocircuito; $I_{s}$ é a corrente curto-circuitada induzida pelo campo incidente quando $Z_{L}=0 ; I_{t}$ é a corrente na antena no modo de transmissão; e $\vec{E}^{t}$ é o campo elétrico irradiado pela antena no modo de transmissão.

Utilizando a eq. 2-9, é possível reescrever a equação 2-14 como:

$$
\vec{E}^{s}\left(Z_{L}\right)=\vec{E}^{s}(0)-\frac{I_{s}}{I_{t}} \frac{1}{2}(1+\Gamma) \vec{E}^{t}
$$

Supondo que há casamento conjugado entre antena e carga — ou seja, $Z_{L}=Z_{A}^{*}$, pode-se escrever: 


$$
\begin{aligned}
\vec{E}^{s}\left(Z_{L}=Z_{A}^{*}\right) & =\vec{E}^{s}(0)-\frac{I_{s}}{I_{t}} \frac{Z_{L}}{Z_{L}+Z_{A}} \vec{E}^{t} \\
& =\vec{E}^{s}(0)-\frac{I_{s}}{I_{t}} \frac{Z_{A}^{*}}{Z_{A}^{*}+Z_{A}} \vec{E}^{t} \\
& =\vec{E}^{s}(0)-\frac{I_{s}}{I_{t}} \frac{Z_{A}^{*}}{2 R_{A}} \vec{E}^{t}
\end{aligned}
$$

Subtraindo 2-16 de 2-14 e rearranjando, demonstra-se que o campo elétrico espalhado é:

$$
\vec{E}^{s}\left(Z_{L}\right)=\vec{E}^{s}\left(Z_{A}^{*}\right)-\frac{I_{m}^{*}}{I_{t}} \Gamma^{*} \vec{E}^{t}
$$

sendo $I_{m}$ é a corrente de espalhamento quando a antena é conectada a uma carga cuja impedância é o complexo conjugado. A conveniência de escrever a equação desta maneira reside no fato que agora há um termo que depende e outro que independe da carga $Z_{L}$. O primeiro termo é chamado de modo estrutural; o segundo, de modo antena.

Basicamente, o modo estrutural é similar ao espalhamento de objetos quaisquer (ex. o espalhamento de um avião ou navio que um sistema de radar tenta detectar) e está relacionado à estrutura, forma e material de que é fabricada a antena [23]. Em contrapartida, o modo antena é consequência direta do fato que a antena é projetada para irradiar ou receber com um determinado padrão. Ou seja, quando receptora, diz respeito à re-irradiação da energia que é refletida na carga. Sendo assim, sistemas RFID geralmente apresentam modo estrutural constante e transmissão de informação via variação do modo antena através de modulação de carga ${ }^{1}$.

Pode-se demonstrar que a equação 2-15 pode ser convenientemente escrita como

$$
\sigma=\left|\sqrt{\sigma^{s}}-(1+\Gamma) \sqrt{\sigma^{a}} e^{j \phi}\right|^{2},
$$

onde $\sigma$ é a RCS de uma antena terminada com carga $Z_{L}, \sigma^{s}$ é a RCS devido ao termo estrutural, $\sigma^{a}$ é a RCS devido ao modo antena e $\phi$ é referente à fase relativa entre os termos dos modos estrutural e antena.

Pode-se efetuar alguns estudos de caso de forma a facilitar a visualização. Por exemplo, para o caso de um curto-circuito, $\Gamma=-1$ e

$$
\sigma_{\text {short }}=\sigma^{s} .
$$

${ }^{1}$ Neste tipo de modulação o interrogador envia um sinal para a etiqueta, e o chip controla quanta energia será re-irradiada de volta para o leitor através de chaveamento da carga $Z_{L}$ (na verdade existem outras maneiras, este seria o caso mais simples de modulação ASK/OOK), possibilitando assim codificação de informação. No caso sem chip, o parâmetro de interesse influencia alguma característica da antena, que pode ser detectada analisando o sinal re-irradiado. 
Ou seja, a RCS total se reduz à RCS do modo estrutural. Para uma carga aberta, $\Gamma=1 \mathrm{e}$

$$
\sigma_{\text {open }}=\left|\sqrt{\sigma^{s}}-2 \sqrt{\sigma^{a}} e^{j \phi}\right|^{2}
$$

e para um circuito casado

$$
\sigma_{\text {matched }}=\left|\sqrt{\sigma^{s}}-\sqrt{\sigma^{a}} e^{j \phi}\right|^{2}
$$

\subsection{3}

\section{Estimativa do alcance de uma Etiqueta sem chip}

Utilizando as equações apresentadas para a seção equivalente de radar é possível estimar o alcance da etiqueta sem chip. Sejam $G_{T X}$ e $P_{T X}$ o ganho e a potência transmitida pelo interrogador/leitor, respectivamente. De acordo com a equação de Friis, a densidade de potência na região da antena é:

$$
S=\frac{G_{T X} P_{T X}}{4 \pi r^{2}} .
$$

Pela definição da seção equivalente de radar apresentada na subseção 2.2.1, a densidade de potência re-irradiada na região do leitor é dada por:

$$
S_{B S}=\sigma \frac{S}{4 \pi r^{2}}=\sigma \frac{G_{T X} P_{T X}}{\left(4 \pi r^{2}\right)^{2}} .
$$

Utilizando (2-6) e (2-23) pode-se estimar a potência $P_{R X}$ recebida no leitor:

$$
P_{R X}=A_{R X} S_{B S}=\frac{\lambda_{0}^{2}}{4 \pi} G_{T X} \frac{\sigma P_{T X} G_{T X}}{\left(4 \pi r^{2}\right)^{2}}=\frac{\sigma}{4 \pi}\left[\frac{G_{T X} \lambda_{0}}{4 \pi r^{2}}\right]^{2} .
$$

Considerando que o leitor é tanto o transmissor como o receptor, $G_{T X}=G_{R X}$ e $A_{T X}=A_{R X}$. Substituindo (2-17) em (2-24), finalmente obtém-se:

$$
P_{R X}=P_{T X}\left[\frac{G G_{T X} \lambda_{0}^{2}}{(4 \pi r)^{2}}\right]^{2}|\Gamma|^{2}
$$

esta equação é similar à de um radar mono-estático ${ }^{2}$ [18]. Isolando $r$ na equação acima, é possível estimar a distância máxima de leitura do sistema:

$$
r=\left(\frac{\lambda_{0}}{4 \pi}\right) \sqrt{G G_{T X}|\Gamma|} \sqrt[4]{\frac{P_{T X}}{P_{R X}}} .
$$

A equação 2-26 ignora efeitos de descasamento de polarização, multipercursos, entre outras hipóteses, porém sua precisão pode ser melhorada através da adição de fatores de não idealidade. Por exemplo, seja $\hat{\rho}_{\text {pol }} \mathrm{o}$

\footnotetext{
${ }^{2}$ Um radar bi-estático utiliza circuitos separados para transmissão e recepção. Um radar mono-estático utiliza a mesma antena como transmissora e receptora, desacoplando os sinais através de blocos de RF como desacopladores ou circuladores. A mesma definição pode ser estendida para sistemas RFID.
} 
vetor unitário cuja direção representa a polarização da antena e $\hat{\rho}_{i n c}$ o vetor unitário cuja direção representa a polarização da onda incidente, os efeitos de descasamento de polarização são adicionados à equação da seguinte maneira:

$$
r=\left(\frac{\lambda_{0}}{4 \pi}\right) \sqrt{G G_{T X}|\Gamma|} \sqrt[4]{\frac{P_{T X}}{P_{R X}} \hat{\rho}_{i n c} \cdot \hat{\rho}_{p o l}}
$$

\section{3}

\section{Metamateriais e Linhas de Transmissão CED}

\subsection{1}

\section{Metamateriais}

Esta seção se baseia principalmente em [24]. A ideia de metamateriais (MTMs) tem sua origem no trabalho publicado em 1968 pelo físico russo Victor Veselago, em [25], no qual ele estuda o comportamento eletromagnético dos materiais se eles apresentassem parâmetros constitutivos negativos.

MTMs são estruturas artificiais projetadas de forma a controlar e manipular características da luz, som, ou outros fenômenos físicos. Elas se inserem em um contexto de estruturas periódicas com dimensões muito menores do que o comprimento de onda guiado, e suas propriedades são derivadas tanto das propriedades inerentes dos seus materiais constituintes, quanto do arranjo geométrico destes materiais. Como consequência, novas propriedades interessantes podem surgir, como por exemplo velocidades de grupo e de fase anti-paralelas, também conhecida como propagação reversa, efeito Doppler invertido, entre outras [24].

A Figura 2.3 ilustra graficamente a classificação dos materiais. O caso clássico e mais conhecido dos dielétricos isotrópicos com $\epsilon$ e positivos é ilustrado no primeiro quadrante. No segundo quadrante com $\epsilon<0$ estão os meios $\epsilon$-negativos. No terceiro quadrante encontra-se o caso dos MTMs à esquerda, ou $\mathrm{ME}^{3}$ (mão esquerda). Este caso apresenta as características peculiares citadas no parágrafo anterior, como propagação reversa. No último quadrante estão ilustrados os casos $\mu$-negativos. Um exemplo de um material $\mu$-negativo encontrado na natureza são os ferrites, para frequências abaixo da frequência de plasma magnético. Conforme será demonstrado posteriormente, pode-se obter este comportamento em micro-ondas através de estruturas periódicas constituídas de materiais não magnéticos. Note que os meios II e IV propagam apenas ondas evanescentes.

${ }^{3} \mathrm{~A}$ origem desta nomenclatura advém do fato que, para ondas se propagando em um MTM, a regra que ilustra a relação entre os vetores $\vec{k}, \vec{E}$ e $\vec{H}$ não é mais a da mão direita como nos materiais clássicos, mas sim a da mão esquerda. 


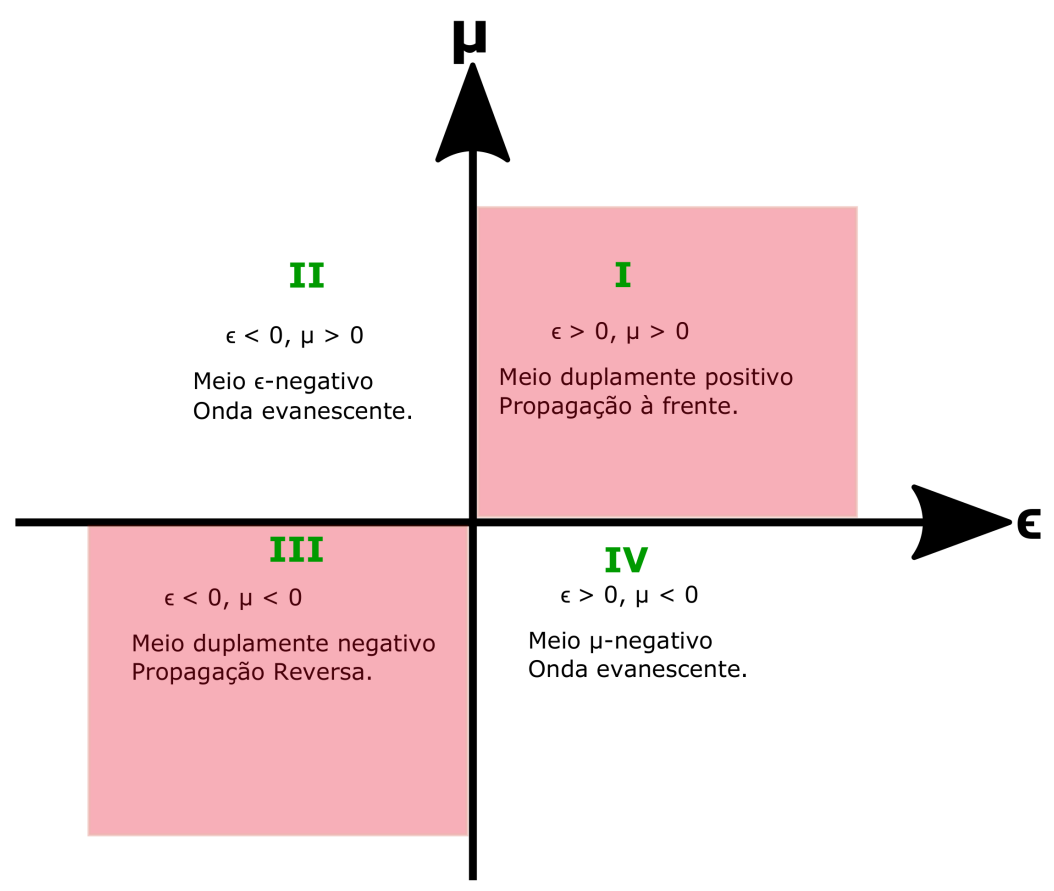

Figura 2.3: Diagrama $\epsilon$ - $\mu$ ilustrando as classificações dos materiais.

O primeiro MTM implementado foi fabricado utilizando as estruturas ilustradas nas Figuras 2.4(a) e 2.4(b). Da mesma forma que um campo elétrico $\vec{E}$ incidindo em um dielétrico cria dipolos elétricos em um material isotrópico clássico ao afastar os elétrons do núcleo, um dielétrico artificial pode ser emulado quando um campo $\vec{E}$ incide paralelamente ao eixo dos fios na estrutura periódica de condutores da Figura 2.4(a) [26]. Para uma determinada faixa de frequências ( $\omega<\omega_{p e}$, onde $\omega_{p e}$ é a frequência de plasma elétrico), este dielétrico artificial apresenta permissividade elétrica negativa. Em contrapartida, se utilizarem-se estruturas ressonantes ao invés de estruturas condutoras, como por exemplo os ressonadores de anel cortados (RACs) da Figura 2.4(b), é viável obter uma resposta magnética com permeabilidade negativa para uma determinada faixa $\left(\omega_{0}<\omega<\omega_{p m}\right.$, onde $\omega_{p m}$ é a frequência de plasma magnético), e $\omega_{0}=c \sqrt{\frac{3 p}{\pi \ln \left(2 w a^{3} / s\right)}}$, onde $a$ e $w$ são o raio interno e a espessura dos anéis, respectivamente, e $s$ é o espaçamento entre eles. Associando ambas as estruturas elétricas e magnéticas, pode-se obter uma estrutura artificial ME.

Utilizando o princípio da dualidade, pode-se mostrar que as estruturas complementares às Figuras 2.4(a) e 2.4(b) ilustradas nas Figuras 2.5(a) e 2.5(b) também apresentam propriedades similares. Por exemplo, a estrutura formada pelos ressonadores de anel cortado complementar da Figura 2.5(b) apresenta permissividade elétrica negativa para uma determinada faixa de frequências, enquanto a estrutura formada pelas fendas na Figura 2.5(a) apresenta permeabilidade magnética negativa para certa faixa de frequências. 


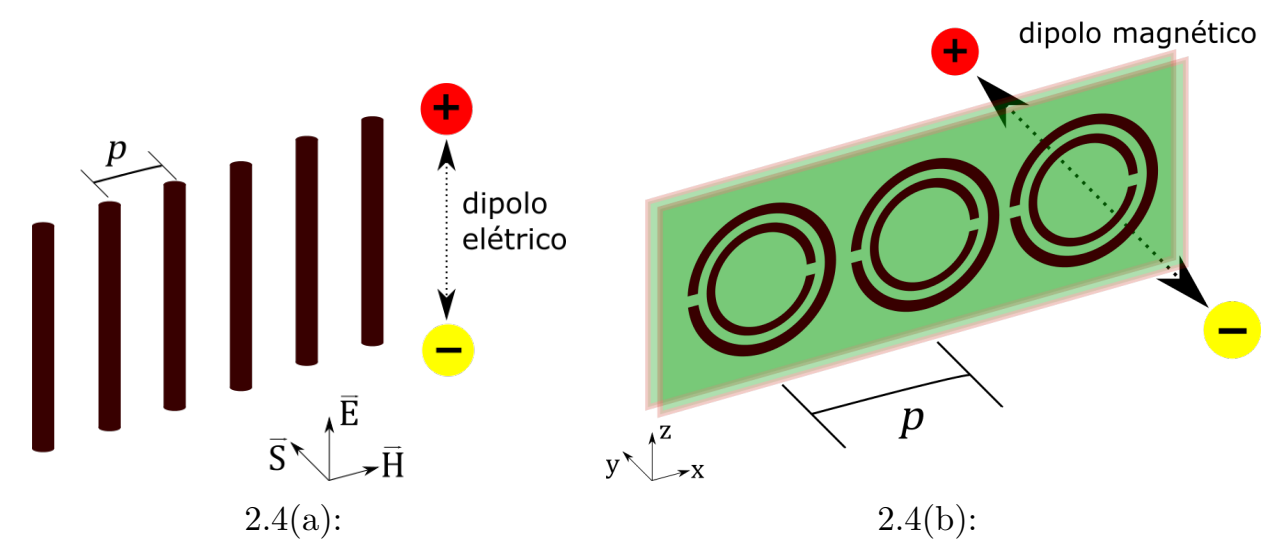

Figura 2.4: Células unitárias básicas de metamateriais (a) dipolos de fio e (b) ressonadores de anel cortado (RACs).
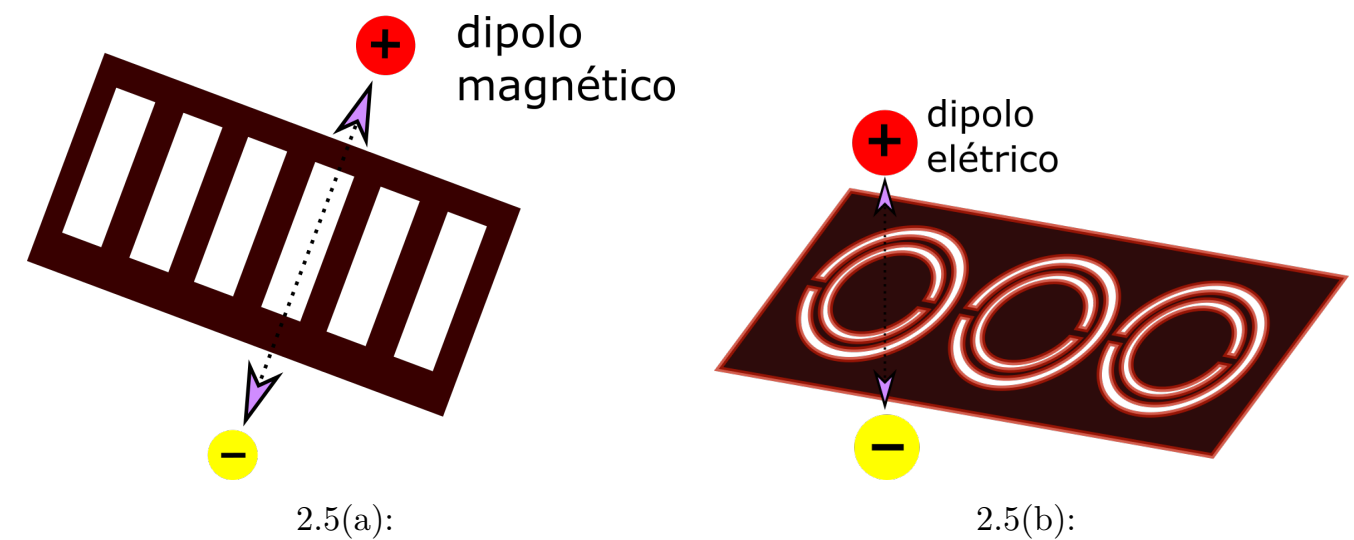

Figura 2.5: Células unitárias complementares de metamateriais (a) dipolos de fendas e (b) ressonadores de anel cortado complementar (RACCs).

Além do caso mais comum de propagação ME obtida através de dipolos de fio + RAC, outras combinações possíveis são [27]:

$-\mathrm{RAC}+\mathrm{RACC}$

- Dipolo de fio + Dipolo de fenda

- RACC + Dipolo de fenda.

\subsection{2}

\section{Linhas de Transmissão Puramente à Esquerda}

Considere o dual do modelo de uma linha de transmissão (LT) clássica conforme a Figura 2.6, chamada de LT puramente de mão esquerda (LTPME). Considerando que neste caso há uma impedância série capacitiva e uma admitância paralela indutiva, pode-se escrever:

$$
Z(\omega)=\frac{1}{j \omega C_{L}}
$$




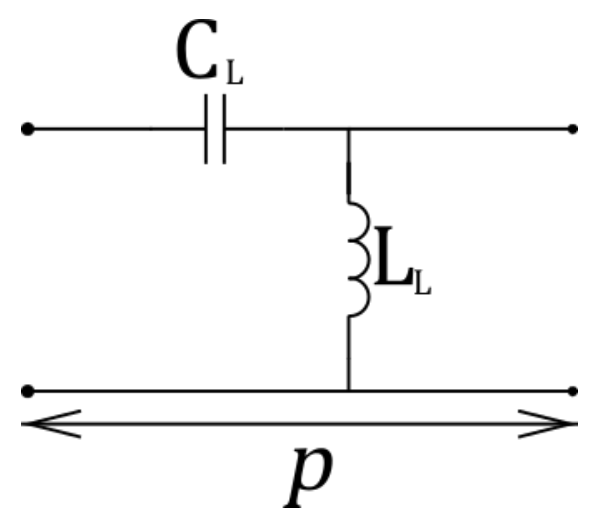

Figura 2.6: Célula unitária de uma linha de transmissão orientada à esquerda.

e

$$
Y(\omega)=\frac{1}{j \omega L_{L}} .
$$

E, da teoria clássica de LTs (equações telegráficas), sabe-se que a constante de fase é dada por:

$$
j \beta(\omega)=\sqrt{Z(\omega) Y(\omega)}=\sqrt{\frac{1}{-\omega^{2} C_{L} L_{L}}}=\frac{-j}{\omega} \frac{1}{\sqrt{C_{L} L_{L}}},
$$

de forma que

$$
\beta(\omega)=\frac{-1}{\omega} \frac{1}{\sqrt{C_{L} L_{L}}}<0 .
$$

A constante de fase negativa implica várias características interessantes. Por exemplo, calculando a velocidade de fase, obtém-se:

$$
v_{p}=\frac{\omega}{\beta(\omega)}=-\omega^{2} \sqrt{C_{L} L_{L}}<0,
$$

e calculando a velocidade de grupo:

$$
v_{g}=\left(\frac{\partial \beta}{\partial \omega}\right)^{-1}=\omega^{2} \sqrt{C_{L} L_{L}}>0 .
$$

Ou seja, as velocidades de fase (relacionada ao vetor de onda $\vec{\beta}$ ) e de grupo (relacionada com o vetor de Poyinting $\vec{S}$ ) são anti-paralelas. Esta característica é conhecida como propagação de onda retrógrada, pois o sentido de propagação da energia continua sendo da fonte para a carga, conforme seria esperado pela causalidade, porém a fase se propaga no sentido oposto ao de propagação da onda.

Finalmente, a impedância característica é dada por:

$$
Z_{0}=\sqrt{\frac{Z(\omega)}{Y(\omega)}}=\sqrt{\frac{L_{L}}{C_{L}}}>0,
$$

a mesma impedância característica de uma LT clássica sem perdas. 


\subsection{3}

\section{Linhas de Transmissão Compostas à Esquerda e à Direita}

Na prática, não é possível implementar uma LTPME. Devido à propagação da corrente nos condutores e aos gradientes de potencial ao longo do substrato (verticalmente) - ou seja, da indutância da metalização e da capacitância entre condutor e plano de terra — os efeitos clássicos são inerentes e inevitáveis. Entretanto, utilizando uma implementação LC $\operatorname{com} p<<\lambda_{g}$, onde $p$ é o período da célula unitária da LT artificial e $\lambda_{g}$ é o comprimento de onda guiado, pode-se emular uma LT composta à esquerda e à direita (LTCED). De forma a compreender melhor esta estrutura artificial, é importante estudar o comportamento da LTCED homogênea ilustrada na Figura 2.7. Os efeitos intrínsecos clássicos chamados de LT de mão direita (LTMD) são modelados por indutâncias e capacitâncias por unidade de comprimento $L_{R}^{\prime}[\mathrm{H} / \mathrm{m}]$ e $C_{R}^{\prime}[\mathrm{F} / \mathrm{m}]$, enquanto os efeitos LTME são modelados por $L_{L}^{\prime}$ [H.m] e $C_{L}^{\prime}$ [F.m]. Retomando cálculos similares aos efetuados na subseção anterior para o caso da LTCED homogênea e sem perdas, pode-se chegar a:

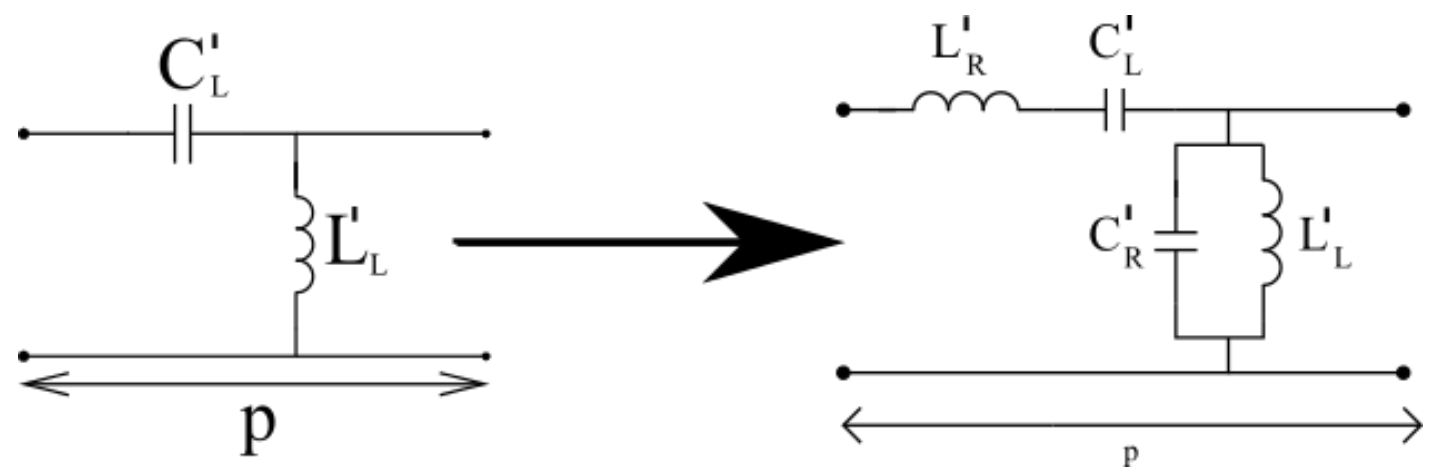

Figura 2.7: Os efeitos inerentes aos fenômenos clássicos, incluídos ao modelo da linha orientada à esquerda, formam a LTCED homogênea.

$$
Z^{\prime}(\omega)=j\left(\omega L_{R}^{\prime}-\frac{1}{\omega C_{L}^{\prime}}\right)
$$

e

$$
\begin{gathered}
Y^{\prime}(\omega)=j\left(\omega C_{R}^{\prime}-\frac{1}{\omega L_{L}^{\prime}}\right) . \\
j \beta(\omega)=\sqrt{Z^{\prime}(\omega) Y^{\prime}(\omega)}=\left[j^{2}\left(\omega L_{R}^{\prime}-\frac{1}{\omega C_{L}^{\prime}}\right)\left(\omega C_{R}^{\prime}-\frac{1}{\omega L_{L}^{\prime}}\right)\right]^{1 / 2},
\end{gathered}
$$

que pode ser reescrita como: 


$$
\beta(\omega)=s(\omega)\left[\left(\frac{\omega}{\omega_{R}^{\prime}}\right)^{2}+\left(\frac{\omega_{L}^{\prime}}{\omega}\right)^{2}-\left(\frac{\omega_{L}^{\prime}}{\omega_{s e}^{\prime}}\right)^{2}-\left(\frac{\omega_{L}^{\prime}}{\omega_{s h}^{\prime}}\right)^{2}\right]^{1 / 2}
$$

onde $\omega_{R}^{\prime}=\left(L_{R}^{\prime} C_{R}^{\prime}\right)^{-1}, \omega_{L}^{\prime}=\left(L_{L}^{\prime} C_{L}^{\prime}\right)^{-1}, \omega_{s h}^{\prime}=\left(L_{L}^{\prime} C_{R}^{\prime}\right)^{-1}$ e $\omega_{s e}=\left(L_{R}^{\prime} C_{L}^{\prime}\right)^{-1}$ são variáveis em $\mathrm{rad} . \mathrm{m} / \mathrm{s}$, e

$$
s(\omega)= \begin{cases}-1, & \text { para } \omega<\omega_{s h} \\ +1, & \text { para } \omega>\omega_{s e}\end{cases}
$$

O sinal negativo representa o comportamento LTME, enquanto o positivo representa o comportamento LTMD. O diagrama de dispersão resultante é ilustrado na Figura 2.8. Conforme pode ser observado, há uma faixa na qual $\beta \leq 0$ para frequências positivas, o que não ocorre em uma LT clássica. Esta é uma propriedade que vem sendo amplamente explorada para o projeto de novos dispositivos de micro-ondas. Analisando a figura, é possível observar que este tipo de estrutura apresenta bandas proibidas tanto na zona de propagação LTME quanto na zona de propagação LTMD.

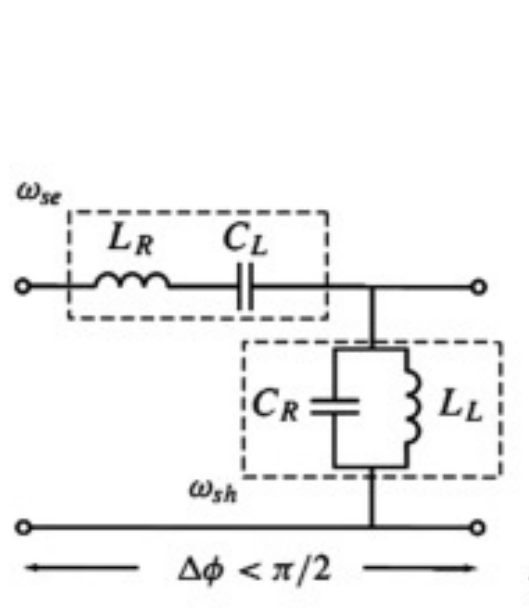

(a)

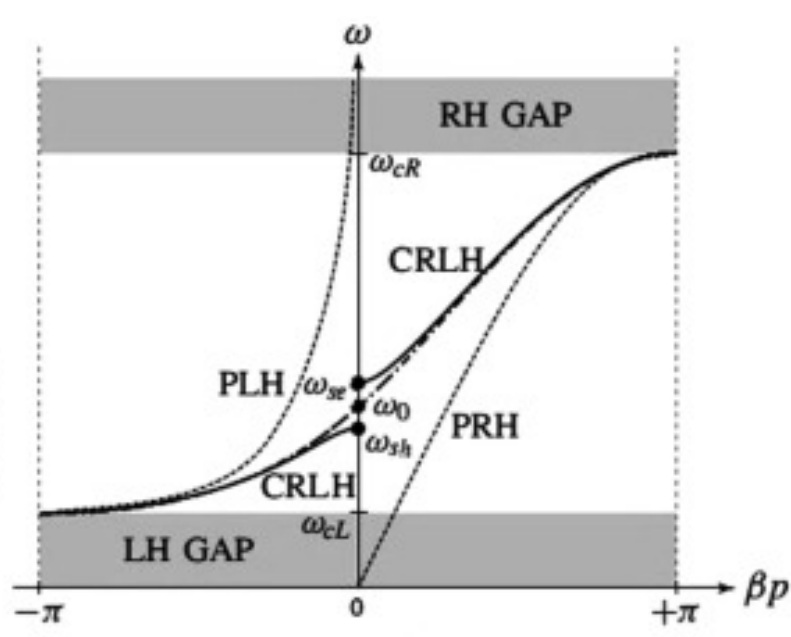

(b)

Figura 2.8: Exemplo de um diagrama de dispersão de uma LTCED [28].

Consideremos agora a LT artificial com célula unitária de comprimento $p$ ilustrada na Figura 2.9. Pelo teorema das condições de contorno periódicas de Bloch-Floquet, a relação de dispersão é dada por [24]:

onde

$$
\beta(\omega)=\frac{1}{p} \cos ^{-1}\left[1+\frac{Z(\omega) Y(\omega)}{2}\right]
$$

$$
Z(\omega)=j\left(\omega L_{R}-\frac{1}{\omega C_{L}}\right)
$$

$\mathrm{e}$ 


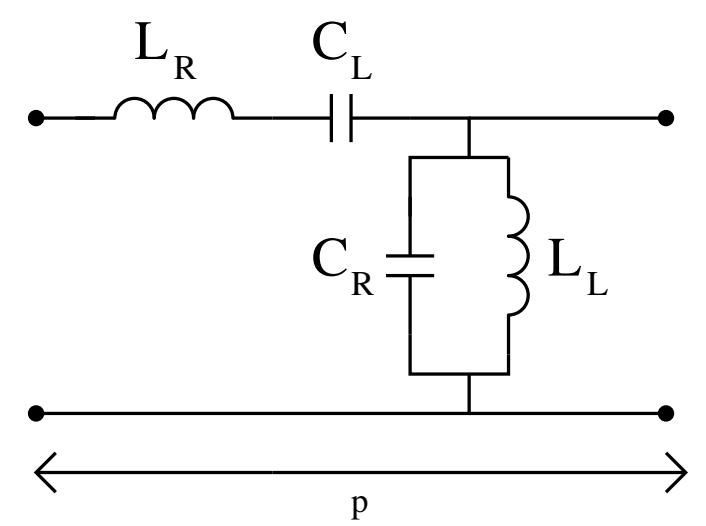

Figura 2.9: Linha de transmissão LTCED artificial.

$$
Y(\omega)=j\left(\omega C_{R}-\frac{1}{\omega L_{L}}\right)
$$

Tomando o cosseno de ambos os lados da equação, lembrando que o comprimento elétrico é pequeno $(\beta p<<1)$ e utilizando a aproximação $\cos (\beta p) \approx 1-(\beta p)^{2} / 2$ para $\beta p<<1$, é possível mostrar que:

$$
\beta(\omega) \approx \frac{s(\omega)}{p}\left[\left(\frac{\omega}{\omega_{R}}\right)^{2}+\left(\frac{\omega_{L}}{\omega}\right)^{2}-\left(\frac{\omega_{L}}{\omega_{s e}}\right)^{2}-\left(\frac{\omega_{L}}{\omega_{s h}}\right)^{2}\right]^{1 / 2}
$$

Ou seja, se o comprimento elétrico é suficiente pequeno, a implementação real LC tem comportamento idêntico ao caso da LT homogênea ideal. Com $L_{R}^{\prime}=L_{R} / p, C_{R}^{\prime}=C_{R}^{\prime} / p, L_{L}^{\prime}=L_{L} p$ e $C_{L}^{\prime}=C_{L} p$, os diagramas de dispersão são semelhantes.

É importante observar que em frequências baixas as reatâncias relativas a $C_{L}$ e $L_{L}$ predominam, de forma que nesta faixa de frequências a LTCED tende a se comportar como uma LTPME. De maneira similar, em altas frequências os efeitos $C_{R}$ e $L_{R}$ prevalecem, de modo que a LTCED se comporta como uma LTPMD. Uma forma intuitiva de visualizar este fato é observando o diagrama de dispersão: para frequências altas as velocidades de fase e de grupo são paralelas. Porém, para a faixa que está do lado esquerdo do diagrama de dispersão, $\omega>0$ e $\beta<0$, de forma que $v_{p}=\omega / \beta<0$, e $v_{g}=\partial \omega / \partial \beta>0$; ou seja, as velocidades são anti-paralelas, como no caso da LTPME.

\section{4}

\section{Componentes e Antenas Baseados em Guias de Onda Integrados em Substrato}

Estruturas baseadas em guias de onda integradas em substrato (GIS) têm sido bastante empregadas nos últimos anos em engenharia de microondas e de radiofrequência, devido principalmente às suas características de 
baixas perdas quando comparadas a estruturas de microlinhas habitualmente empregadas. A sintetização planar viabiliza também a integração com outros circuitos planares convencionais como transições, antenas e dispositivos ativos. Além disso, quando comparadas às guias de onda comerciais, seu custo e simplicidade de fabricação são consideravelmente menores. Estas estruturas são normalmente fabricadas utilizando cilindros condutores (vias) que fazem o papel das paredes do caso clássico, viabilizando assim a implementação de guias de onda retangulares na forma planar, além de outros tipos de circuitos como dispositivos ativos e antenas [29].

\subsection{1}

\section{Componentes GIS}

A geometria de uma estrutura GIS é ilustrada na Figura 2.10. Suas características de propagação são similares às de um guia de onda retangular clássico, desde que o espaçamento das vias seja pequeno em relação ao comprimento de onda (de forma que para a onda eletromagnética a estrutura se comporte como uma parede contínua) e a irradiação possa ser desprezada. Devido aos gaps entre vias metalizadas, o modo transversal magnético (TM) não é permitido, e temos apenas os modos transversais elétricos (TE) $\mathrm{TE}_{n 0}$, com modo fundamental $\mathrm{TE}_{10}$, de forma similar ao caso de um guia de onda retangular [29].

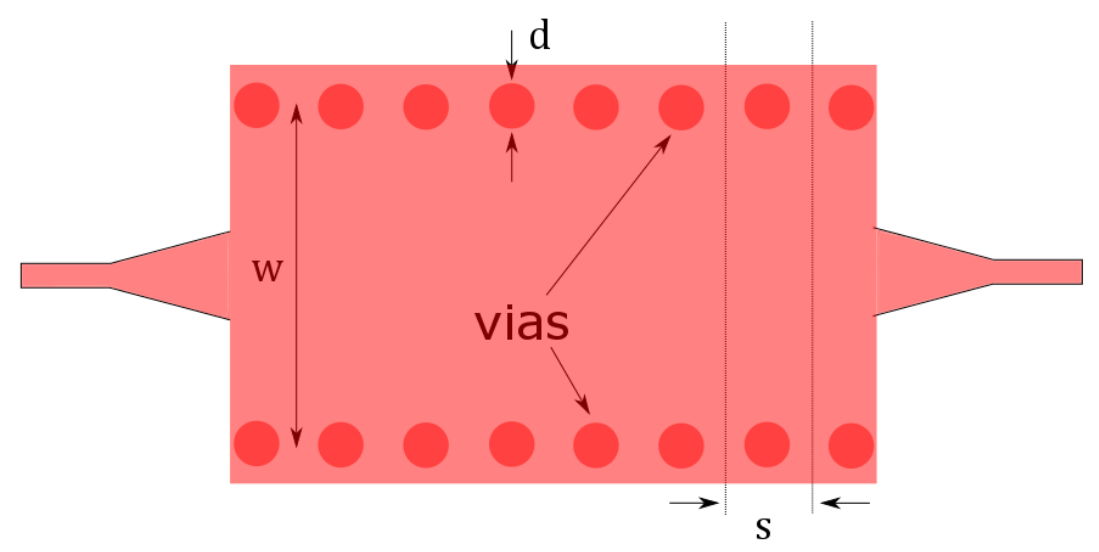

Figura 2.10: Geometria de uma guia de onda integrada em substrato (GIS).

Graças à similaridade entre GIS e guias de onda retangular, algumas relações empíricas foram extraídas de forma a relacionar as dimensões da estrutura GIS a uma largura efetiva $w_{\text {eff }}$ de um guia de onda retangular com as 
mesmas características, viabilizando assim uma condição inicial para o projeto. Uma das equações mais utilizadas para esse fim é:

$$
w_{e f f}=w-\frac{d^{2}}{0,95 s}
$$

onde $d$ é o diâmetro das vias, $s$ é o espaçamento longitudinal entre vias e $w$ representa o espaçamento transversal entre vias.

Duas outras equações mais refinadas podem ser utilizadas:

$$
w_{e f f}=w-1,08 \frac{d^{2}}{s}+0,1 \frac{d^{2}}{w},
$$

e

$$
w=\frac{2 w_{e f f}}{\pi} \cot ^{-1}\left[\frac{\pi s}{4 w_{e f f}} \ln \left(\frac{s}{2 d}\right)\right] .
$$

Embora estas relações ajudem no projeto, elas são apenas aproximações e normalmente se faz necessária a utilização de simulações eletromagnéticas para refinamento do projeto.

\subsection{2}

\section{Antenas baseadas em GIS}

Conforme descrito na subseção 2.4.1, pode-se projetar guias de onda e cavidades ressonantes integradas em substrato utilizando tecnologia GIS. Assim como no caso de antenas de abertura em guias de onda e cavidades clássicas, é possível realizar aberturas nas estruturas de forma a torná-las irradiativas. Um exemplo das estruturas citadas é ilustrado nas Figuras 2.11(a) e 2.11(b). As condições de contorno aberta e de curto-circuito fazem com que formem-se ondas estacionárias ao longo de seu comprimento, e quando uma abertura é realizada, irradiação ocorre em um determinado número de frequências de ressonância.

Em [30] mostra-se que estas células unitárias podem ser modeladas como LTCEDs, o corte central fazendo o papel da capacitância $C_{L}$ e as vias metálicas o da indutância $L_{L}$. Para o circuito ilustrado na Figura 2.9 os capacitores ME se encontram nas extremidades da célula unitária, porém para as células unitárias ilustradas na Figura 2.11 o capacitor se encontra no centro, e portanto elas são caracterizadas pelo circuito da Figura 2.12, conhecido como o modelo $\pi$ de uma LTCED. As características LTMD intrínsecas à LT clássica novamente são representadas por $C_{R}$ e $L_{R}$. Os valores de $C_{L}$ podem ser controlados alterando o comprimento e largura do capacitor interdigital no centro da estrutura, enquanto o valor de $L_{L}$ pode ser controlado através da escolha de diferentes larguras para a guia-de-onda, influenciando também na frequência de corte da mesma. Além disso, o diâmetro da via de curto-circuito também 


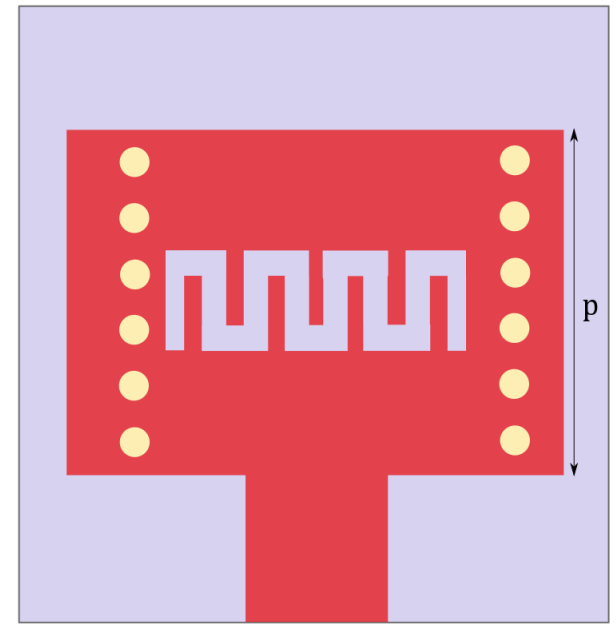

$2.11(\mathrm{a})$ :

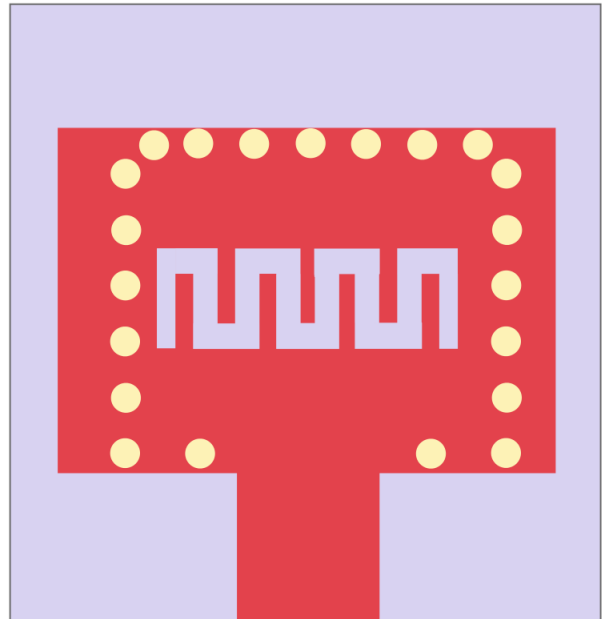

2.11(b):

Figura 2.11: Exemplos de antenas baseadas em GIS utilizadas neste trabalho, condições de contorno (a) aberta e (b) curto.

tem forte influência no valor da indutância. Embora o comprimento da via também influencie neste valor, para o projeto desenvolvido neste trabalho a espessura do substrato é constante, e portanto este grau de liberdade não é explorado.

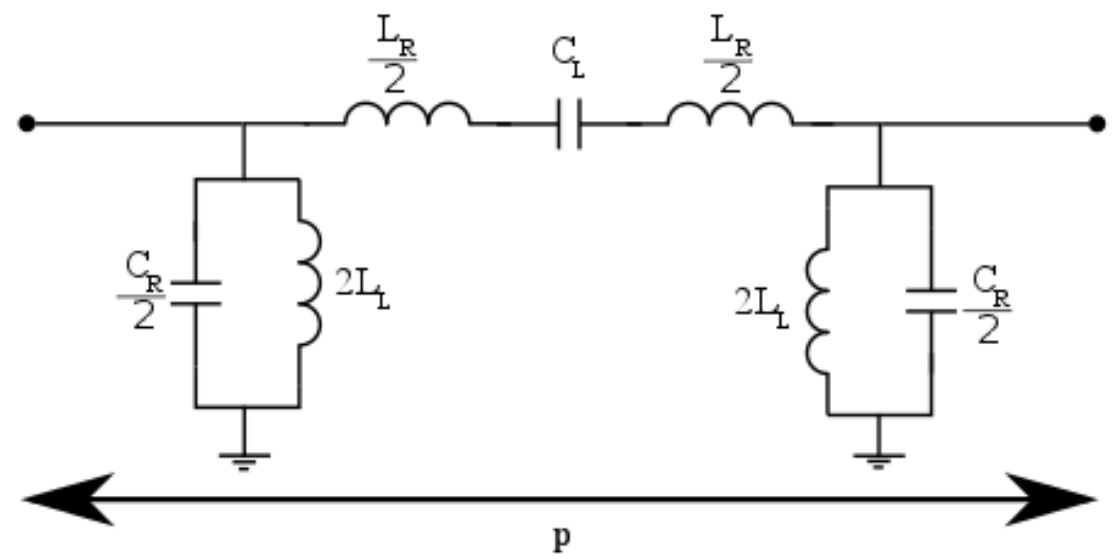

Figura 2.12: Modelo $\pi$ de uma linha de transmissão LTCED para modelo das antenas baseadas em guias de onda integradas em substrato.

Assim como para o modelo T, o modelo $\pi$ apresenta duas ressonâncias de ordem zero em seu diagrama de dispersão, dadas por:

$$
f_{s e}=\frac{1}{2 \pi \sqrt{L_{R} C_{L}}}, f_{s h}=\frac{1}{2 \pi \sqrt{L_{L} C_{R}}},
$$

que são conhecidos como os pontos de comprimento de onda infinito $(\beta=0)$. Geralmente, quando a condição de contorno da célula unitária é aberta, a frequência de ressonância é $f_{s h}$; e quando é curto-circuitada, a ressonância 
ocorre na frequência $f_{\text {se }}$. Entretanto, como $\beta=0$ o campo elétrico $\vec{E}$ é uniforme ao longo da superfície da antena. Desta forma, particularmente para o caso curto, como o campo $\vec{E}=0$ na extremidade da estrutura devido às condições de contorno das Equações de Maxwell, isto força campo nulo ao longo de todo o comprimento, e portanto a ressonância de ordem zero desaparece. As frequências de ressonância dos outros modos para uma LTCED de $M$ estágios pode ser extraída do diagrama de dispersão quando a seguinte condição é satisfeita:

$$
\theta_{M}=\beta M p=n \pi,
$$

ou seja

$$
\beta p=\frac{n \pi}{M} \begin{cases}n=0, \pm 1, \pm(M-1) & \text { para célula unitária do tipo } \mathrm{T} \\ n=0, \pm 1, \pm M & \text { para célula unitária do tipo } \pi\end{cases}
$$

A principal consequência da equação acima é que para apenas uma célula unitária tipo $\mathrm{T}(M=1)$, apenas a ressonância de ordem zero é possível. Entretanto, para apenas uma célula unitária do tipo $\pi$ obtém-se três ressonâncias no caso geral, 0 e \pm 1 . Como na estrutura curto-circuito mostrou-se que a ressonância de ordem zero não pode existir pelas leis do eletromagnetismo, para este caso temos os modos \pm 1 .

\section{5}

\section{Estruturas baseadas em Grafeno}

Esta seção tem como intuito prover uma pequena introdução às estruturas de grafeno e derivados, como por exemplo o OG e OGr, os métodos para sua produção e deposição e suas respectivas aplicações em sensores de gás.

\subsection{1}

\section{Introdução e Propriedades do Grafeno}

Conforme mencionado no capítulo de introdução, o grafeno é uma estrutura bidimensional alótropa do carbono, onde os átomos são ligados entre si por meio de ligações $\operatorname{sp}^{2}$ [10]. A estrutura possui formato de colmeia de abelha. A hibridização formada por um orbital s e dois orbitais p faz com que se formem ligações $\sigma$ entre os átomos de carbono, que são separados por uma distância de 1,42 A. Além disso, cada orbital p mantém um elétron livre, de forma que a estrutura pode fazer também ligações covalentes, as ligações $\pi$. As ligações $\sigma$ são extremamente fortes, enquanto as ligações $\pi$ são fracas, e este fato é que diferencia o diamante do grafite: o arranjo dos átomos no diamante 
ocorre de forma que existam apenas ligações $\sigma$; o grafite, por outro lado, pode ser descrito como um empilhamento de camadas de grafeno, sendo que cada camada se liga com a próxima através de ligações $\pi$.

O grafeno foi isolado pela primeira vez em 2004 [11], pelos professores Geim e Novoselov, da universidade de Manchester, utilizando exfoliação micromecânica $^{4}$, rendendo a eles o Prêmio Nobel de Física em 2010. Depois da sua descoberta o número de publicações e pesquisas na área cresceram astronomicamente, devido às propriedades surpreendentes do grafeno. Para citar algumas, ele tem a maior mobilidade de elétrons que qualquer outro material ${ }^{5}$, maior que $200000 \mathrm{~cm}^{2} \mathrm{~V}^{-1} \mathrm{~s}^{-1}$. Além disso, ele é um dos melhores condutores de eletricidade, com resistividades da ordem de $10^{-6} \Omega \cdot \mathrm{cm}$. Outras características não elétricas incluem:

- É o material mais fino conhecido, com apenas $0,34 \mathrm{~nm}$ de espessura;

- Maior razão superfície/volume, $2630 \mathrm{~m}^{2} / \mathrm{g}$;

- É o filme contínuo mais leve, com apenas $0,38 \mathrm{mg} / \mathrm{m}^{2}$;

- Tem a maior resistência tênsil que qualquer outro material, com módulo de Young de 1TPa;

- É o melhor condutor de calor, condutividade térmica de $5300 \mathrm{~W} \cdot \mathrm{m}^{-1}$. $\mathrm{K}^{-1}$;

- Um dos materiais mais elásticos;

- Um dos materiais mais flexíveis;

- Totalmente impermeável até mesmo para o menor átomo (hélio).

Devido a estas características, estruturas baseadas em grafeno têm demonstrado potencial em diversas áreas, incluindo eletrônica, processamento da luz, geradores e armazenamento de energia, sensores, plasmônica, e metamateriais, além de aplicações em medicina [31]. Além disso, as propriedades condutoras deste material são facilmente modificadas por agentes externos [12], especialmente pela adsorção de espécies na superfície do material, viabilizando assim a sua aplicação como sensor.

Existem diversos métodos para produção de grafeno. Um dos mais utilizados é a DQV. A esfoliação em fase líquida é bastante utilizada para casos onde não se faz necessária uma qualidade extrema do grafeno, devido ao seu baixo custo e simplicidade. Ela também é utilizada quando a estrutura onde

\footnotetext{
${ }^{4}$ Este método consiste em remover as camadas de grafite com uma fita adesiva repetidamente, até o limite em que reste apenas uma camada.

${ }^{5}$ Graças a este fato, o grafeno também tem os elétrons mais rápidos, atingindo velocidades de até $\approx 10^{6} \mathrm{~m} / \mathrm{s}$, apenas 100 vezes menor que a velocidade da luz.
} 
o grafeno vai ser depositado não suporta temperaturas muito altas, sendo que o método DQV atinge temperaturas de até $1000^{\circ} \mathrm{C}$. Outros métodos incluem esfoliação mecânica (utilizado por Geim e Novoselov) e carbono em carbeto de silício (SiC), também conhecido como sublimação de carbetos. Neste trabalho utiliza-se apenas esfoliação em fase líquida, e portanto foca-se neste processo em detrimento dos outros.

\subsection{2}

\section{Óxido de Grafeno e Óxido de Grafeno Reduzido}

OG é definido como um material de uma ou poucas camadas formado de carbono, hidrogênio, e moléculas de oxigênio pela oxidação de cristais de grafite. Sua estrutura é ilustrada na Figura 2.13. Estes cristais são abundantes e de baixo custo, dispersáveis em água e relativamente fáceis de processar. Além disso, o OG pode ser parcialmente reduzido para folhas similares ao grafeno através da remoção dos grupos de oxigênio, restaurando as ligações $s p^{2} \mathrm{C}=\mathrm{C}$, como na estrutura hexagonal de grafeno. As folhas de OGr são usualmente consideradas um tipo de grafeno derivado quimicamente. Duas características fazem com o que o OG seja tão amplamente estudado e utilizado: ele pode ser produzido utilizando grafite como matéria-prima, que apresenta um custo consideravelmente baixo, juntamente com métodos químicos de alto rendimento; e é altamente hidrofílico ${ }^{6}$ podendo formar coloides aquosos estáveis, facilitando a montagem de estruturas macroscópicas via processos simples e de baixo custo. Além disso, a grande densidade de defeitos ao longo da sua estrutura faz com que ele seja um sensor com desempenho ainda melhor que grafeno primitivo. Apesar do OG apresentar comportamento isolante (resistências de folha de $\approx 10^{10} \Omega / \square$ ), estruturas baseadas em OG quimicamente reduzido podem apresentar condutividades tão altas quanto a do grafeno pristino, além de apresentar excelentes propriedades eletromecânicas [31].

\subsection{3}

\section{Síntese de OG e OGr}

O OG pode ser fabricado através da oxidação de cristais de grafite, conforme ilustrado na Figura 2.14, introduzindo assim funcionalidades oxigenadas na estrutura de grafite que não apenas expandem a separação das camadas como também tornam o material hidrofílico.

Graças a esta propriedade, o óxido de grafite pode ser exfoliado em água através de sonicação, produzindo assim OG com uma ou poucas camadas. $\mathrm{O}$

${ }^{6}$ Tem a tendência de se misturar com ou se dissolver em água. 


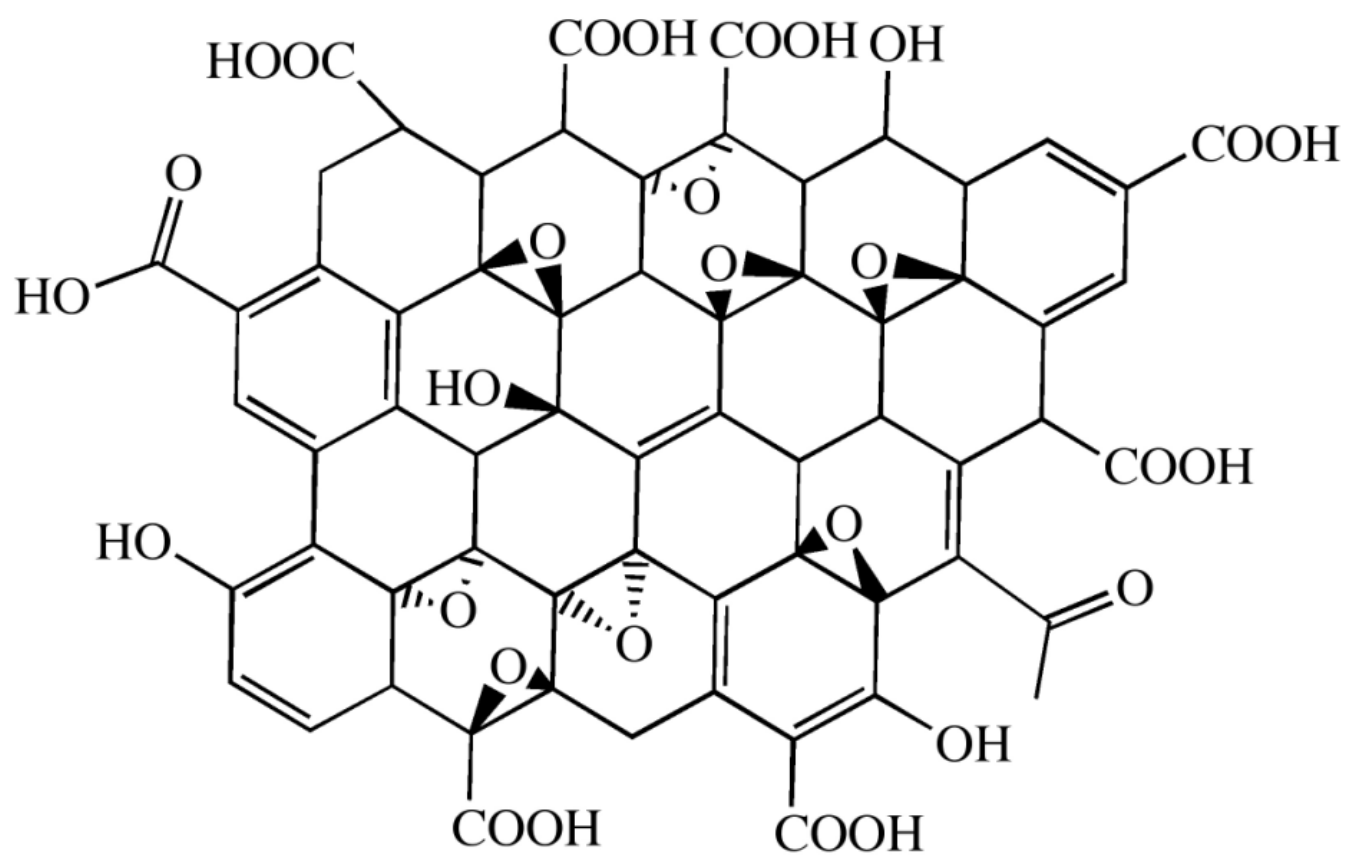

Figura 2.13: Estrutura de OG e suas ligações.

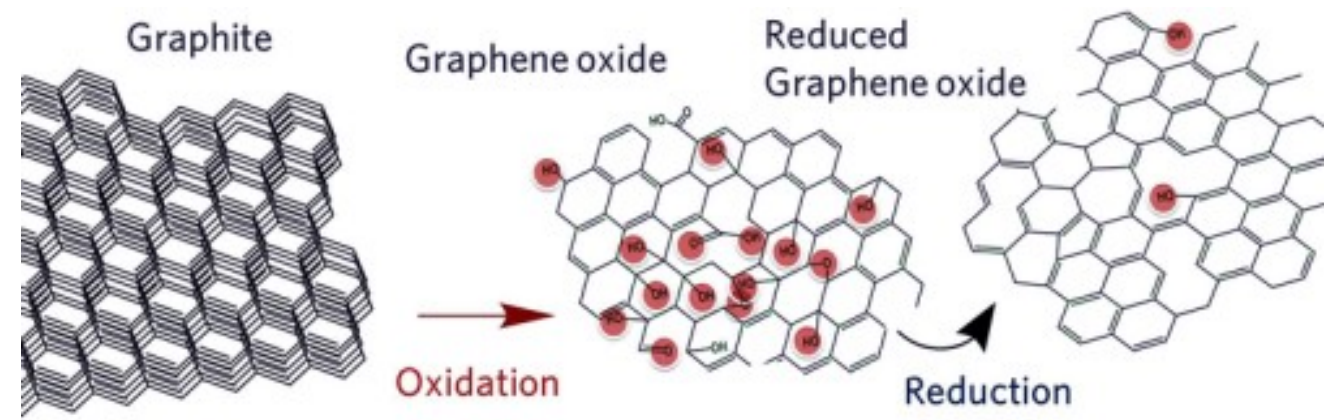

Figura 2.14: Produção de OG e OGr.

método de Hummer foi o primeiro a ser reportado na literatura, no qual o grafite é oxidado através de uma solução de permanganato de potássio em ácido sulfúrico. Outros métodos para obtenção de OG são usualmente baseados no de Hummer [34], apenas utilizando diferentes soluções, sendo normalmente chamados de métodos de Hummer modificados. Conforme citado, OG apresenta propriedades elétricas de um isolante. Porém através de tratamento térmico, químico ou utilizando luz pode-se restaurar diversas características inerentes ao grafeno pristino.

\subsection{4}

\section{Espectroscopia Raman}

A técnica mais utilizada para caracterização de estruturas baseadas em carbono é a espectroscopia Raman, devido à sua alta sensibilidade à estrutura geométrica e ligação entre moléculas dos alótropos do carbono, onde 
os diferentes tipos variam entre si apenas as posições relativas na estrutura e a natureza de suas ligações moleculares [35].

A Figura 2.15 ilustra alguns exemplos de espectros Raman. Por ser extremamente sensível ao número de camadas da amostra, e espectroscopia Raman pode ser utilizada para diferenciação de grafeno monocamada, bicamada e multicamada. O espectro característico do grafeno monocamada é representado pela linha preta. A banda $\mathrm{G}$ ocorre aproximadamente no comprimento de onda $1587 \mathrm{~cm}^{-1}$, e corresponde a um modo vibracional relacionado às vibrações tangenciais dos átomos de carbono com hibridização $s p^{2}$. A banda $2 \mathrm{D}$ do grafeno monocamada geralmente apresenta largura em torno de de $33-40 \mathrm{~cm}^{-1}$. A figura ilustra também os espectros de grafeno bicamada, multicamada e grafite, que, como mencionado, nada mais é que um empilhamento de diversas camadas de grafeno.

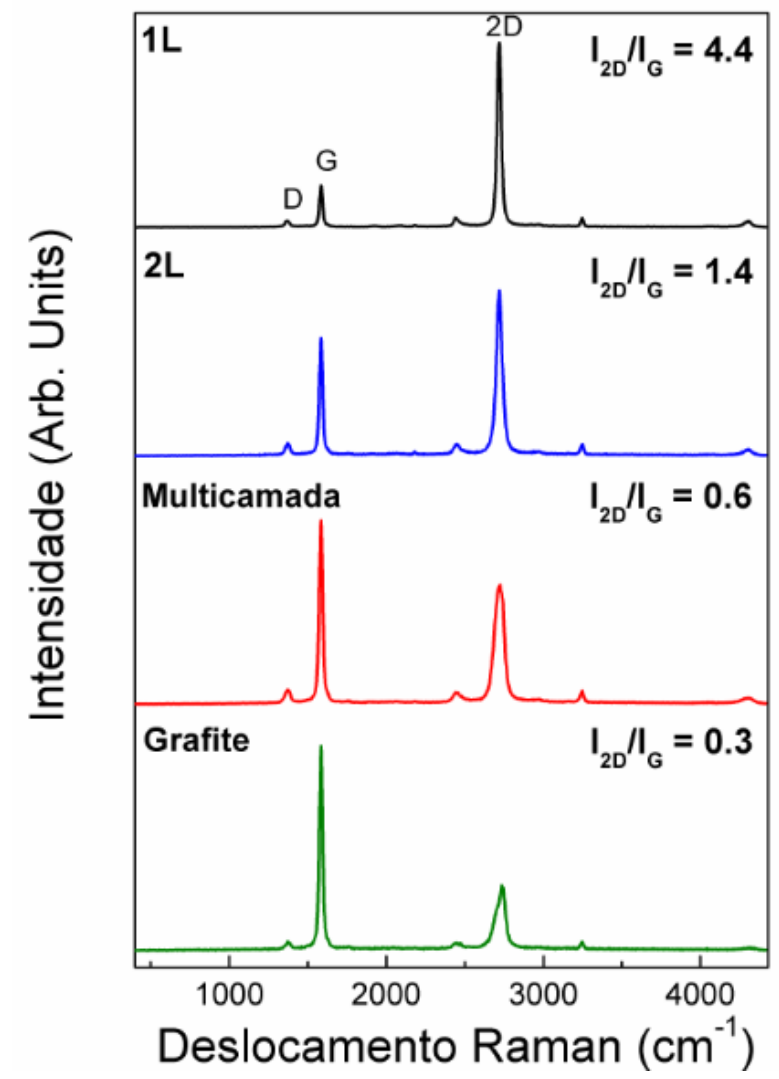

Figura 2.15: Espectro Raman de grafeno e suas respectivas interpretações para caracterização de grafeno monocamada, bicamada, multicamada e grafite.

A banda D está relacionada aos defeitos existentes na estrutura de carbono. Ela é relativamente pequena no grafeno de alta qualidade. Já a banda 2D é a segunda ordem da banda D. Ela corresponde ao espalhamento de duplo fônon em torno do ponto $\mathrm{K}$ da zona de Brillouin. Apesar de ser um harmônico da banda D, ela não depende da primeira para existir, sendo 
sempre pronunciado no grafeno. A banda 2D também pode ser utilizada para caracterização do número de camadas do grafeno, sendo que tanto sua posição quanto o seu formato variam com o número de camadas. Uma medida utilizada para determinar se o grafeno é de boa qualidade é, além de uma banda D pequena, é o raio $I_{2 D} / I_{G}$, normalmente apresentando valor aproximadamente maior que dois para grafeno de alta qualidade. Isto pode ser observado também na Figura 2.15. Para estruturas de OG/OGr o espectro Raman é bastante diferente do grafeno puro. Um exemplo de um espectro Raman de OG e OGr encontrado na literatura [36] é ilustrado na Figura 2.16.

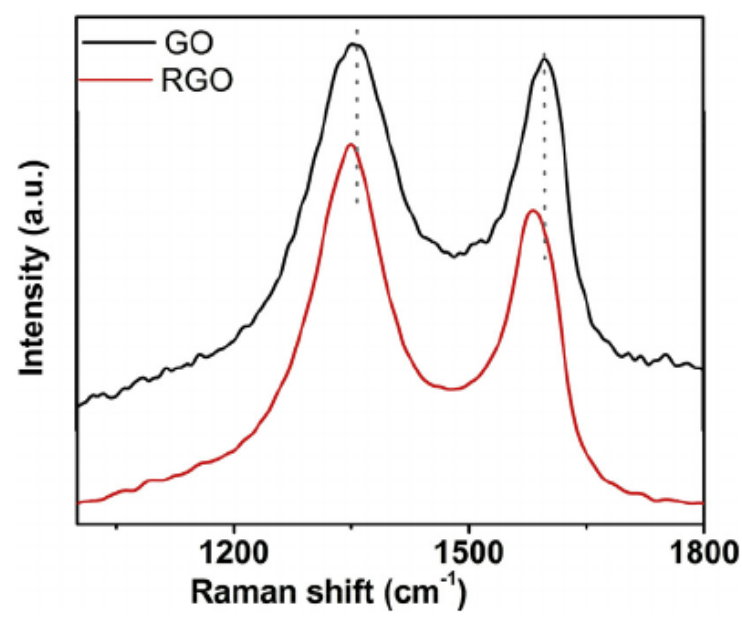

Figura 2.16: Exemplo de Espectro Raman de OG e OGr.

\section{6}

\section{Considerações finais do Capítulo 2}

Neste capítulo foi apresentado o embasamento teórico necessário para posterior compreensão do que é exposto no trabalho. Partindo da teoria básica de antenas, discorreu-se sobre a teoria da re-irradiação, a base fundamental do eletromagnetismo dos sistemas de RFID. Posteriormente, tratou-se da teoria de MTMs e LTCEDs, já que este trabalho explora as características deste tipo de estrutura para aplicações em sensores. O tema de GIS também é tratado, já que as antenas aqui utilizadas são baseadas nesta abordagem. Futuramente, o Capítulo 4 tratará sobre a relação entre LTCEDs e GIS. Finalmente, foi apresentada a base teórica sobre estruturas baseadas em grafeno, com destaque para OG e OGr. 


\section{3}

\section{Projeto Sensores GIS: Abordagem Paramétrica}

Este capítulo trata da primeira parte do projeto dos sensores de gás sem fio utilizando estruturas baseadas em grafeno. Optou-se por apresentar o conteúdo na ordem cronológica dos fatos, de forma a ilustrar também o ganho de know-how que foi sendo obtido ao longo da linha do tempo de desenvolvimento do mesmo. Desta forma, este é um capítulo mais focado em uma abordagem experimental, deixando para os próximos a apresentação com embasamento teórico mais sólido. Na primeira parte do capítulo, focase no projeto das antenas baseadas em GIS implementadas em substrato Rogers RT5880. Na segunda parte, atenta-se ao projeto de uma estrutura análoga à primeira, porém implementada em substrato FR4 e com OG/OGr. A metodologia completa desenvolvida para projeto das antenas baseadas em GIS foi deixada para o Capítulo 4.

\section{1}

Sensor de Gás sem Fio em Substrato Rogers RT5880

\subsection{1}

\section{Condição de Contorno de Circuito Aberto}

Antes do desenvolvimento de uma metodologia específica para o projeto dos sensores, decidiu-se projetar as antenas variando parametricamente suas dimensões via simulação eletromagnética no software comercial ADS (Advanced Design System), da Keysight. Uma antena GIS com condição de contorno aberta análoga à da Figura 2.11(a) é projetada no ADS em substrato RT5880 $\left(\epsilon_{r}=2.2, \tan \delta=0,0009\right)$. Na Figura 3.1 pode-se observar o resultado da simulação da parte real da impedância de entrada. A frequência de ressonância ocorre em $11 \mathrm{GHz}$ e, como pode ser observado, a impedância de entrada é de $\approx 241,8 \Omega$, bastante diferente da impedância característica de $50 \Omega$. De forma a facilitar a caracterização da antena, se faz necessária a realização de um casamento de impedâncias. Como o projeto envolve uma estrutura ressonante de banda estreita, o método escolhido foi o do transformador de quarto de onda, devido à sua simplicidade e fácil integração com tecnologia de microlinhas. Seja $Z_{A}$ a impedância de entrada da antena e $Z_{0}$ a impedância caracterís- 
tica da linha de transmissão que alimenta a antena, pode-se demonstrar que a impedância "enxergada" pelo gerador é dada por:

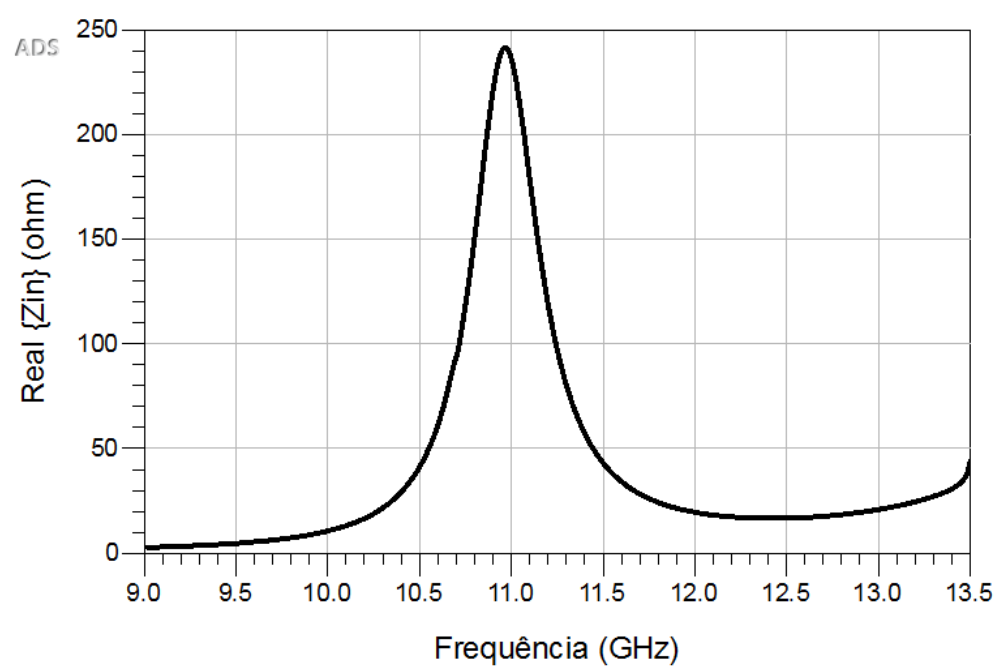

Figura 3.1: Simulação impedância de entrada para antena GIS RT5880, condição de contorno aberta.

$$
Z_{\text {in }}=Z_{0}\left[\frac{Z_{A}+j Z_{0} \tan (\beta L)}{Z_{0}+j Z_{A} \tan (\beta L)}\right] .
$$

Se a linha tem comprimento $L=\lambda / 4, \tan (\beta L)=\tan \left(\frac{2 \pi}{\lambda} \frac{\lambda}{4}\right)=\tan (\pi / 2) \rightarrow \infty$, e a equação $3-1$ se resume a

$$
Z_{\text {in }}=\frac{Z_{0}^{2}}{Z_{A}}
$$

ou seja, a impedância característica da linha de transmissão para casamento de impedâncias entre alimentação e antena deve ser a média geométrica entre as duas impedâncias:

$$
Z_{0}=\sqrt{Z_{i n} Z_{A}}=\sqrt{50 Z_{A}}
$$

já que a impedância que se deseja enxergar da entrada é $Z_{i n}=50 \Omega$. Desta forma, a impedância característica da linha do transformador de quarto de onda é $Z_{0} \approx 110 \Omega$. O layout da geometria da antena projetada no ADS é ilustrada na Figura 3.2(a). Depois de realizado o casamento de impedâncias, um processo de otimização adicional é efetuado. A Figura 3.2(b) ilustra as simulações do coeficiente de reflexão da antena casada em função de variações do diâmetro das vias. Conforme pode ser observado, o melhor casamento ocorre para um diâmetro de $0,3 \mathrm{~mm}$, e este foi o diâmetro escolhido para implementação das antenas. Além disso, o diagrama de irradiação simulado nos planos $\phi=0$ e $\phi=90^{\circ}$ é ilustrado na Figura 3.3. O ganho simulado na frequência de 10,19 GHz é 6,60 dBi, e a eficiência de irradiação $95 \%$. 


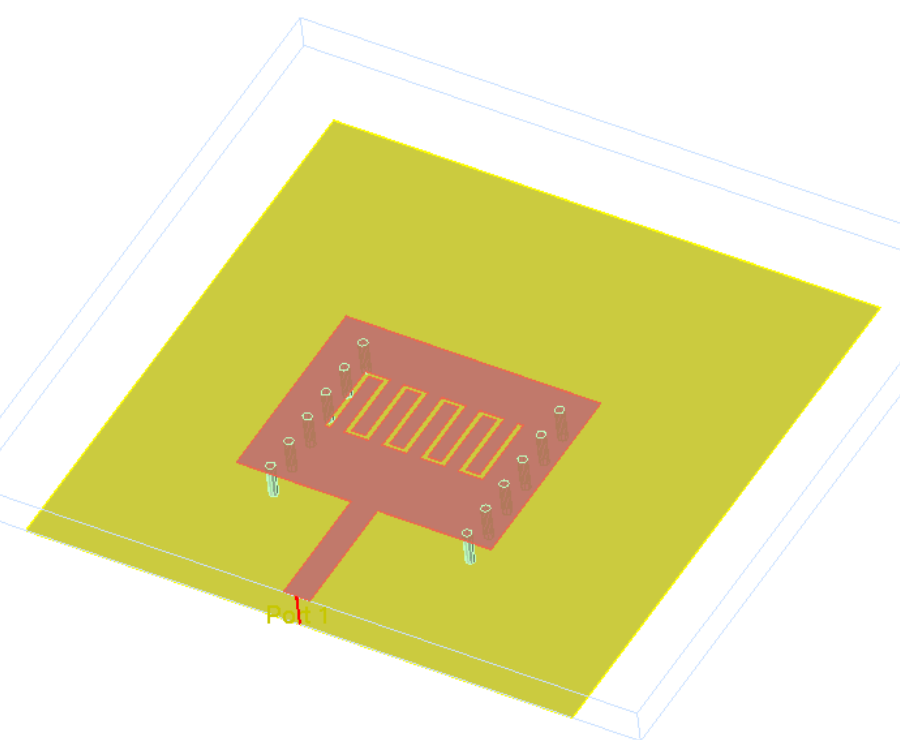

$3.2(\mathrm{a})$ :

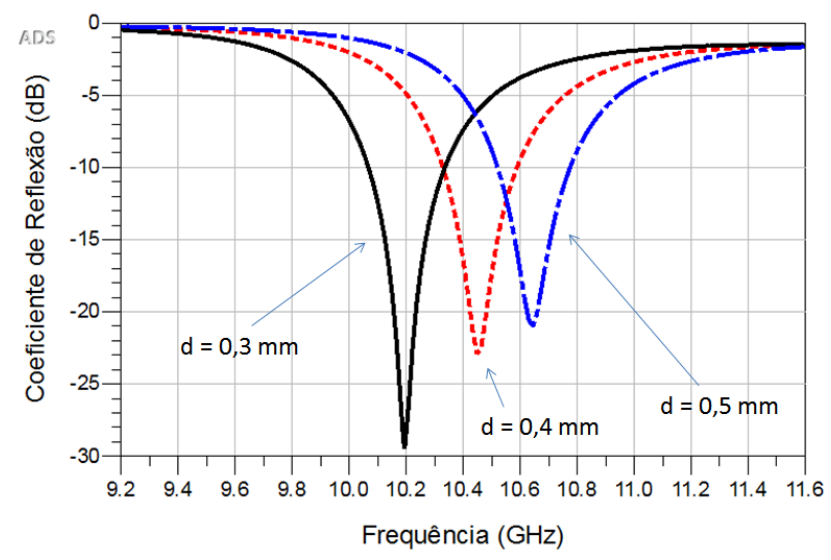

$3.2(\mathrm{~b})$ :

Figura 3.2: Simulação coeficiente de reflexão para antena GIS RT5880 casada com transformador quarto de onda, condição de contorno aberta: (a) layout e (b) otimização diâmetro das vias.

A Figura 3.4 ilustra o protótipo da antena de condição de contorno aberta em substrato RT5880. A fabricação é feita utilizando fresagem em uma máquina comercial da LPKF, incluindo a furação para passagem das vias. Uma pasta epóxi é depositada manualmente nos furos e curada termicamente, de forma a implementar as vias. São fabricadas três cópias da estrutura, de forma a testar a variabilidade do processo tanto de fabricação da antena quanto de deposição de grafeno.

Os resultados experimentais do coeficiente de reflexão de entrada são ilustrados na Figura 3.5. Note que há uma grande variação nas frequências 

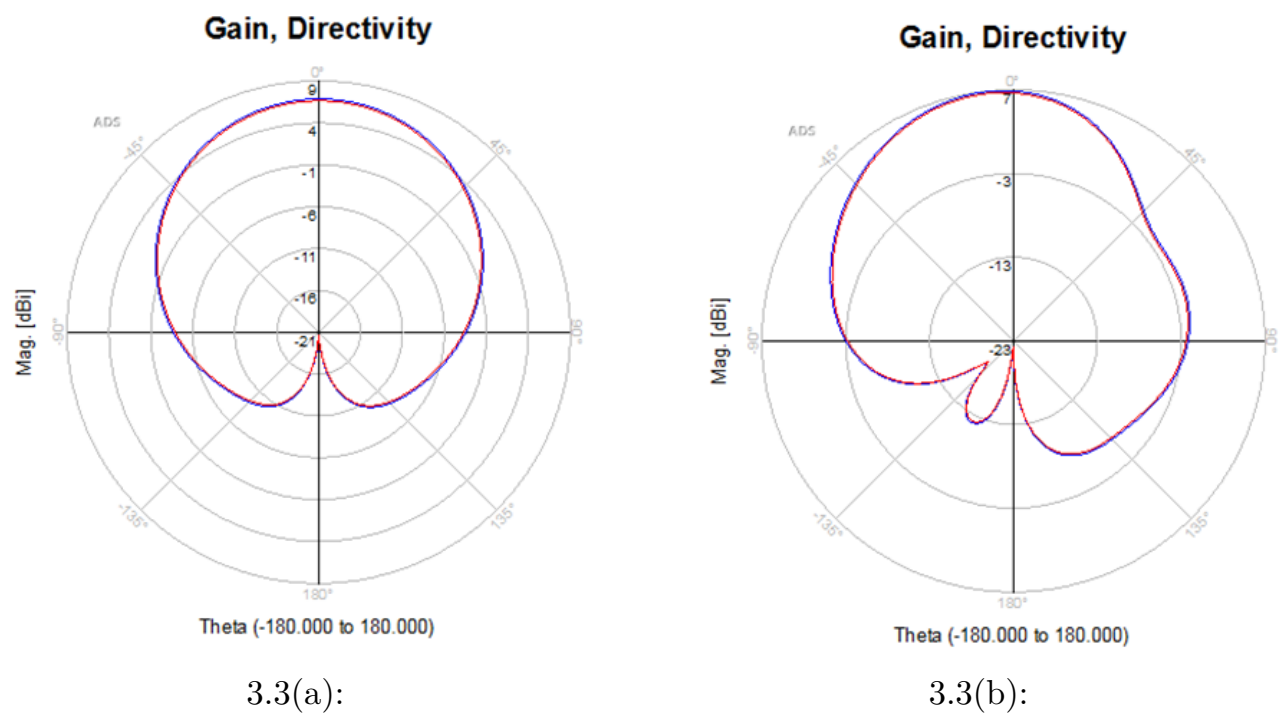

Figura 3.3: Simulação diagrama de irradiação para antena GIS RT5880, condição de contorno aberta: (a) $\phi=0$ e (b) $\phi=\pi / 2$.

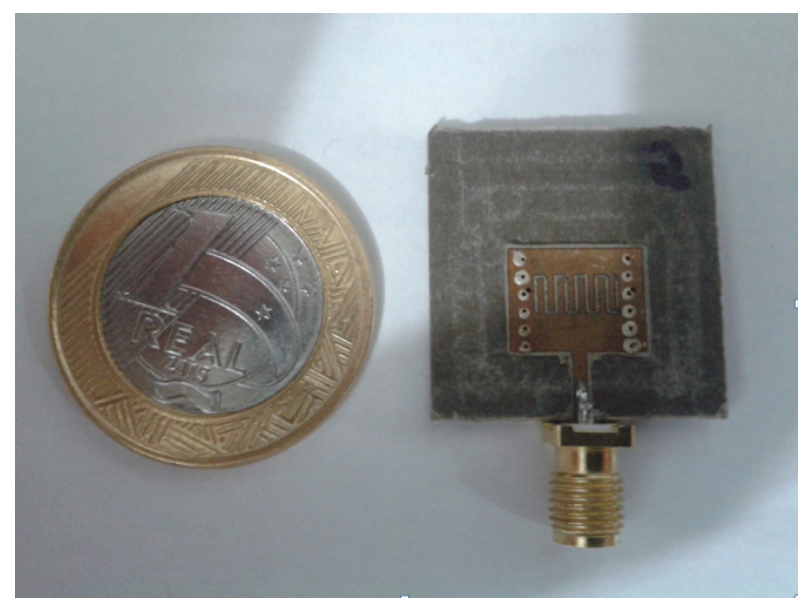

Figura 3.4: Protótipo da antena GIS com condição de contorno aberta em substrato RT5880.

de ressonância, tanto em relação à simulação, quanto em relação às diferentes implementações da mesma estrutura. Além disso, os diagramas de irradiação experimentais das três estruturas são medidos em ambiente aberto em suas respectivas frequências de ressonância utilizando o sistema Lab-Volt, e são ilustrados na Figura 3.6. Como as medidas não foram efetuadas dentro de uma câmara anecoica, os efeitos multipercurso ${ }^{1}$ causados pelas múltiplas reflexões da onda em objetos ao redor influenciam no resultado, e o que se obtém é apenas uma estimativa do ganho da antena. Como o sistema Lab-Volt calcula

${ }^{1}$ Efeitos multipercurso ocorrem como consequência dos diversos caminhos que a onda eletromagnética pode percorrer antes de atingir a antena receptora. As diferenças de fase promovidas por esses trajetos distintos podem acarretar interferências destrutivas na recepção, de forma a atenuar o sinal recebido. 
a largura de feixe de meia potência (LFMP), é possível estimar o ganho utilizando a seguinte aproximação:

$$
G_{0} \approx 10 \log \left(\frac{32400}{\Theta_{E} \Theta_{H}}\right)
$$

onde $\Theta_{E}$ e $\Theta_{H}$ são as LFMP em graus nos planos E e H, respectivamente. Note que assim como no diagrama de irradiação simulado na Figura 3.3, os diagramas experimentais também apresentam ganho máximo em um ângulo diferente da vertical no plano $\mathrm{H}(\phi=\pi / 2)$. Isto se deve ao fato de as antenas estarem operando na ressonância de ordem -1 [30]. A Tabela 3.1 resume os valores medidos das LFMP e os ganhos experimentais estimados. Lembrando que o valor simulado foi de $6,6 \mathrm{dBi}$, os resultados aproximados dão uma estimativa razoável do ganho das antenas implementadas.

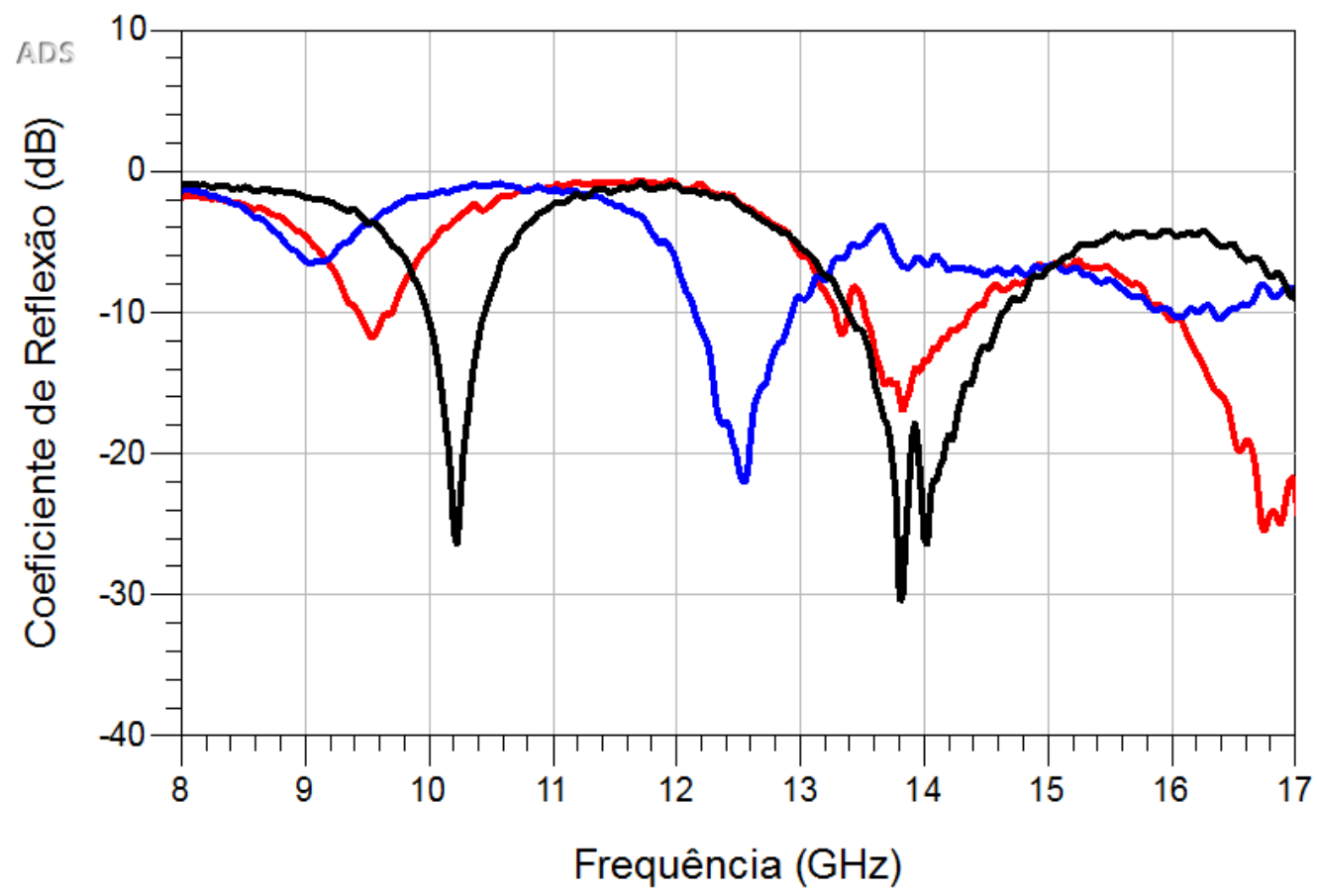

Figura 3.5: Medidas coeficiente de reflexão da antena GIS em RT5880 condição de contorno aberta para as três diferentes implementações (vermelho protótipo 1 , azul 2, preto 3$)$.

Tabela 3.1: Medidas Antenas GIS: Aberta

\begin{tabular}{c|cc|cc|cc}
\hline \hline & $\Theta_{E 1}$ & $\Theta_{H 1}$ & $\Theta_{E 2}$ & $\Theta_{H 2}$ & $\Theta_{E 3}$ & $\Theta_{H 3}$ \\
\hline & $92,05^{\circ}$ & $57,79^{\circ}$ & $76,7^{\circ}$ & $71,36^{\circ}$ & $76,79^{\circ}$ & $60,89^{\circ}$ \\
\hline \hline$f_{r}(\mathrm{GHz})$ & \multicolumn{2}{|c|}{9.55} & 9,05 & 10,23 \\
Ganho $(\mathrm{dBi})$ & \multicolumn{2}{|c|}{7.85} & 7,70 & 8,40 \\
\hline \hline
\end{tabular}



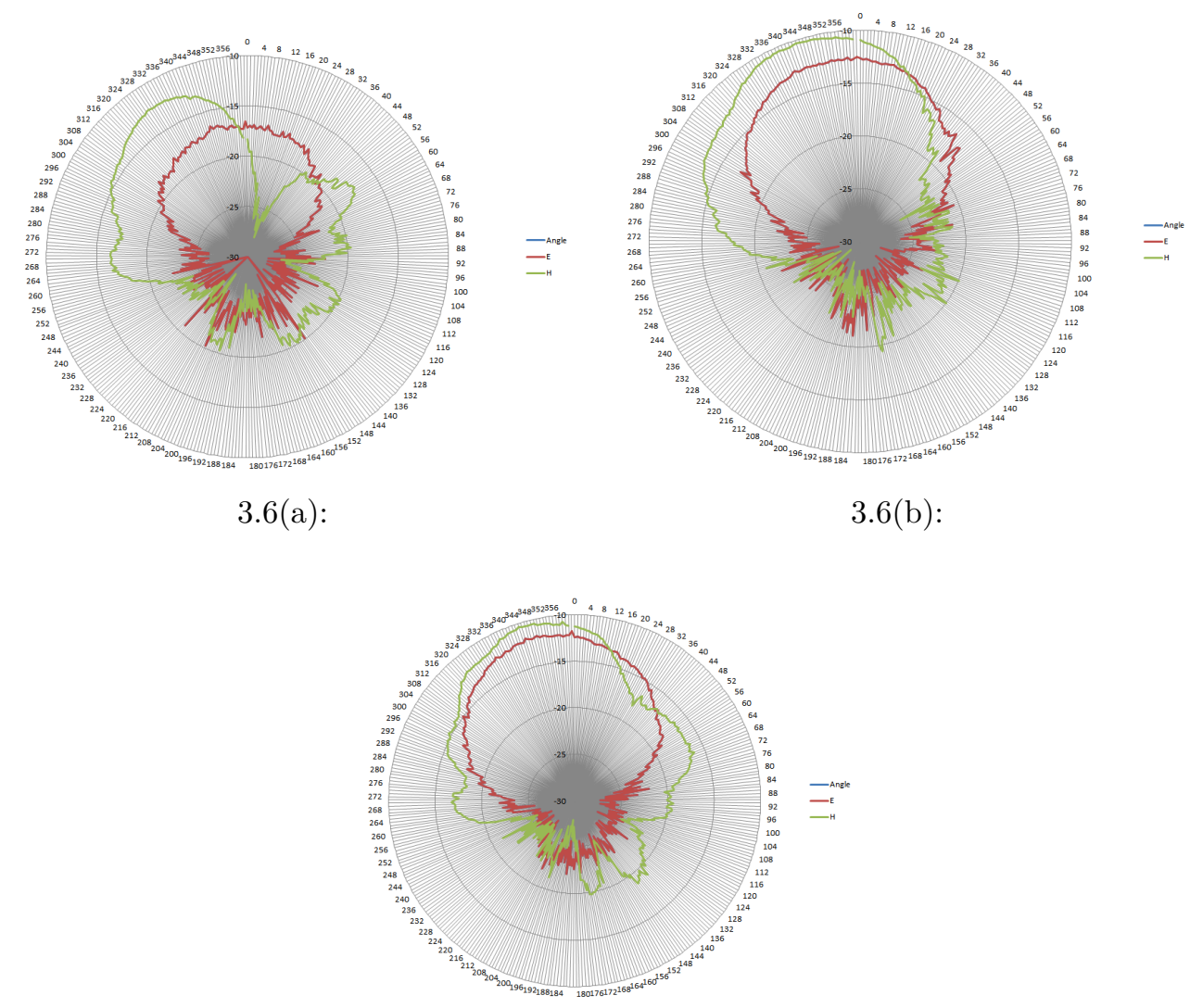

$3.6(\mathrm{c})$ :

Figura 3.6: Medidas diagrama de irradiação das antenas de condição de contorno aberta (a) protótipos 1, (b) 2 e (c) 3.

\subsection{2}

\section{Condição de Contorno Curto-Circuito}

A Figura 3.7(a) ilustra o layout do protótipo de condição de contorno de curto-circuito em substrato RT5880, e a Figura 3.7(b) ilustra as simulações do coeficiente de reflexão da antena para diferentes valores de diâmetros das vias. Conforme pode ser observado, a impedância de entrada da antena apresenta valor próximo à $50 \Omega$, eliminando a necessidade de efetuar casamento de impedâncias. Desta forma, a linha de alimentação é uma microlinha com impedância característica de $50 \Omega$. A melhor topologia obtida é a de vias com diâmetros de $0,3 \mathrm{~mm}$. O diagrama de irradiação simulado nos planos $\phi=0$ e $\phi=90^{\circ}$ é ilustrado na Figura 3.8. O ganho simulado na frequência de $10,13 \mathrm{GHz}$ é $6,72 \mathrm{dBi}$, e a eficiência de irradiação $92,5 \%$.

A Figura 3.9 apresenta o protótipo da antena com condição de contorno de curto-circuito em substrato RT5880. As vias também foram implementadas manualmente com epóxi. Da mesma forma que no caso do circuito aberto, três versões idênticas são fabricadas, de forma a verificar a influência do processo de fabricação. A Figura 3.10 ilustra as medidas dos coeficientes de reflexão 


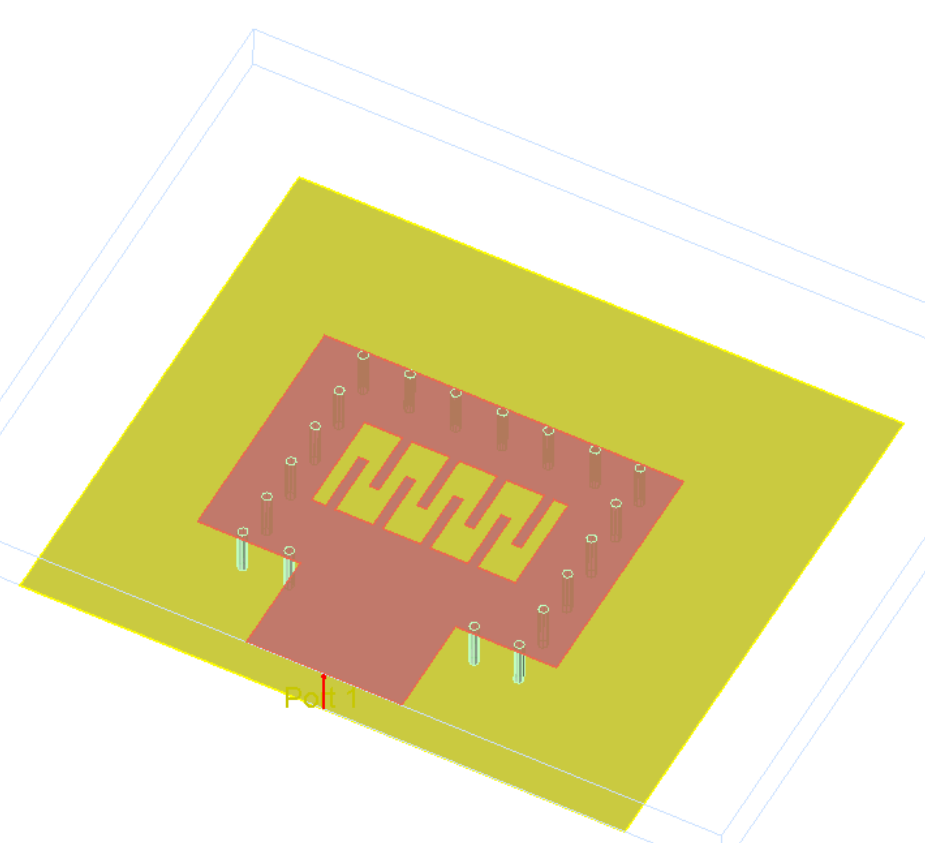

$3.7(\mathrm{a})$ :

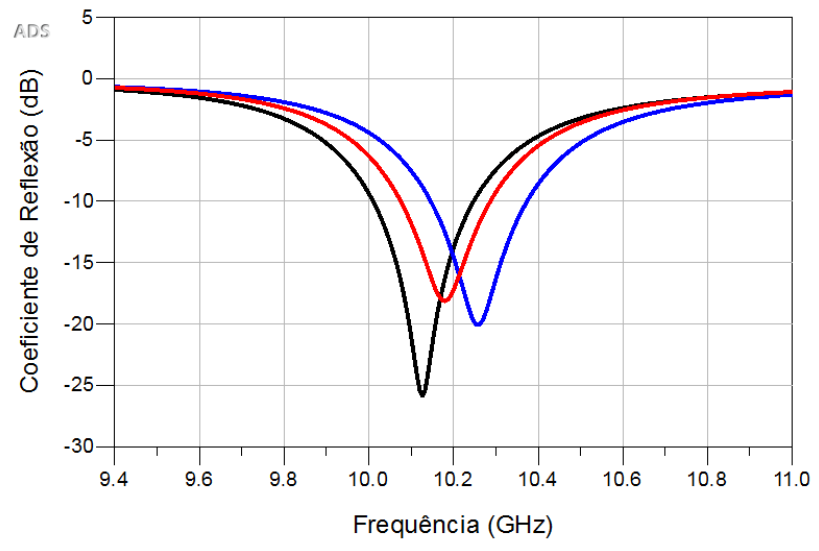

$3.7(\mathrm{~b})$ :

Figura 3.7: Simulação coeficiente de reflexão para antena GIS RT5880 condição de contorno curto-circuito: (a) layout e (b) otimização diâmetro das vias.

de entrada para os três protótipos em conjunto com o resultado da simulação eletromagnética. Assim como no caso de condição de contorno aberta, obtevese diferentes frequências de ressonância para cada um dos protótipos montados. Os diagramas de irradiação experimentais são medidos também utilizando o Lab-Volt, e são ilustrados na Figura 3.11. Analogamente ao caso aberto, o diagrama no plano $\mathrm{H}$ apresentou uma angulação em relação à vertical. Utilizando novamente a equação 3-3, o ganho experimental pode ser estimado. Os resultados são resumidos na Tabela 3.2.

Considerando as variações experimentais observadas para os seis dife- 

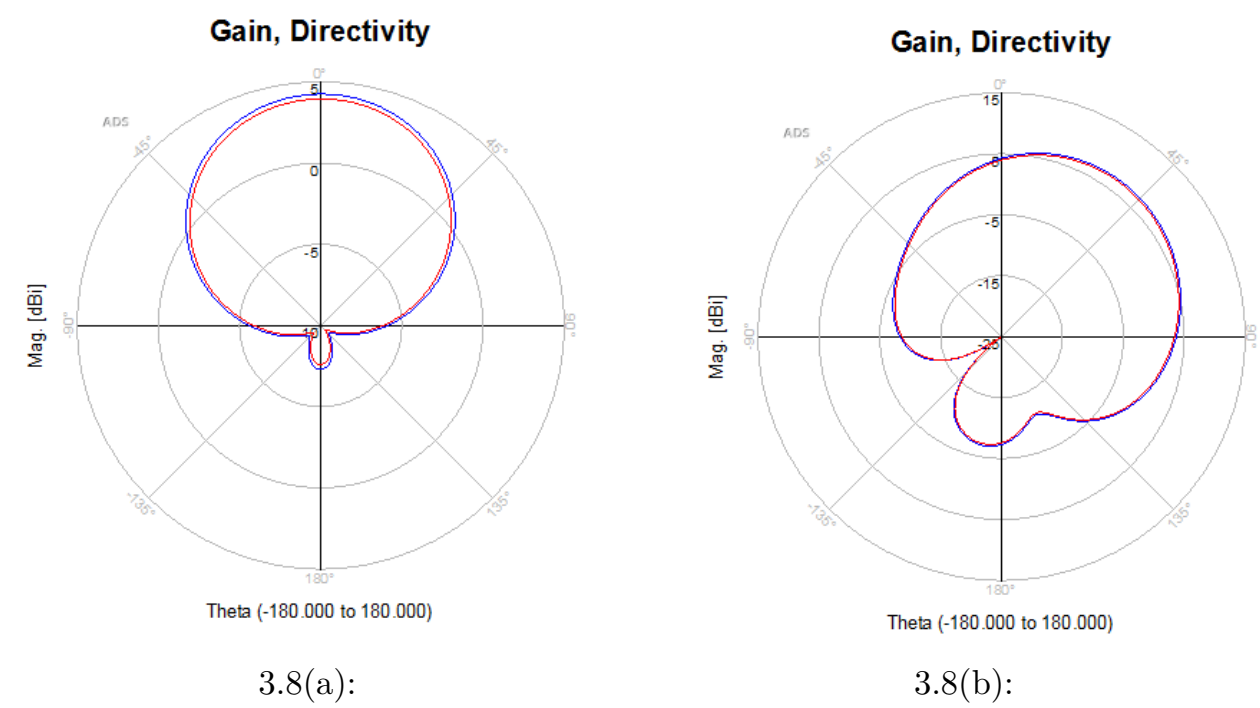

Figura 3.8: Simulação diagrama de irradiação da antena GIS RT5880 condição de contorno curto-circuito: (a) $\phi=0$ e (b) $\phi=\pi / 2$.

Tabela 3.2: Medidas Antenas GIS: Curto-Circuito

\begin{tabular}{c|cc|cc|cc}
\hline \hline & $\Theta_{E 1}$ & $\Theta_{H 1}$ & $\Theta_{E 2}$ & $\Theta_{H 2}$ & $\Theta_{E 3}$ & $\Theta_{H 3}$ \\
\hline & $80^{\circ}$ & $100,3^{\circ}$ & $101,7^{\circ}$ & $118^{\circ}$ & $89,4^{\circ}$ & $108,5^{\circ}$ \\
\hline \hline$f_{r}(\mathrm{GHz})$ & 10,78 & 10,4 & \multicolumn{2}{c}{10,4} \\
Ganho $(\mathrm{dBi})$ & \multicolumn{2}{|c|}{6,1} & 4,3 & \multicolumn{2}{c}{5,24} \\
\hline \hline
\end{tabular}

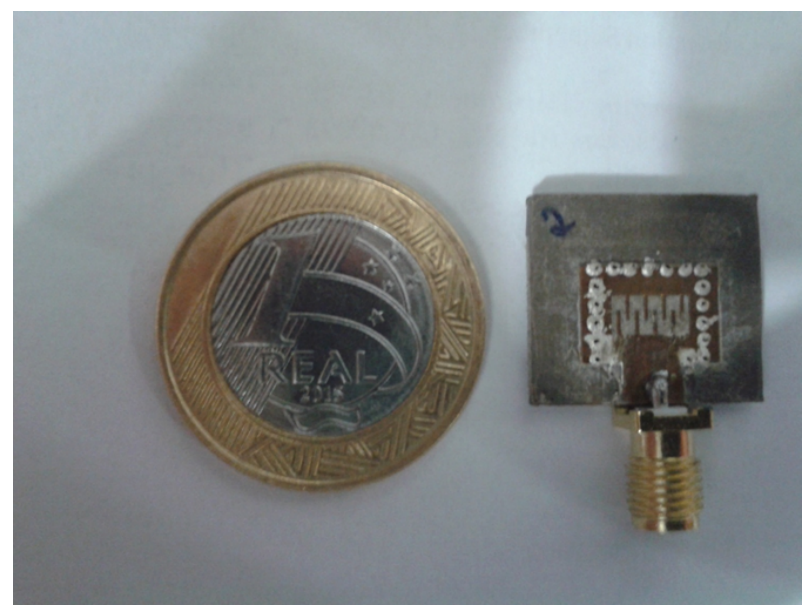

Figura 3.9: Protótipo antena GIS RT5880 com condição de contorno curtocircuito em substrato RT5880.

rentes protótipos das condições de contorno aberta e curto-circuito, conclui-se que a deposição do epóxi das vias foi efetuada de forma imperfeita, influenciando assim o valor da indutância $L_{L}$ do modelo LTCED - e consequentemente das respectivas frequências de ressonância das diferentes implementações. Esta conclusão é baseada no fato que o processo de fabricação é automatizado e confiável, porém a deposição da resina epóxi é totalmente manual, e, portanto, 


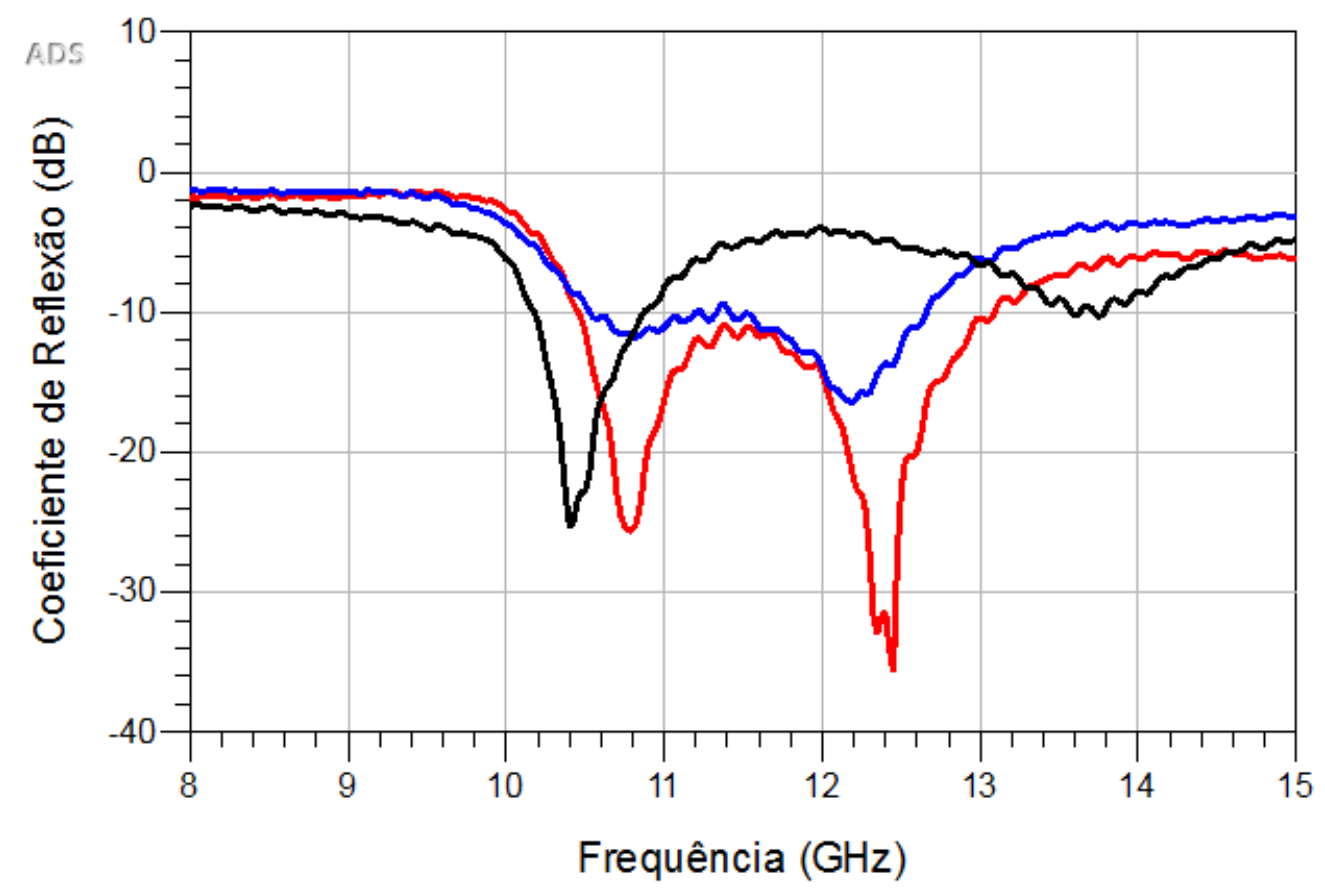

Figura 3.10: Medidas coeficiente de reflexão condição de contorno curtocircuito em substrato RT5880 (vermelho protótipo 1, azul 2, preto 3).

sujeita a imperfeições em dimensões tão miniaturizadas. Desta forma, faz-se necessária a implementação das vias utilizando outras técnicas, e isto é ilustrado posteriormente na sequência do capítulo.

\section{2}

\section{Sensor de Gás sem Fio em Substrato FR4 Utilizando OG e OGr}

Devido aos problemas apresentados pela versão implementada em RT5880, optou-se por reprojetar uma estrutura análoga utilizando uma metodologia similar, agora em substrato FR4 $\left(\epsilon_{r}=4,6, \tan \delta=0,02\right)$. Embora as perdas ôhmicas deste substrato sejam consideravelmente altas se comparadas às perdas de substratos especiais para micro-ondas e radiofrequência, e seus parâmetros geométricos e de permissividade não sejam tão bem especificados como no caso do que o precedeu, seu baixo custo e facilidade de compra no mercado são bons argumentos para sua utilização, ao menos na fase inicial do desenvolvimento do primeiro protótipo do sensor de gás.

A metodologia empregada é similar à que foi utilizada na seção anterior, e portanto optou-se por omitir alguns passos de forma a não tornar tediosa a leitura. As antenas são projetadas para operar próximo à faixa de $8,5 \mathrm{GHz}$, sendo que ao final das simulações a frequência de ressonância de ambas as condições de contorno foram de fato $f_{-1} \approx 8,65 \mathrm{GHz}$, conforme ilustrado 

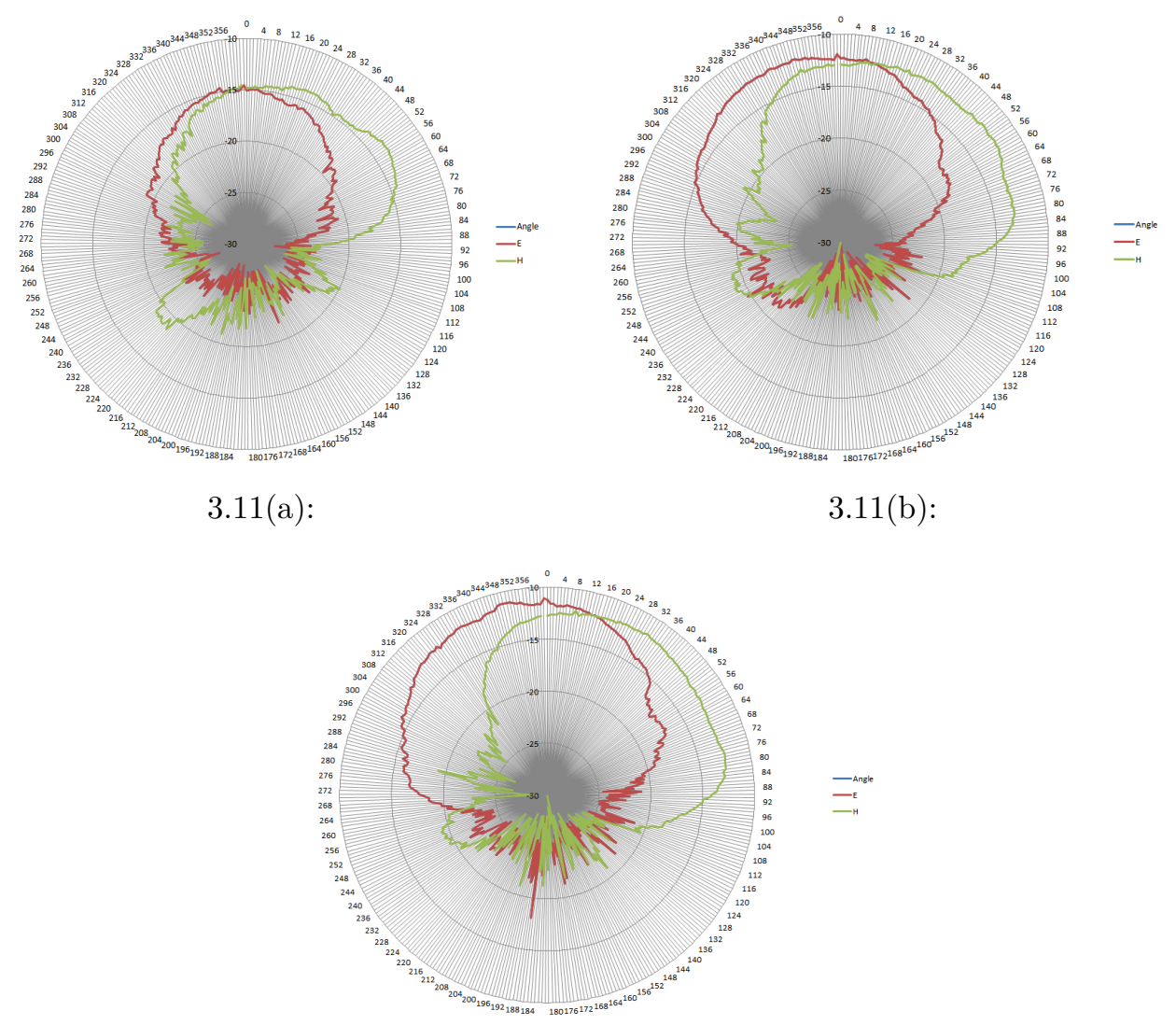

$3.11(\mathrm{c})$ :

Figura 3.11: Medidas diagrama de irradiação das antenas de condição de contorno curto-circuito (a) 1, (b) 2 e (c) 3 .

na Figura 3.12. Mais uma vez, foi utilizado casamento de impedâncias via transformador de quarto de onda. As antenas são construídas utilizando uma máquina de fotolitografia à laser do laboratório Giga da PUC-Rio, sendo que desta vez o epóxi condutivo é introduzido na furação da antena pela própria máquina, viabilizando assim uma deposição muito mais uniforme, quando comparada à realizada manualmente. Os protótipos das antenas são ilustrados na Figura 3.13.

A caracterização experimental do coeficiente de reflexão de ambas as antenas é ilustrada na Figura 3.14. Conforme pode ser observado na Figura 3.14(a), o resultado experimental da condição aberta é bastante similar ao simulado, ao contrário da condição curto-circuitada da Figura 3.14(b), onde há um desvio considerável da frequência de ressonância de ordem negativa, com enormes discrepâncias para cada uma dos diferentes protótipos. O diâmetro das vias na antena de circuito aberto é de $1,2 \mathrm{~mm}$, enquanto na de curtocircuito é de $0,5 \mathrm{~mm}$, e os desvios experimentais da última ocorrem devido à imprecisão da deposição da máquina.

De forma a aproveitar a amostra que apresentou bom desempenho, a 


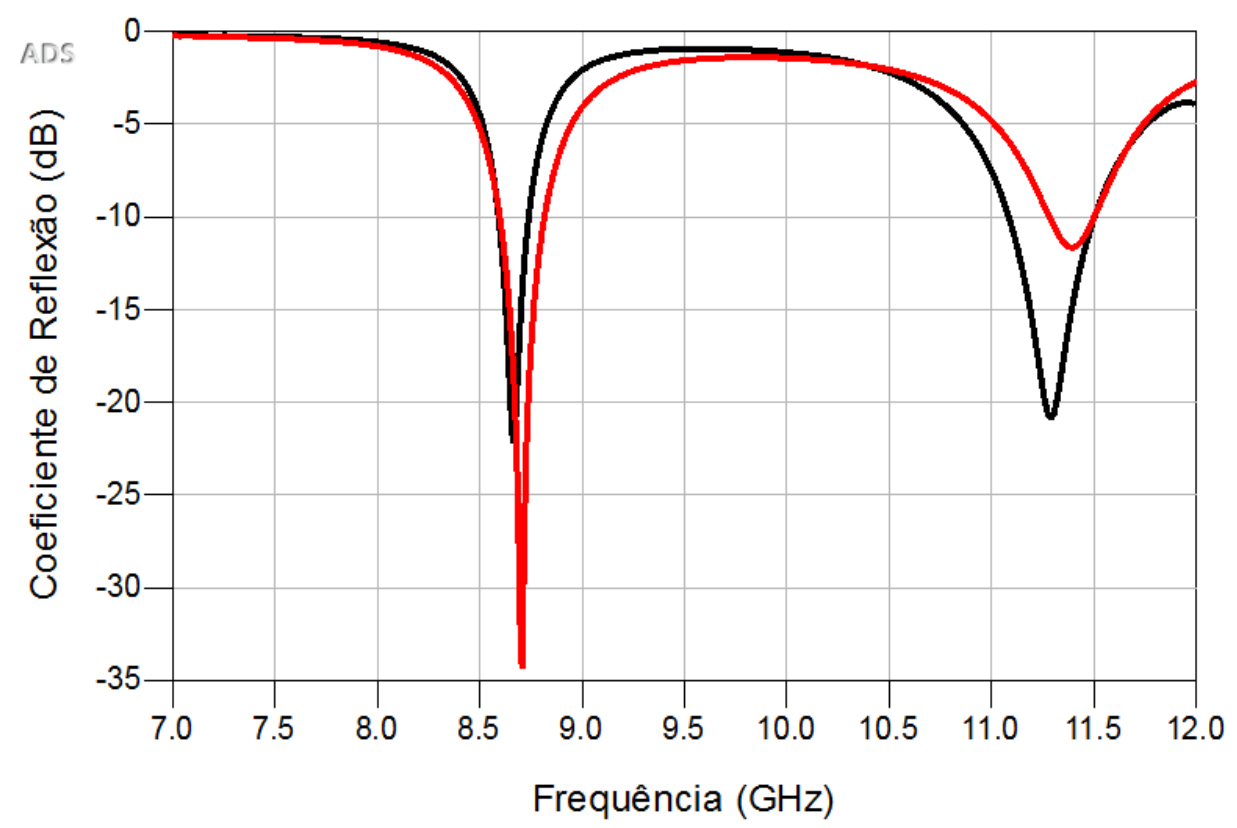

Figura 3.12: Simulação do coeficiente de reflexão das novas amostras projetadas em substrato FR4 (Preto aberto, vermelho curto.)

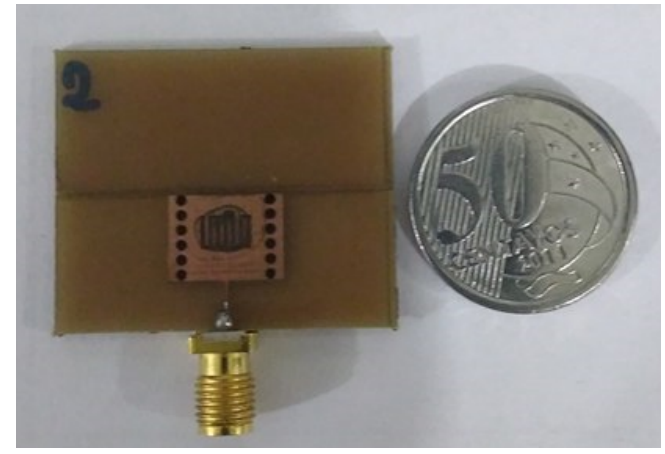

$3.13(\mathrm{a})$ :

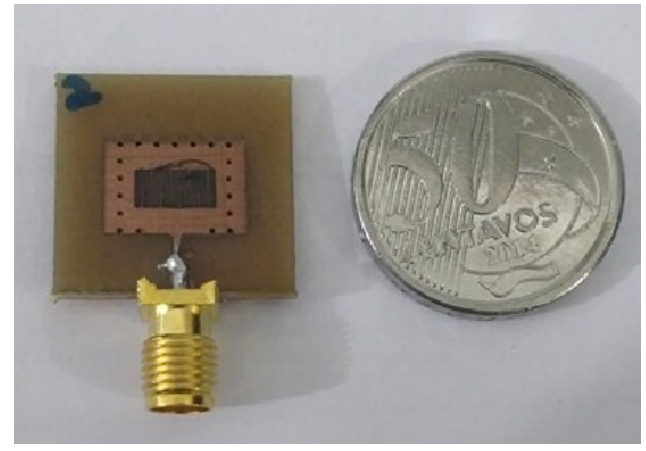

$3.13(\mathrm{~b})$ :

Figura 3.13: Protótipos das antenas GIS em FR4, condições de contorno (a) aberta e (b) curto-circuitada.

antena de condição de contorno curto-circuito é momentaneamente descartada. Conforme mencionado no Capítulo 1, diversos sensores utilizando OG têm sido apresentados [17]. A ideia inicial é depositar OG na antena e fazer testes empíricos de detecção de gases em ambiente saturado, para posteriormente investir em um sistema específico para detecção de volumes pequenos e/ou soluções diluídas.

Conforme demonstrado em [30], a distribuição do campo elétrico na frequência de ressonância de ordem -1 é análoga à de um patch retangular. Desta forma, o campo pode ser descrito aproximadamente como $\propto \sin (\pi / \ell)$, onde $\ell$ é o comprimento da antena. Como consequência o campo elétrico é 


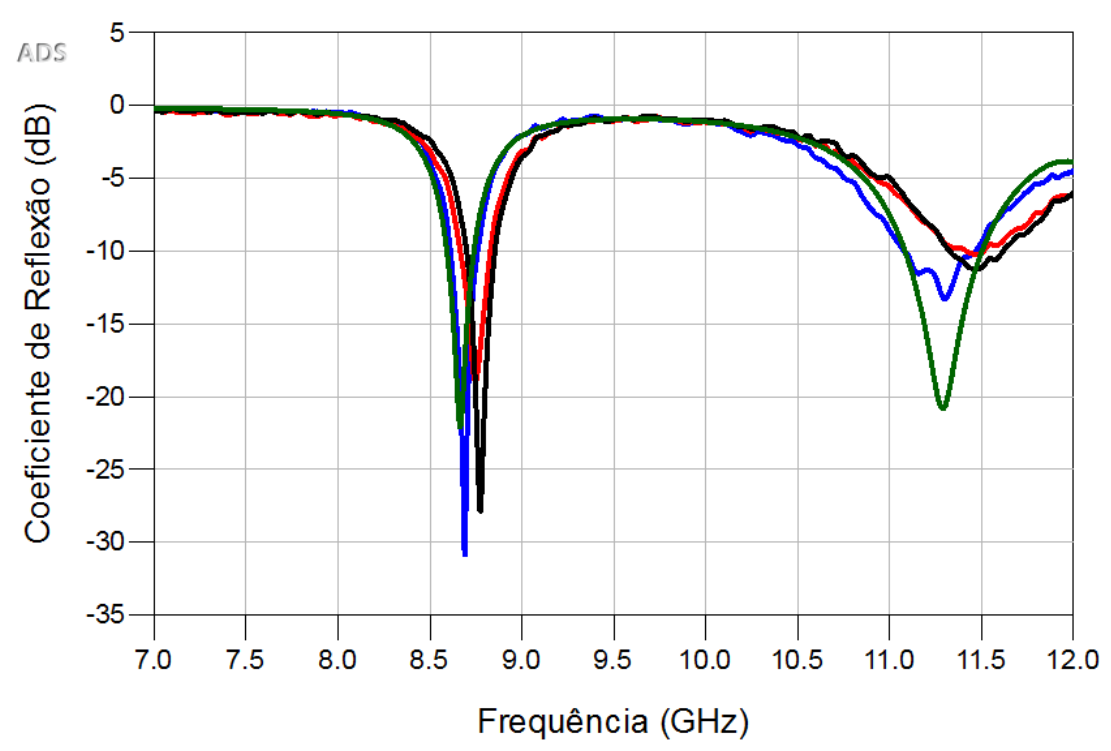

3.14(a):

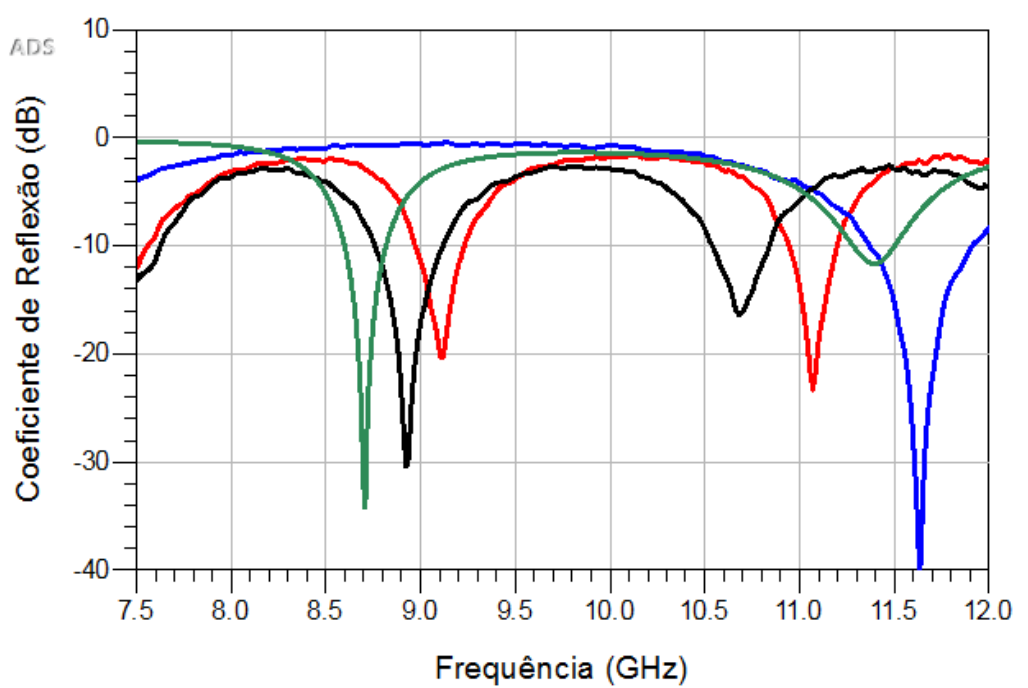

$3.14(\mathrm{~b})$ :

Figura 3.14: Resultados experimentais dos coeficientes de reflexão das antenas GIS em FR4 (as linhas verdes correspondem à simulação), condições de contorno (a) aberta e (b) curto-circuito.

extremamente intenso no interior da fenda, devido às magnitudes opostas do campo elétrico nas extremidades do capacitor interdigital, viabilizando assim uma boa irradiação na direção perpendicular ao plano da antena [30]. Isto pode ser visualizado observando o resultado das simulações ilustradas na Figura 3.16 para as duas condições de contorno. Por este motivo, o capacitor interdigital foi o local escolhido para deposição das estruturas de carbono.

O OG é preparado de acordo com o método de Hummer que, conforme mencionado, consiste na mistura anidra de ácido sulfúrico concentrado, nitrato 


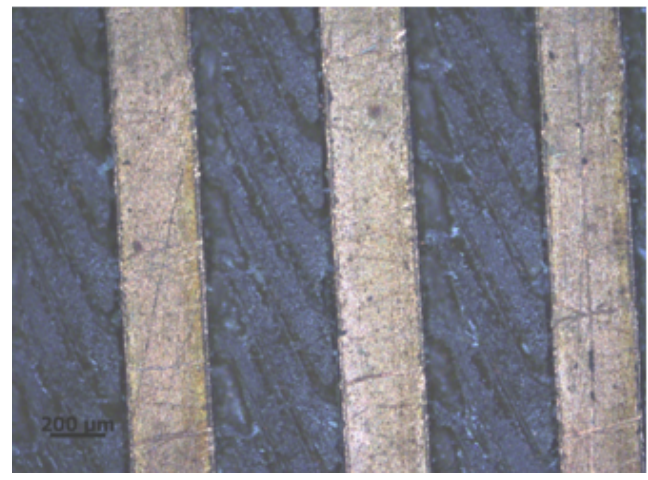

$3.15(\mathrm{a})$ :

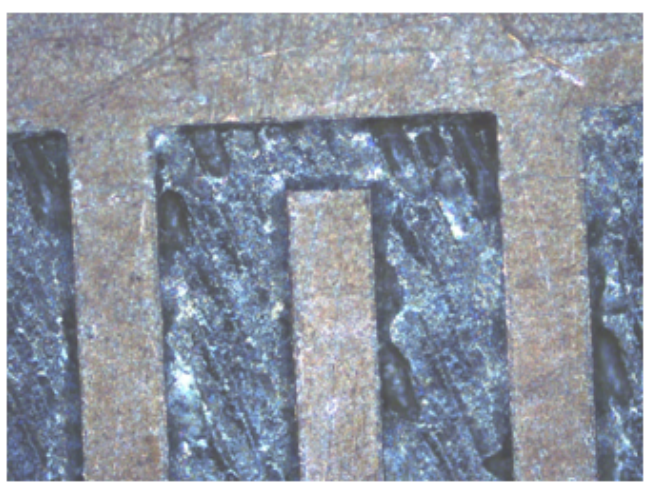

3.15(b):

Figura 3.15: Imagens de microscopia óptica da antena aberta em FR4 (a) referência e (b) amostra com OG.

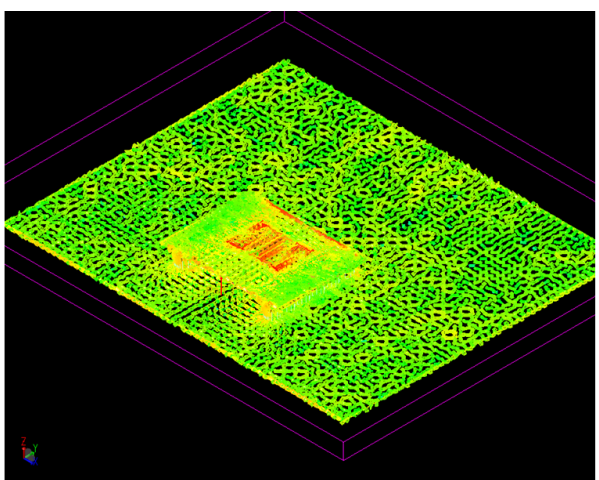

3.16(a):

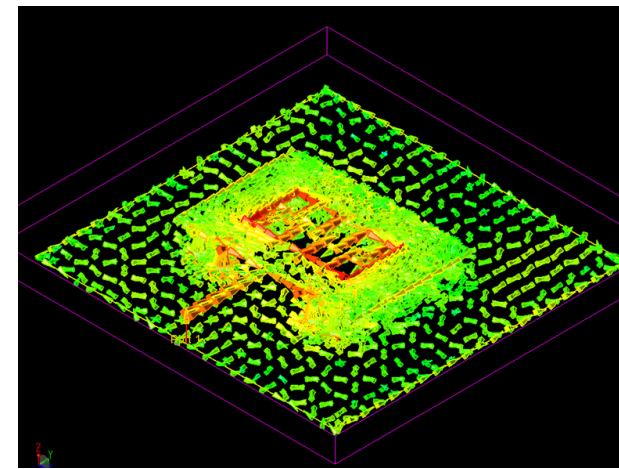

$3.16(\mathrm{~b})$ :

Figura 3.16: Simulação da intensidade do campo elétrico ao longo da estrutura da antena GIS em FR4, destacando a sua grande intensidade no capacitor interdigital, para condições de contorno (a) aberta e (b) curto-circuito.

de sódio e permanganato de potássio à grafite natural (Grafite do Brasil S.A.). A proporção em massa de reagentes utilizada é 1:1,2:6,0 g, respectivamente para a grafite, $\mathrm{NaNO}_{3}$ (P.A. 99\% de pureza, Sigma-Aldrich) e $\mathrm{KMnO}_{4}$ (P.A. 99\% de pureza, Sigma-Aldrich), em excesso de $\mathrm{H}_{2} \mathrm{SO}_{4}$ (concentrado, 9598\%, Sigma-Aldrich). Adiciona-se o permanganato de potássio lentamente para evitar grandes aumentos de temperatura. Após o término da reação, é adicionada água destilada tratada com peroxido de hidrogênio (P.A. 30$32 \%$, Sigma-Aldrich), de forma a reduzir as impurezas. Posteriormente, o OG produzido é diluído em água com uma concentração de $5 \mathrm{mg} / \mathrm{mL}$, e a solução é depositada na fenda no centro da antena e deixado por $12 \mathrm{~h}$ em temperatura ambiente para evaporação da água. A imagem de microscopia óptica comparando o caso de referência com o de OG é ilustrada na Figura 3.15. Conforme pode ser observado, a deposição cobre eficientemente a área disponível no capacitor interdigital. 
O setup inicial para medida é ilustrado na Figura 3.17. Uma câmara improvisada é utilizada de forma a aprisionar o gás em um recipiente em contato com a antena carregada com OG, que está conectada a um analisador de rede vetorial (VNA). Uma válvula é instalada de forma a obter um ambiente em vácuo antes da inserção do gás via outra entrada disponível na lateral, que está ligada a um cilindro de $\mathrm{CO}_{2}$. A temperatura do ambiente é controlada e o gás é inserido lentamente na câmara, de forma a garantir que quaisquer variações no parâmetro $S_{11}$ sejam observadas apenas devido aos efeitos da adsorção do gás pelo OG depositado na antena.

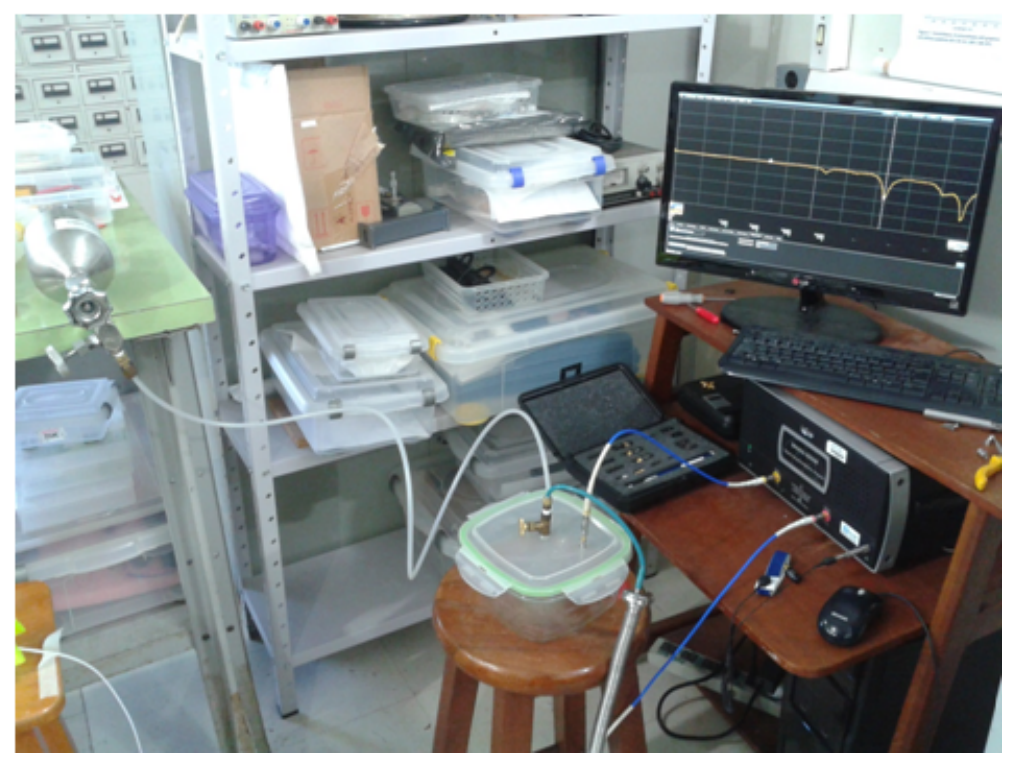

Figura 3.17: Setup medição antena/OG $+\mathrm{CO}_{2}$.

Depois de sucessivas repetições do teste com a antena em contato com o gás, nenhum efeito foi observado nos parâmetros da amostra em medição. De forma a investigar a razão desta inércia, recorre-se ao modelo LTCED que foi introduzido no Capítulo 2. De forma a incluir no modelo a influência do OG, a resistência do OG é modelada como uma resistência $R(t)$ que varia no tempo em função da adsorção de moléculas de gás em paralelo com a capacitância $C_{L}$. Conforme citado no Capítulo 2, a resistividade do OG é bastante alta, da ordem de $\mathrm{M} \Omega . c m$. Como $R(t) \propto \rho$, conclui-se que o valor da resistência também é alto, de forma que o paralelo de $R(t)$ e $1 /\left(j \omega C_{L}\right)$ é:

$$
Z_{L}(\omega)=\frac{R(t)\left(\frac{1}{j \omega C_{L}}\right)}{R(t)+\frac{1}{j \omega C_{L}}}=\frac{R(t)}{j \omega C_{L} R(t)+1} \approx \frac{1}{j \omega C_{L}}, \text { para } R(t)>>\frac{1}{\omega C_{L}}
$$

ou seja, mesmo que o valor da resistência varie ao longo do tempo através da adsorção de moléculas de gás, não há influência na operação da antena 
como desejado. A investigação desta hipótese via simulações eletromagnéticas é explanada mais detalhadamente na Seção 3.3.

\section{3}

\section{Simulações Antena + OG/OGr}

Os programas comerciais utilizados por engenheiros de micro-ondas geralmente não vêm com suporte para trabalhar com estruturas como grafeno, e por esta razão a metodologia anterior havia sido adotada, projetando primeiro a antena e posteriormente depositando as estruturas de carbono. Porém existe a possibilidade de definir no software uma camada semicondutora de filme na região da fenda, cuja variável é a resistividade do filme, de forma a emular a influência de um filme fino cuja resistividade varia no tempo. Desta forma, define-se no ADS a camada "resi", conforme ilustrado na Figura 3.18, com uma espessura de $17,5 \mu \mathrm{m}$ (metade da espessura do cobre) e resistividade $\rho$.

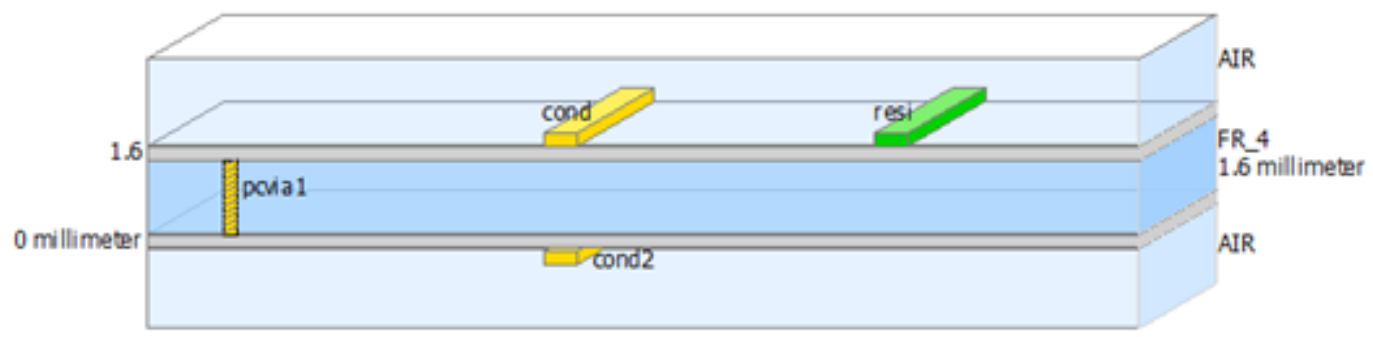

Figura 3.18: Definição de substrato no ADS utilizando a camada "resi"para simulação de OG/OGr.

Depois de definido o substrato, o sensores são exportados para o programa EMPRO, também da Keysight, para simulação eletromagnética. Primeiramente as estruturas são simuladas com resistividades da ordem de $\mathrm{M} \Omega . c \mathrm{~m}$ de forma a verificar o que foi mencionado no final da Seção 3.2, e os resultados obtidos são ilustrados na Figura 3.19. Conforme pode ser observado, mesmo com uma grande variação na resistividade o coeficiente de reflexão se mantém constante, inclusive quando comparada ao caso sem filme. Além disso, na Figura 3.20 pode-se observar a comparação dos ganhos das antenas de referência e com filme de OG nos planos principais. Conforme pode ser observado, não há variação considerável.

As simulações com valores mais baixos de resistividade são ilustrados na Figura 3.21. Note que há uma resposta acentuada para esta faixa de resistividades. Esta corresponde à faixa onde a resistência é baixa o suficiente para que $R(t)$ não seja muito maior do que $1 /\left(\omega C_{L}\right)$, porém não baixa a ponto 


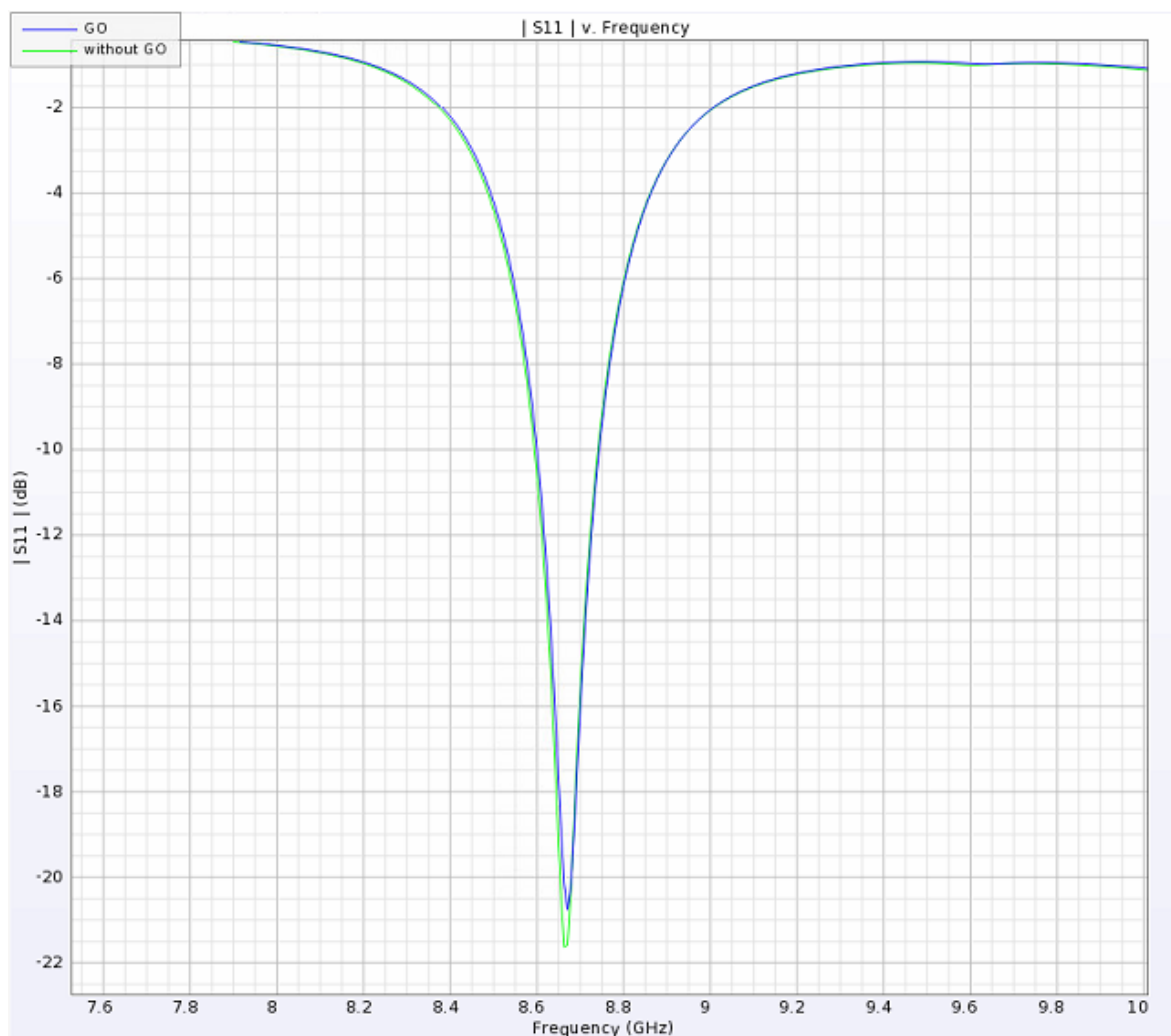

Figura 3.19: Simulação comparando os coeficientes de reflexão da antena GIS FR4 curto-circuito para o caso sem filme e com OG.

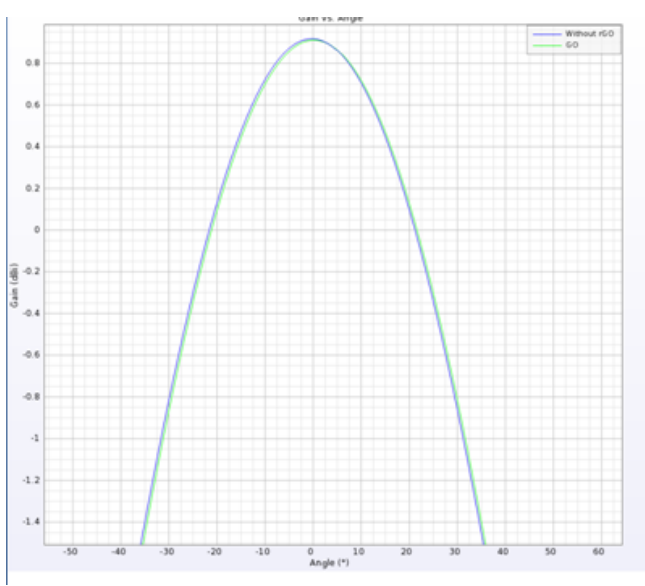

$3.20(\mathrm{a}):$

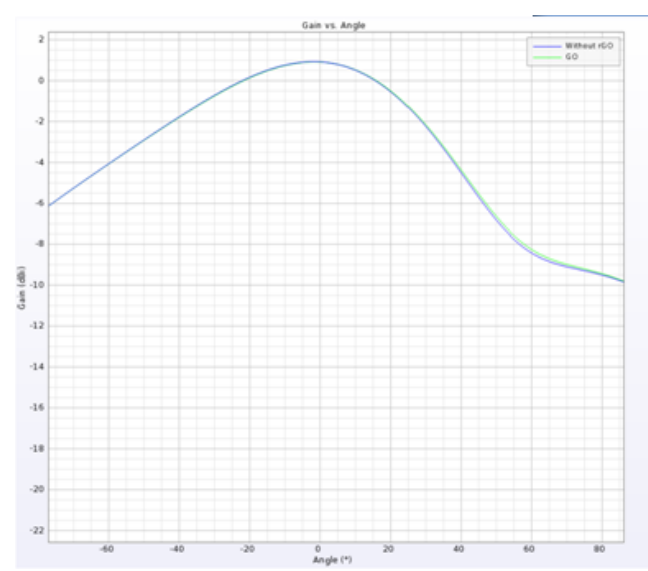

$3.20(\mathrm{~b})$ :

Figura 3.20: Simulação diagrama de irradiação GIS FR4 condição de contorno aberta com OG (a) $\phi=0$ e (b) $\phi=\pi / 2$.

de a fenda se comportar como um curto-circuito, e a estrutura se comportar como uma guia de onda aberta ou cavidade ressonante. Na Figura 3.22 são ilustrados os ganhos nos dois planos principais em função da resistividade. Como pode-se observar, o ganho acompanha a queda da resistividade. A eficiência de irradiação é ilustrada na Figura 3.23 e, como esperado, seu valor também é reduzido. Analisando à luz do eletromagnetismo clássico, isto faz 
sentido. Pela lei de Ohm microscópica sabemos que:

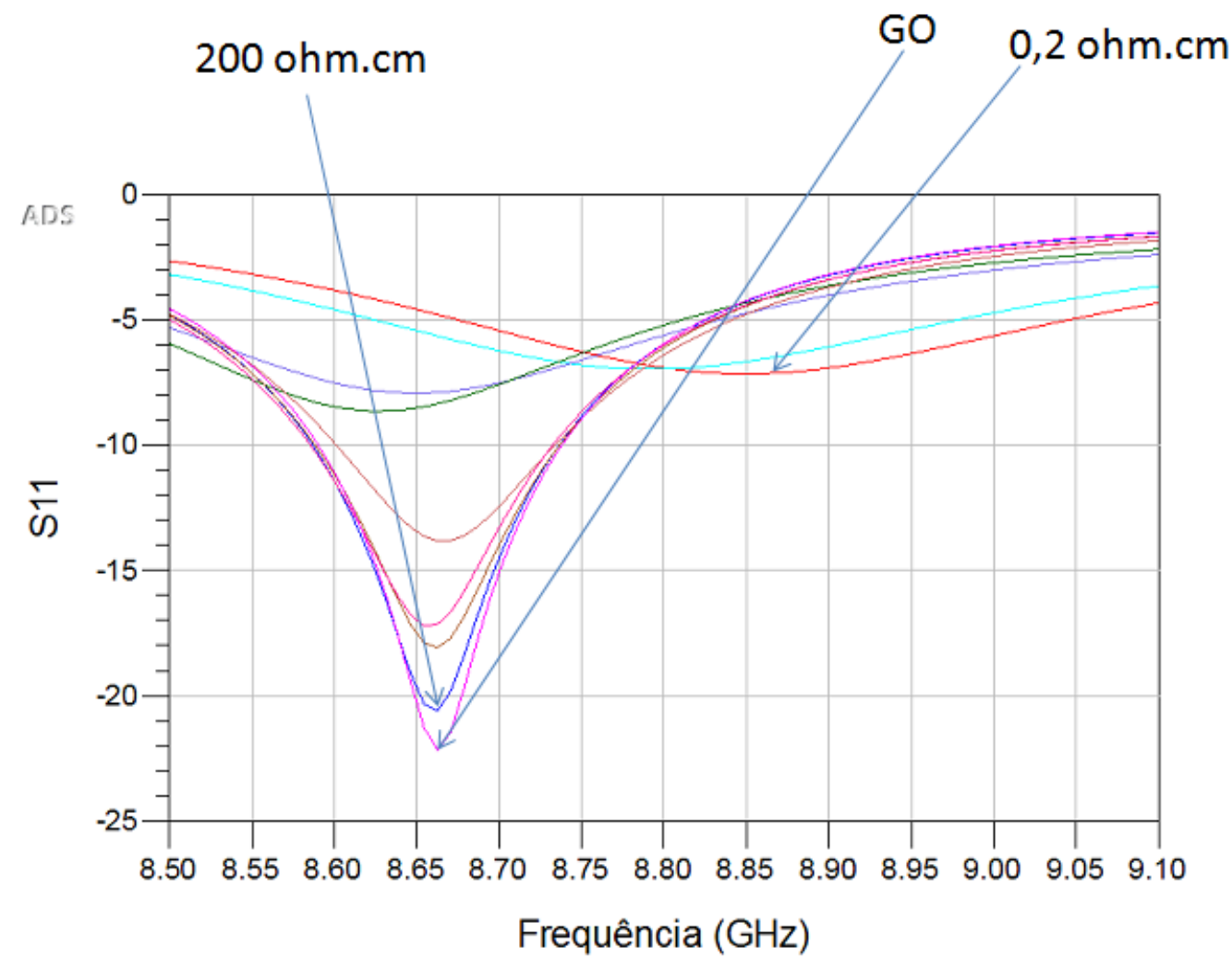

Figura 3.21: Simulação variação do coeficiente de reflexão da antena GIS FR4 em função da resistividade OGr.

$$
\vec{J}=\sigma \vec{E}=\frac{1}{\rho} \vec{E}
$$

e assim é fácil notar que para um mesmo campo elétrico a densidade de corrente $\vec{J}$ aumenta na superfície do filme semicondutivo conforme a resistividade diminui. No limite quando $\rho \rightarrow 0$ e consequentemente $\vec{E} \rightarrow 0$ devido às condições de contorno, cai-se no caso do condutor perfeito e reflexão total das ondas eletromagnéticas - ou seja, confinamento total dos campos no interior da estrutura. Este raciocínio torna mais intuitivo o fato da eficiência de irradiação diminuir com o aumento da condutividade. Além disso, cabe também reescrever uma importante equação demonstrada no Capítulo 2, que permite calcular a seção de radar equivalente em função de parâmetros da antena:

$$
\sigma=\frac{\lambda_{0}^{2} G_{t a g}^{2}}{4 \pi}|\Gamma|^{2}=\frac{\lambda_{0}^{2} G_{t a g}^{2} R_{A}^{2}}{\pi\left|Z_{A}+Z_{L}\right|^{2}}
$$

Observa-se, analisando os resultados das simulações nas Figuras 3.21 e 3.22, que tanto $\Gamma$ quanto $G_{t a g}$ variam com a queda da resistividade, demonstrando 


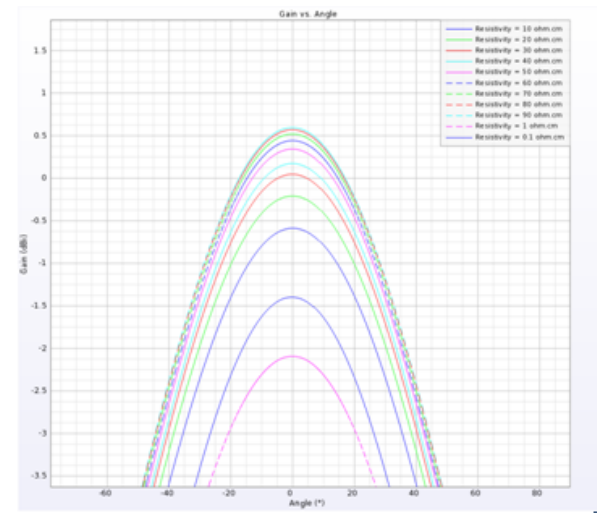

$3.22(\mathrm{a})$ :

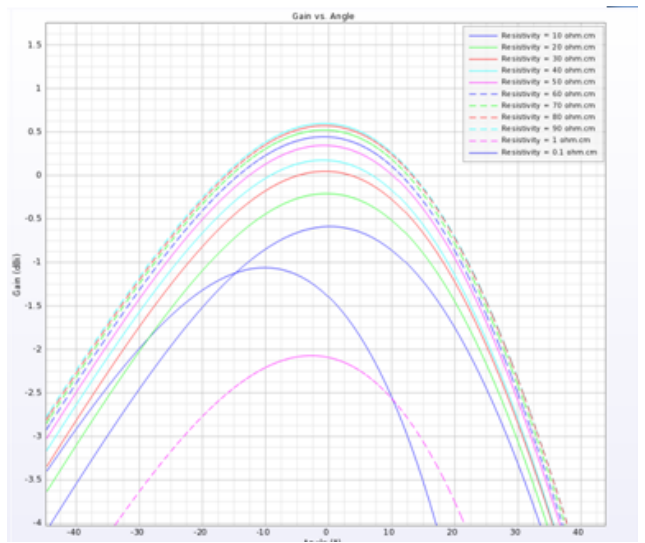

$3.22(\mathrm{~b}):$

Figura 3.22: Simulação diagrama de irradiação da antena GIS FR4 condição de contorno aberta com resistividade na faixa de interesse (a) $\phi=0$ e (b) $\phi=\pi / 2$.

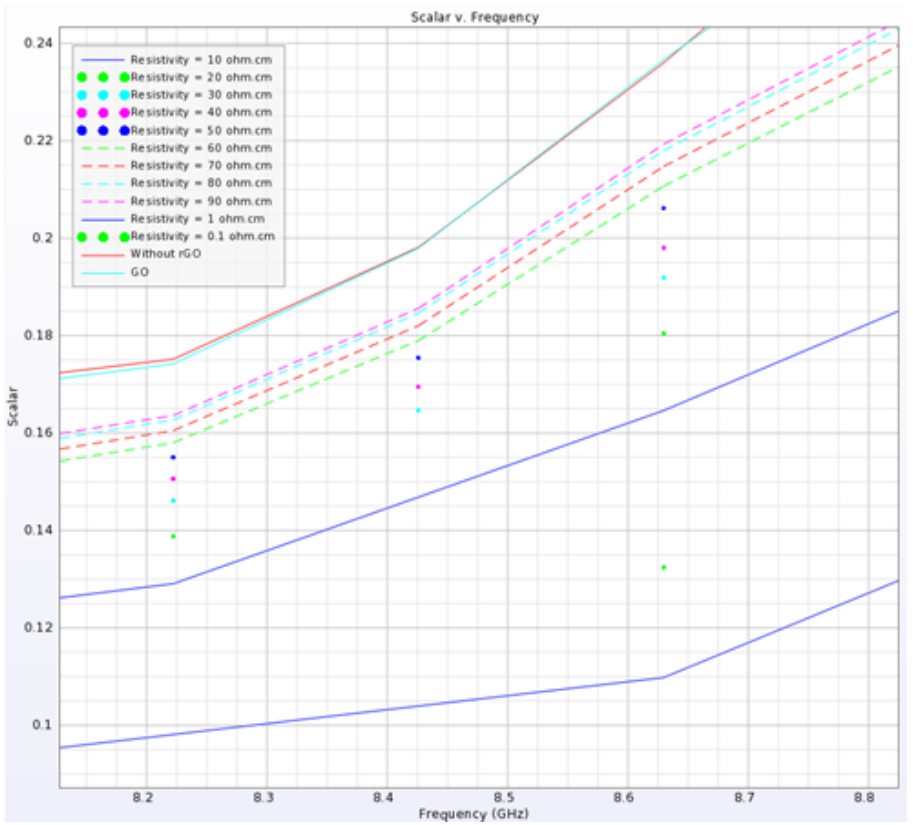

Figura 3.23: Simulação da eficiência de irradiação da antena GIS FR4 em função da resistividade da folha de OGr.

assim que é possível detectar gases sem fio à distância utilizando esta estrutura.

Além disso, analisando a equação 2-17, observa-se que o campo elétrico espalhado para uma impedância de carga $Z_{L}$ é igual à espalhada pela carga $Z_{L}=Z_{A}^{*}$ - o modo estrutural - menos o fator do modo antena, que depende das características de transmissão da antena e do coeficiente de reflexão de entrada. Em praticamente todos os sistemas RFID com modulação de carga a impedância da antena $Z_{A}$ (ou seja, o modo estrutural) é constante enquanto o chip transmite a informação desejada via modulação de $Z_{L}$ - ou seja, os módulos antena e circuito são separados, com o chip montado nos terminais 
de entrada da antena. O mesmo é verdadeiro para a grande maioria das tags RFID comumente utilizadas [3,37].

Observe que a mesma circunstância não ocorre neste caso, já que as variações na verdade ocorrem para uma impedância de carga constante $\left(Z_{L}=\right.$ $50 \Omega$ ), e o que de fato varia é a impedância $Z_{A}$. A Figura 3.24 ilustra a variação da parte real da impedância da antena para diversos valores de resistividade, comprovando que foi exposto. As implicações deste fato são que agora além do modo antena variar, já que o coeficiente de reflexão é alterado independentemente de qual das duas impedâncias é modificada após a interação com o gás, também há variação do modo estrutural, já que ele é determinado por $\vec{E}^{s}\left(Z_{A}^{*}(t)\right)$. Este fator somado à forte concentração do campo elétrico na capacitor interdigital são fatores que apresentam grande potencial para aumento da sensibilidade do sensor sem fio.

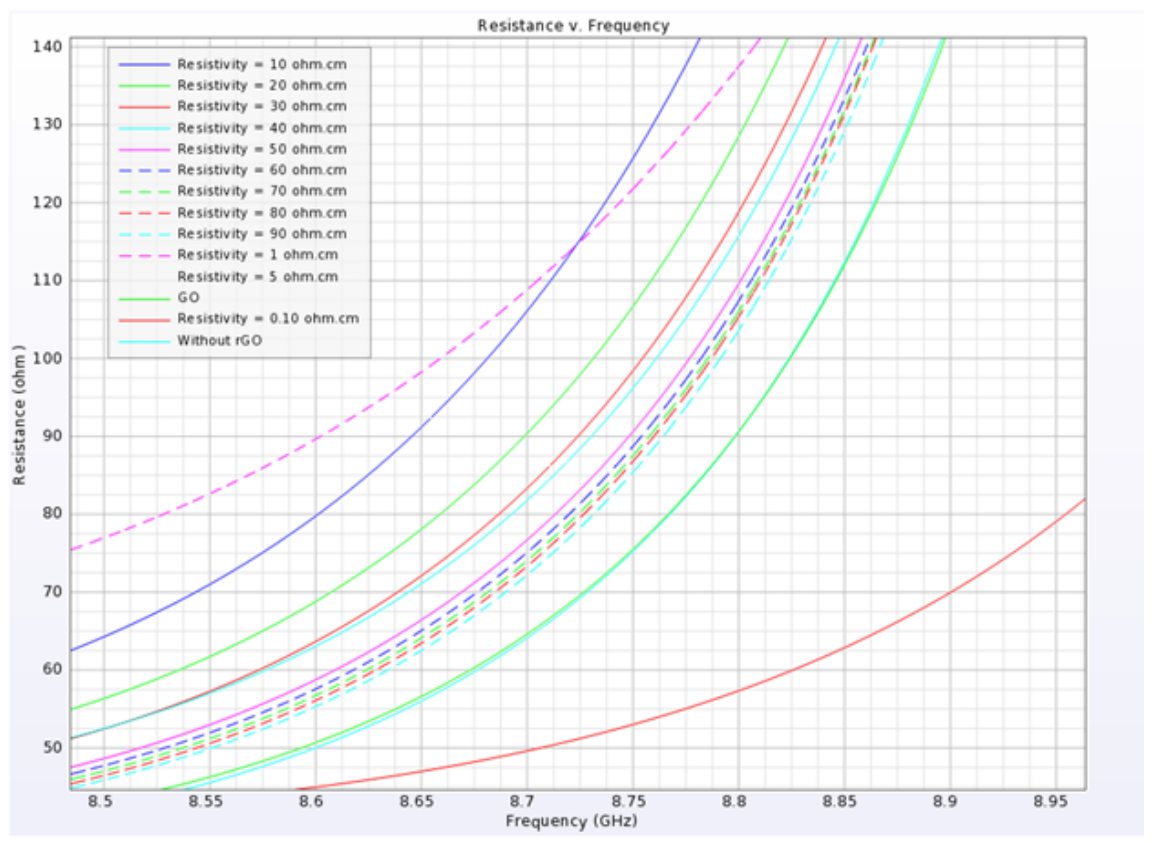

Figura 3.24: Variação da resistência de entrada da antena GIS FR4 em função da resistividade.

\section{4}

\section{Resultados Experimentais}

Conforme demonstrado nas Seções 3.2 e 3.3, existe apenas uma faixa de resistividades na qual o sensor sem fio responde à adsorção do gás. Como mencionado no Capítulo 2, a redução de OG em OGr remove os grupos hidroxílicos e carboxílicos, aumentando a condutividade dos filmes. Isto pode ser explorado para obter amostras quase tão condutivas quanto grafeno primitivo, porém, neste caso, um filme que apresente uma resistividade na 
faixa na qual a antena responde ao gás deve ser obtido. Logo, optou-se pela caracterização da resistividade de diversas reduções térmicas parciais de OG, de forma a obter um processo otimizado para fabricação do sensor.

O método de Van der Pauw para medição da resistência de folha e coeficiente Hall de filmes finos foi desenvolvido por Van der Pauw em 1958, trabalhando pelo grupo de pesquisa da Philips [38]. A grande vantagem deste método consiste no fato de que basta a estrutura ser simétrica para obter a resistência de folha de forma relativamente simples. Considerando a Figura 3.25, o método consiste nos seguintes passos:

1. Inserir as pontas nos contatos A, B, C e D;

2. Forçar uma corrente entre dois contatos adjacentes (por exemplo A e B, ou C e D, e assim sucessivamente);

3. Medir a tensão entre os dois contatos restantes.

Conduzidos os passos acima, considera-se a seguinte igualdade:

$$
\exp \left(\frac{\pi R_{A}}{R_{\text {folha }}}\right)+\exp \left(\frac{-\pi R_{B}}{R_{\text {folha }}}\right)=1
$$

sendo que

$$
R_{A}=R_{A B, C D}=\frac{V_{C D}}{I_{A B}} .
$$

Devido à simetria, $R_{A} \approx R_{B}$, e, portanto, invertendo a equação acima obtémse:

$$
R_{\text {folha }}=\frac{\pi}{\ln 2} R_{A}
$$

Para obter um valor mais próximo, deve-se rotacionar a medida e tomar a média aritmética das resistências obtidas:

$$
R_{\text {folha }}=\frac{\pi}{\ln 2}\left(\frac{R_{A}+R_{B}}{2}\right) .
$$

De forma a caracterizar as amostras de OGr, primeiramente cortam-se diversas placas quadradas de FR4 de $1 \times 1 \mathrm{~cm}^{2}$. Como as moléculas de carbono se ligam ao substrato sobre o qual são depositadas, este fator pode influenciar na resistividade, e portanto é importante que a caracterização seja efetuada no mesmo substrato das antenas. O OG de concentração $5 \mathrm{mg} / \mathrm{mL}$ é depositado sobre as placas e reduzido termicamente à $200^{\circ} \mathrm{C}$ por $2 \mathrm{~h}$ e $3 \mathrm{~h}$, e à $100^{\circ} \mathrm{C}$ por 5 h, de forma a obter uma noção inicial da influência dos tempos e temperaturas na condutividade do OGr.

O protótipo da amostra e o aparato para medição são ilustrados na Figura 3.26. É utilizado um sistema comercial baseado no método Van der Pauw para 

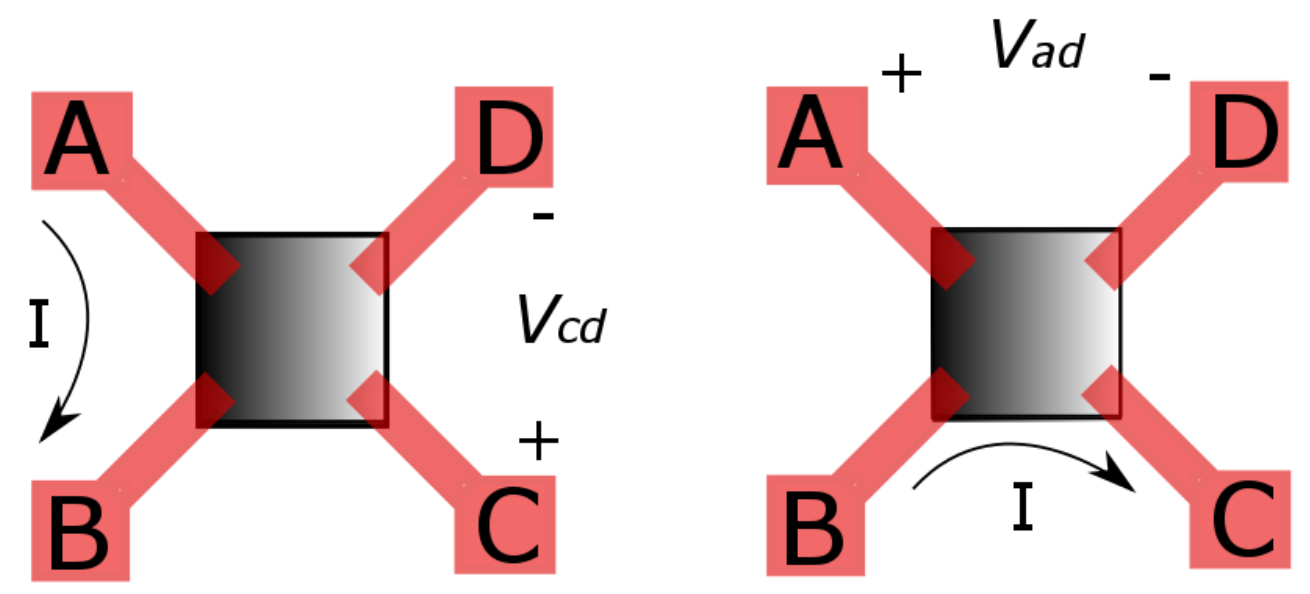

Figura 3.25: Esquemático do método de Van der Pauw para caracterização da resistência de folha.

caracterização da resistividade de filmes finos. No momento da deposição do OG na antena não é possível utilizar um spin coater, devido ao fato que desejase OG apenas na região da fenda, e a técnica do spin coating ${ }^{2}$ espalharia o material em toda a área superficial da antena. Desta forma, decidiu-se por não utilizar esta técnica para caracterização da resistividade, de forma a emular o máximo possível as condições da deposição posterior nas antenas. Porém, a consequência disto é uma amostra não uniforme. Um perfilômetro é utilizado para estimar a espessura média do filme, de forma a obter a resistividade, dada por $\rho=R_{\text {folha }} / t$, onde $t$ é a espessura.

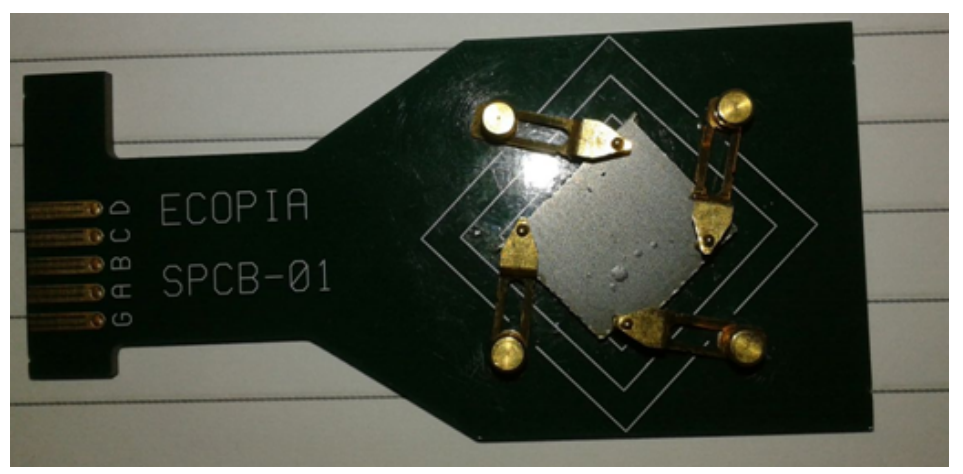

Figura 3.26: Aparato para caracterização da resistência de folha das amostras de OGr, utilizando método Van der Pauw.

A Tabela 3.3 resume os resultados obtidos. Como esperado, a resistividade do $\mathrm{OG}$ é consideravelmente alta, da ordem de $\mathrm{M} \Omega$. A redução à $100^{\circ} \mathrm{C}$,

\footnotetext{
${ }^{2}$ Esta técnica é amplamente utilizada para deposição uniforme de filmes finos em substratos planos. Uma pequena quantidade do material de revestimento é inserido no centro da amostra e o substrato é girado em alta velocidade, de forma a espalhar uniformemente o material via força centrífuga.
} 
Tabela 3.3: Medidas iniciais de resistividade OG/OGr

\begin{tabular}{c|c|c|c|c}
\hline \hline & OG puro & OGr $100^{\circ} \mathrm{C} / 5 \mathrm{~h}$ & OGr $200^{\circ} \mathrm{C} / 2 \mathrm{~h}$ & OGr $200^{\circ} \mathrm{C} / 3 \mathrm{~h}$ \\
\hline \hline Espessura média $(\mu \mathrm{m})$ & 40 & 34 & 4 & 2 \\
\hline$\rho(\Omega . c m)$ & $3 \mathrm{M}$ & $2,8 \mathrm{M}$ & 0,346 & 0,196 \\
\hline \hline
\end{tabular}

mesmo sendo a mais longa, não é eficaz em reduzir a amostra de OG. Esta temperatura é demasiadamente baixa para remover os grupos epóxis e hidroxilas. É importante salientar que as medidas efetuadas em filmes de resistividade tão altas são de baixa confiabilidade, devido ao fato que as correntes inseridas têm que ser muito baixas (no caso, da ordem de nA), e a precisão do medidor nesta faixa é bastante baixa. De qualquer forma, optou-se por incluir os resultados de forma a ilustrar a ordem de grandeza das medidas. Quanto às medidas à $200^{\circ} \mathrm{C}$ de $2 \mathrm{~h}$ e $3 \mathrm{~h}$, as resistividades são menores que $1 \Omega . \mathrm{cm}$, o que se encontra uma ordem de grandeza abaixo dos valores onde a resposta da antena é razoável. Para valores tão baixos, é possível observar na Figura 3.21 que a resposta da antena é demasiadamente deteriorada devido ao descasamento de impedâncias.

Mesmo com todos os valores fora da faixa, estas medidas corroboram com o discernimento necessário sobre redução térmica de OG, de forma a viabilizar a sequência dos experimentos. Assim sendo, decidiu-se preparar mais amostras reduzidas à $200^{\circ} \mathrm{C}$, agora com tempos de 30, 60 e 90 min. Espera-se obter valores de resistividade entre os extremos obtidos anteriormente, na faixa que é de interesse do projeto.

Como deseja-se atingir uma faixa e não um valor muito específico de resistividades, optou-se por utilizar um método mais pragmático, rápido e de mais fácil acesso. O método das duas pontas de prova é considerado o método mais simples para caracterização de resistência de amostras. Em contrapartida, ele não é um método exato, servindo apenas para uma estimativa da resistência em questão. Este problema torna-se mais acentuado quando a condutividade apresenta valores extremos, ou seja, para condutores e isolantes. Porém, como o OGr utilizado apresenta resistividade na faixa de valores de semicondutores, e como é necessário projetar o OGr para uma determinada faixa e não para um valor exato de resistividade, este método é suficiente. Sabe-se que a resistência é dada por:

$$
R=\frac{\rho}{t} \frac{L}{W}=R_{\text {folha }} \frac{L}{W}
$$

onde $L, W$ e $t$ são o comprimento, largura e espessura do filme, respectivamente, e $R_{\text {folha }}=\rho / t$ é a resistência de folha. Fazendo a amostra quadrada ( $L=W$ ), medindo $R=R_{\text {folha }}$ com um ohmímetro comercial e medindo a 


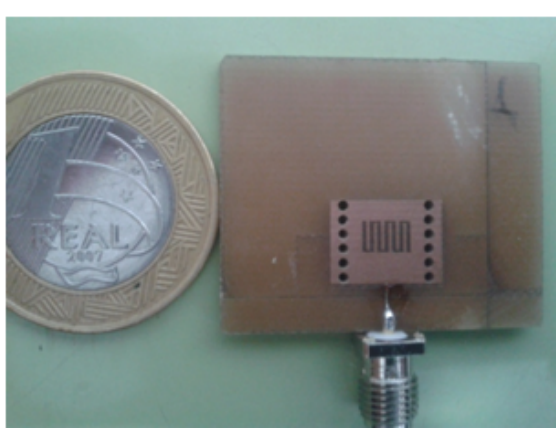

$3.27(\mathrm{a})$ :

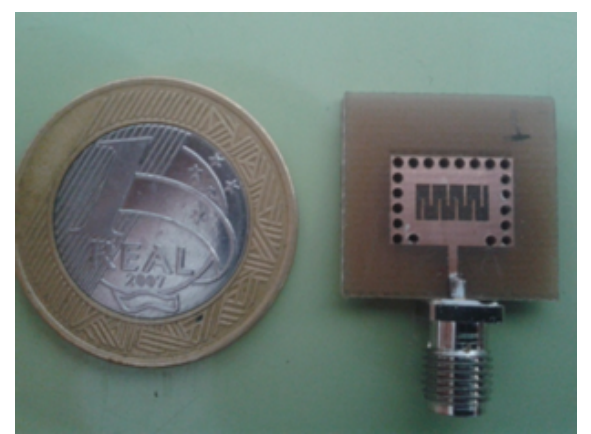

$3.27(\mathrm{~b})$ :

Figura 3.27: Protótipos da segunda versão das antenas GIS em substrato FR4.

espessura com um perfilômetro, pode-se estimar a resistividade utilizando:

$$
\rho=t R_{\text {folha }}
$$

Os resultados obtidos são sumarizados na Tabela 3.4. Observe que a espessura do filme diminui conforme aumenta o tempo de redução. Considerando as simulações efetuadas para as condições de contorno aberta e curto, observase que os tempos mais promissores são 60 e 90 min para aberta, e 30 e 60 min para curto.

Tabela 3.4: Medidas resistividade OG/OGr à $200^{\circ} \mathrm{C}$.

\begin{tabular}{c|c|c|c}
\hline \hline & OGr $200^{\circ} \mathrm{C} / 30$ min & OGr $200^{\circ} \mathrm{C} / 60$ min & OGr $200^{\circ} \mathrm{C} / 90$ min \\
\hline \hline Espessura média $(\mu \mathrm{m})$ & 34 & 23 & 18 \\
\hline$\rho(\Omega . c m)$ & 377 & 112,9 & 46,91 \\
\hline \hline
\end{tabular}

\subsection{1}

\section{Ensaio para caracterização do sensor de vapor}

As antenas de condição de contorno curto-circuito são reprojetadas com vias de maior diâmetro, de forma a solucionar o problema obtido anteriormente com as vias finas, e a segunda versão das antenas GIS em substrato FR4 é ilustrada na Figura 3.27. A deposição de OG nas antenas é efetuada novamente como no caso anterior de OG puro. O processo de redução é análogo ao utilizado no processo de caracterização da resistividade, agora com 60 e 90 min para estrutura aberta e 30 e 60 min para curto, todas à temperatura de $200^{\circ} \mathrm{C}$.

Como o $\mathrm{CO}_{2}$ é um gás relativamente inerte, optou-se pela utilização de outra via para caracterização dos sensores. Outros gases disponíveis no laboratório cuja energia de ligação com estruturas de OG/OGr são altas são $\mathrm{NH}_{3}$ e CO, ambos extremamente tóxicos e até mesmo letais, o último além de 
tudo inodoro. Embora gases deste tipo sejam mais propensos à aplicação do sensor sem fio descrito neste trabalho em uma situação prática, por motivos de segurança decidiu-se validar sua operação via prova de conceito utilizando primeiro vapor de álcool etanol.

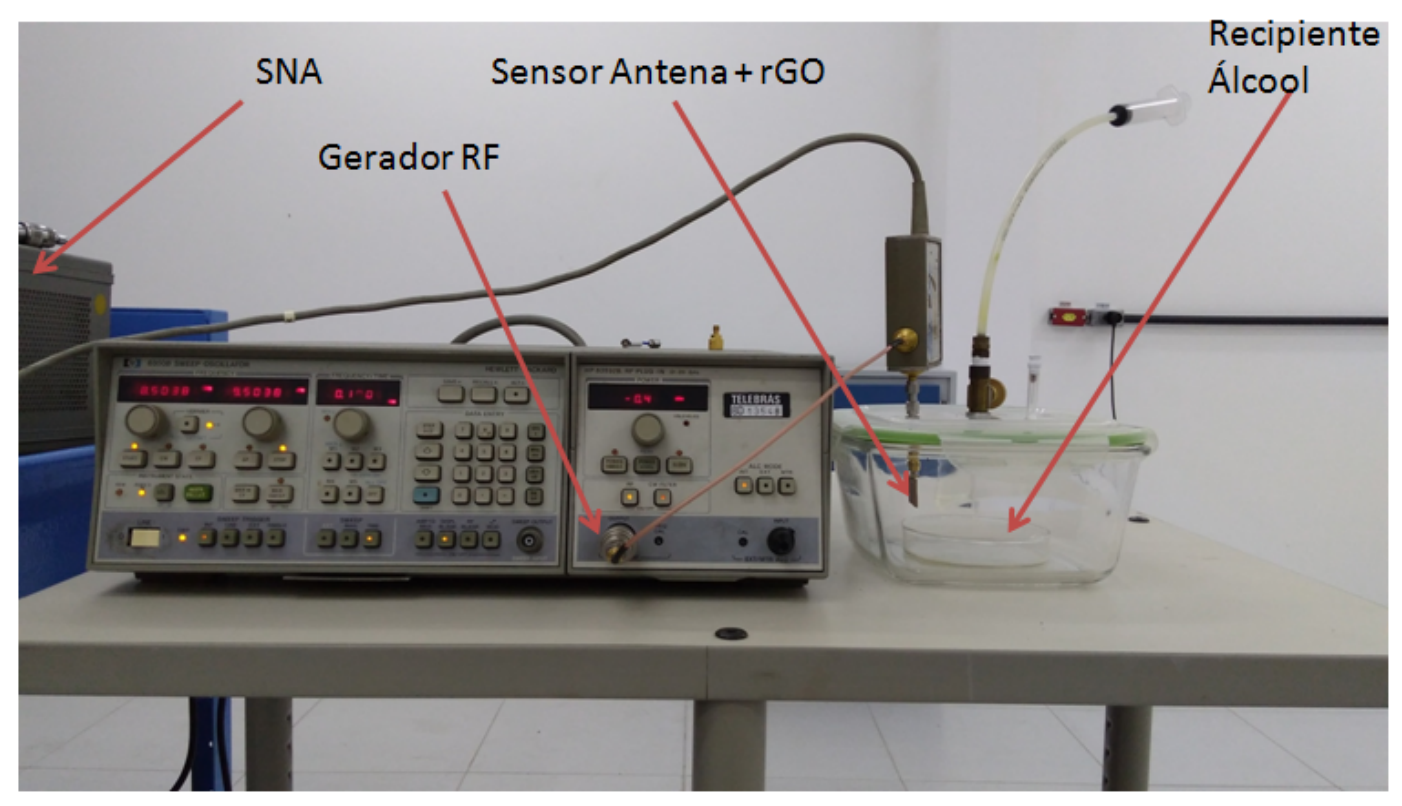

Figura 3.28: Novo setup de medição para prova de conceito do sensor de álcool.

O setup de medição adaptado da configuração utilizada anteriormente para caracterização com $\mathrm{CO}_{2}$ é ilustrado na Figura 3.28. Uma Placa de Petri vazia é inserida dentro do recipiente com uma mangueira presa logo acima. A antena é fixada dentro do recipiente via conector SMA, ligada a um gerador de sinais RF. O sinal refletido vai para um analisador de rede escalar (ARE), de forma a caracterizar o coeficiente de reflexão de entrada da antena. A temperatura da sala é mantida à temperatura ambiente, controlada por arcondicionados, de forma a evitar influências externas no teste. Depois de garantir que o coeficiente de reflexão está estável em um valor fixo e não sofre influências externas consideráveis, $30 \mathrm{ml}$ de etanol de extrema pureza $(\geq 99,5 \%)$ são inseridas na mangueira através de uma seringa em $t=0$, de forma a findar na Placa de Petri. Conforme o álcool evapora sobre a estrutura, preenchendo a atmosfera interna do recipiente, e o OGr adsorve as moléculas de etanol, a resposta pode ser obsevada em tempo real no ARE. Como a resposta de estruturas de OG/OGr não funcionalizadas usualmente são lentas, a medida foi efetuada em uma janela de tempo de 90 minutos. O coeficiente de reflexão é convertido para a parte real da impedância, e a sensibilidade é calculada como: 


$$
\operatorname{Sens}(t)=\left|\frac{R_{A}(t)-R_{A}(0)}{R_{A}(0)}\right| \times 100 \%,
$$

onde $R_{A}(t)$ é a resistência de entrada instantânea da antena, e $R_{A}(0)$ é a resistência da antena no tempo $t=0$.

Os resultados experimentais e a comparação de sensibilidades dos sensores aberto com OGr 60 e 90 min e curto com OGr 30 e 60 min são ilustradas na Figura 3.29, e resumidas na Tabela 3.5. Conforme pode ser observado, a estrutura aberta 90 min apresenta sensibilidade de 1,62\% ao fim de uma hora e meia de teste, enquanto a curto 30 min apresenta sensibilidade de 2,06\%. A melhor sensibilidade ocorre para a estrutura aberta 60 min, com 8,96\%. A antena curto-circuito com OGr 60 min apresenta sensibilidade de 3,67\%.

Tabela 3.5: Resultados Medidas Sensores GIS

\begin{tabular}{c|cc|cc|}
\hline \hline & Curto 30 min & Curto 60 min & Aberto 60 min & Aberto 90 min \\
\hline Sensibilidade & $2,06 \%$ & $3,67 \%$ & $8,96 \%$ & $1,62 \%$ \\
\hline \hline
\end{tabular}

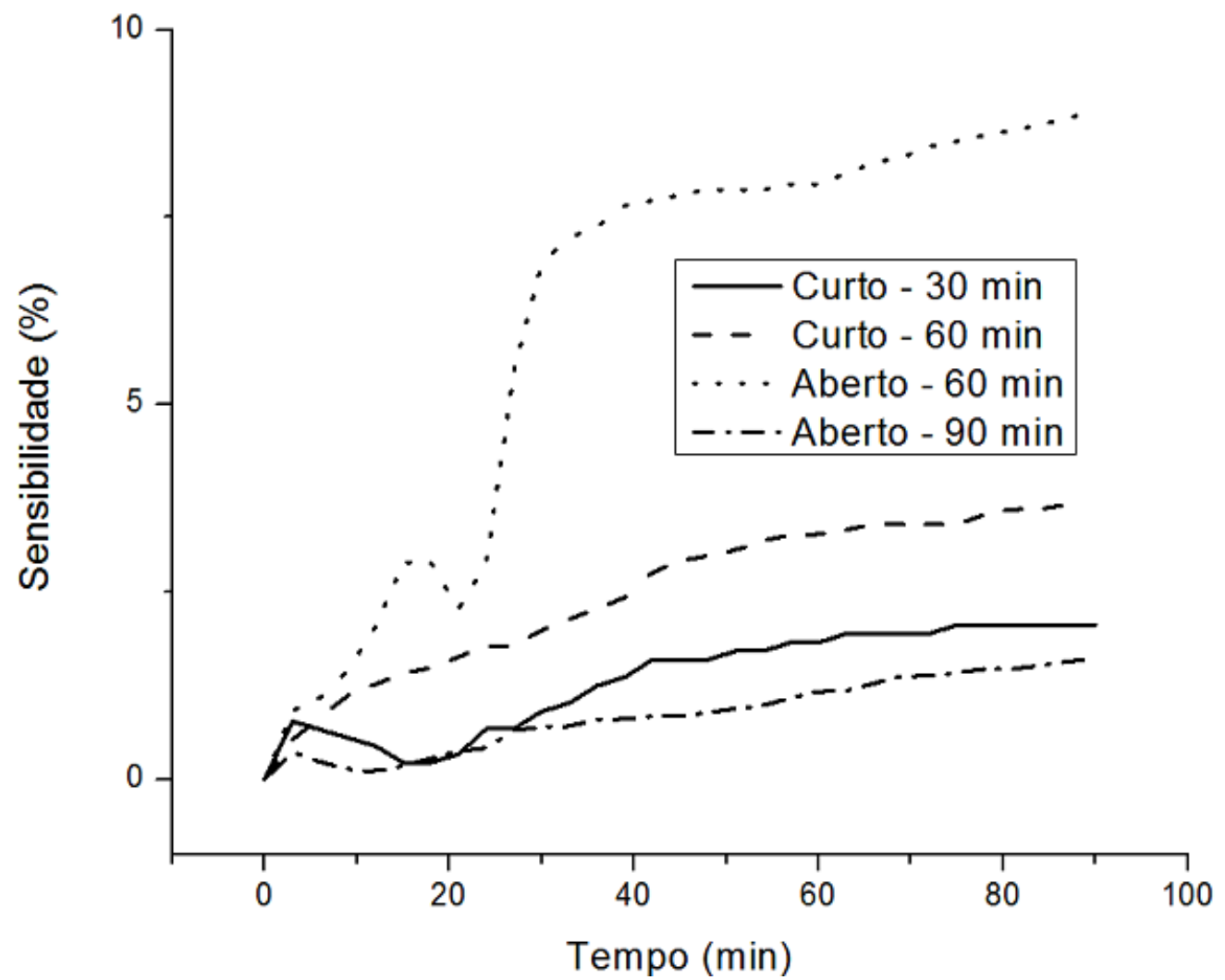

Figura 3.29: Sensibilidade medida versus tempo dos quatro sensores implementados. 


\section{5}

\section{Considerações finais Capítulo 3}

Demonstrou-se neste capítulo uma prova de conceito de um sensor sem fio de etanol. A sensibilidade mais alta ocorreu para a condição de contorno aberta com OGr reduzido por uma hora e meia. A contribuição principal do capítulo foi a demonstração teórica, simulada e verificada experimentalmente de que o sensor responde apenas para uma determinada faixa de resistividades. Desta forma, a folha de OGr é caracterizada e projetada para operar nesta faixa de interesse. Validada a operação dos sensores utilizando uma metodologia empírica, o próximo capítulo descreve uma abordagem mais metodológica do projeto dos sensores. 


\section{4 \\ Projeto Sensores GIS em FR4 utilizando OGr}

Para projeto dos novos sensores sem fio baseados em antenas GIS, definiuse como diretriz inicial a seguinte metodologia:

- Projeto da guia de onda integrada em substrato com frequência de corte na faixa desejada;

- Inserção do dipolo magnético — ou seja, da fenda —, caracterizando o seu comportamento ainda com duas portas;

- Simulação das estruturas projetadas acima com condições de contorno abertas e curto-circuitadas, além da influência do tamanho do plano de terra;

- Se necessário, casamento de impedâncias via transformador quarto de onda;

- Simulação com folha de resistividade variável de forma a encontrar a faixa de valores de interesse;

- Implementação física dos protótipos das antenas e deposição de OG e posterior redução para OGr na faixa de interesse;

- Caracterização experimental.

\section{1}

\section{Projeto da Guia de Onda Integrada em Substrato}

Conforme mencionado no Capítulo 2, estruturas GIS apresentam modo fundamental $\mathrm{TE}_{10}$, e pode-se relacionar suas dimensões a uma largura efetiva $w_{\text {eff }}$ de uma guia de onda retangular com as mesmas características. Portanto, da teoria eletromagnética:

$$
f_{10}=\frac{1}{2 w_{e f f} \sqrt{\epsilon \mu}}=\frac{c}{2 w_{e f f} \sqrt{\epsilon_{r}}}
$$

sendo que diversas fórmulas para cálculo da largura efetiva foram apresentadas no Capítulo 2. Lembrando que $s$ é o espaçamento e $d$ o diâmetro das vias, é comum adotar duas condições de projeto de forma a minimizar a irradiação da onda através das paredes da GIS: $s / d<2,5$ e $d<<\lambda$, usualmente $d / \lambda<1 / 10$. 


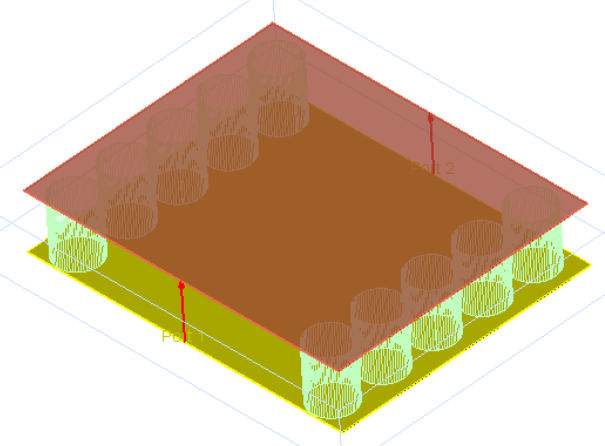

4.1(a):

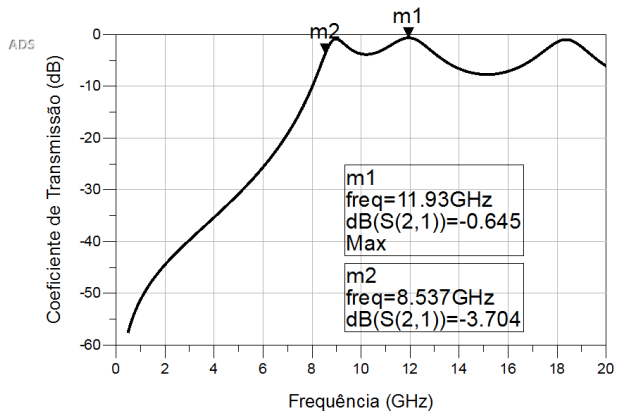

4.1(b):

Figura 4.1: Simulação do GIS em FR4: (a) layout e (b) Coeficiente de transmissão $S_{21}$.

Desta forma, utilizou-se o substrato FR-4 $\left(\epsilon_{r}=4,6\right.$, $\left.\tan \delta=0,02\right)$, com $d=1,2 \mathrm{~mm}$ e $s=1,5 \mathrm{~mm}$. Projetando a frequência de corte da guia de onda para aproximadamente $f_{10}=8,5 \mathrm{GHz}$, temos:

$$
w_{\text {eff }}=\frac{c}{2 f_{10} \sqrt{\epsilon_{r}}} \approx 8,22 \mathrm{~mm} .
$$

Utilizando uma das equações fornecidas no Capítulo 2, temos:

$$
w=w_{e f f}+\frac{d^{2}}{0,95 s}=9,23 \approx 9 \mathrm{~mm} .
$$

O layout montado para simulação no ADS é ilustrado na Figura 4.1(a), e a simulação do coeficiente de transmissão $\left(S_{21}\right)$ na Figura 4.1(b). A frequência de corte, definida como a frequência onde a transmissão é $3 \mathrm{~dB}$ abaixo da banda passante, é $f_{c}=8,537 \mathrm{GHz}$, próximo à frequência teórica calculada, com erro percentual de $0,44 \%{ }^{1}$.

Utilizando novamente a teoria eletromagnética clássica, é conveniente lembrar que o número de onda de uma onda propagante em um guia de onda é dado por:

\footnotetext{
${ }^{1}$ Lembrando que o erro percentual é calculado como erro\% $=\frac{\text { |obtido-calculadol }}{\text { calculado }} \times 100 \%$.
} 


$$
k=\frac{\omega}{c} \sqrt{\mu_{r} \epsilon_{e f f}}
$$

sendo que a permissividade elétrica efetiva pode ser calculada como:

$$
\epsilon_{e f f}=\epsilon_{r}\left(1-\frac{f_{c}^{2}}{f^{2}}\right) .
$$

Analisando as equações 4-4 e 4-5, observa-se que para frequências abaixo da frequência de corte, a permissividade elétrica eficaz é menor que zero $\left(\epsilon_{e f f}<0\right)$, e portanto $k$ é imaginário. Desta forma, apenas modos evanescentes se propagam na guia de onda para frequências inferiores à frequência de corte.

Conforme mencionado no Capítulo 2, pelo princípio da dualidade, uma fenda dual do dipolo de fio pode apresentar permeabilidade magnética abaixo de zero para uma determinada faixa de frequências. Se esta faixa de frequências ocorrer em $f<f_{c}, k=\frac{\omega}{c} \sqrt{\left(-\mu_{r}\right)\left(-\epsilon_{e f f}\right)}=\frac{\omega}{c} \sqrt{\mu_{r} \epsilon_{e f f}}$; portanto, pode-se gerar assim um modo propagante na guia de onda em frequências abaixo da frequência de corte. Por outro lado, se a permeabilidade negativa ocorrer em $f>f_{c}$, gera-se assim uma onda evanescente para uma faixa de frequências acima da frequência de corte. Esta propriedade pode ser explorada por exemplo para projetos de filtros rejeita-faixa [27].

De forma a visualizar o que foi mencionado acima, corta-se uma fenda no condutor superior da GIS, de forma que o campo magnético seja paralelo ao eixo da fenda (da mesma forma que, no caso elétrico, a resposta ocorre para campo elétrico incidente paralelo ao eixo dos fios). O layout da estrutura é ilustrado na Figura 4.2(a). A Figura 4.2(b) ilustra a simulação que compara os coeficientes de transmissão das duas estruturas. Conforme pode ser observado na linha tracejada, há uma banda de rejeição em frequências acima da frequência de corte da guia de onda para a estrutura com fenda, o que significa que $\mu_{r}<0$ em uma faixa de $f>f_{c}$.

Note que se a permeabilidade for negativa para $f<f_{c}$ a ressonância negativa ocorre em uma frequência inferior à definida inicialmente no projeto. Desta forma, a guia de onda é reprojetada para uma frequência de corte mais alta $(11 \mathrm{GHz})$, de forma que a ressonância de ordem negativa ocorra próxima à faixa de 8,5 GHz. Para atingir esse objetivo, a mesma metodologia empregada anteriormente é utilizada, com os mesmos valores de espaçamento e diâmetro das vias. Logo:

$$
w_{e f f}=\frac{c}{2 f_{10} \sqrt{\epsilon_{r}}} \approx 6,36 \mathrm{~mm} .
$$

Utilizando novamente a equação para correção, obtem-se:

$$
w=w_{\text {eff }}+\frac{d^{2}}{0,95 s}=7,37 \approx 7,4 \mathrm{~mm} .
$$

A nova GIS com frequência de corte de $11 \mathrm{GHz}$ é simulada utilizando as 


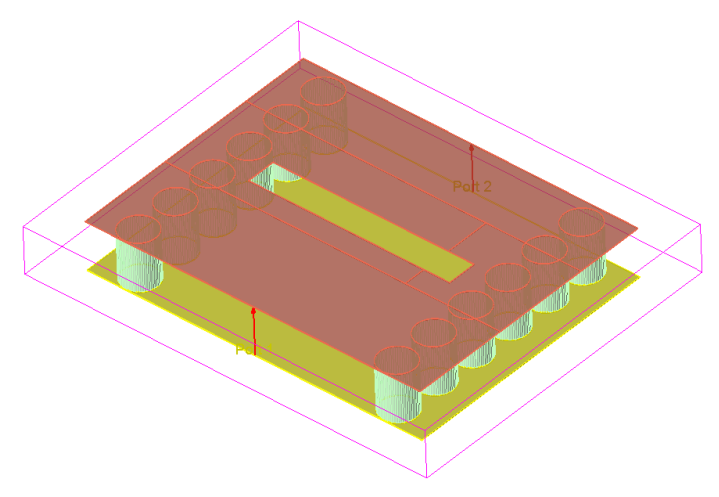

永

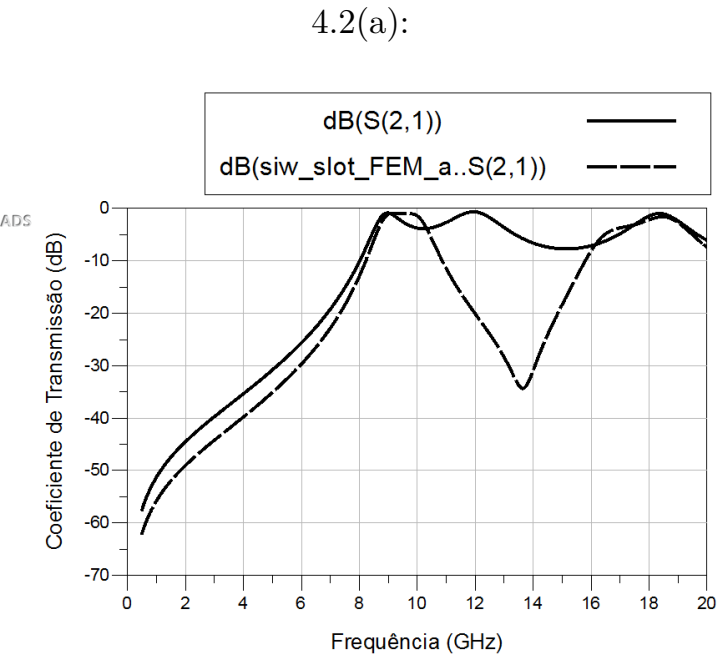

$4.2(\mathrm{~b})$ :

Figura 4.2: Simulação GIS com fenda em FR4: (a) layout e (b) Coeficiente de transmissão $S_{21}$, linha contínua para a GIS pura e tracejada para o caso com fenda.

dimensões calculadas, e, posteriormente, uma fenda similar à da Figura 4.2(a) é implementada, e a simulação de ambas as estruturas é ilustrada na Figura 4.3. A frequência de corte é aproximadamente 10,6 GHz, e o erro percentual é $3,67 \%$.

Como esperado, um comportamento similar ao caso anterior é observado, e a estrutura apresenta banda de rejeição em uma faixa de $f>f_{c}$, devido às ondas evanescentes que passam a se propagar na guia no intervalo onde $\mu_{r}<0$. Como é desejada uma operação no modo $n=-1$, de modo a investigar a influência da amplificação dos campos próximos na operação da estrutura como sensor sem fio, além da miniaturização da antena, a fenda é ziguezagueada de forma a aumentar seu comprimento [27], conforme ilustrado na Figura 4.4(a). O resultado das simulações é ilustrado na Figura 4.4(b). Note que a estrutura apresenta uma banda passante em uma faixa que se encontra abaixo da frequência de corte da guia de onda, conforme desejado. 


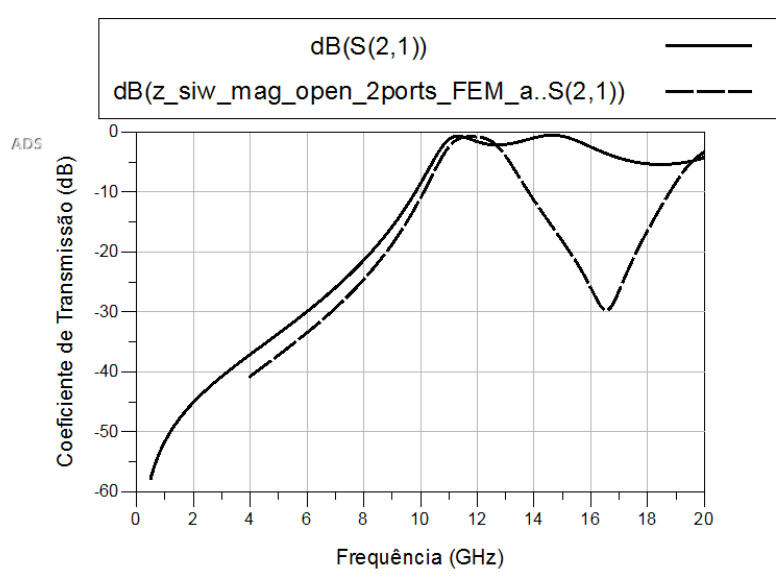

Figura 4.3: Simulação coeficiente de transmissão $S_{21}$ GIS com fenda em FR4 para $f_{c}=11 \mathrm{GHz}$. Linha contínua: guia de onda pura; linha tracejada: estrutura com fenda.

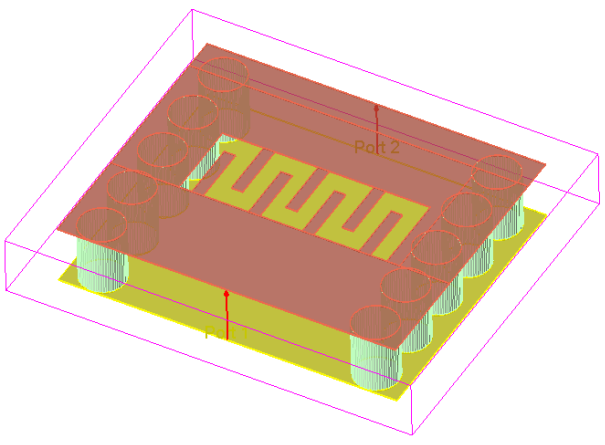

Ex

4.4(a):

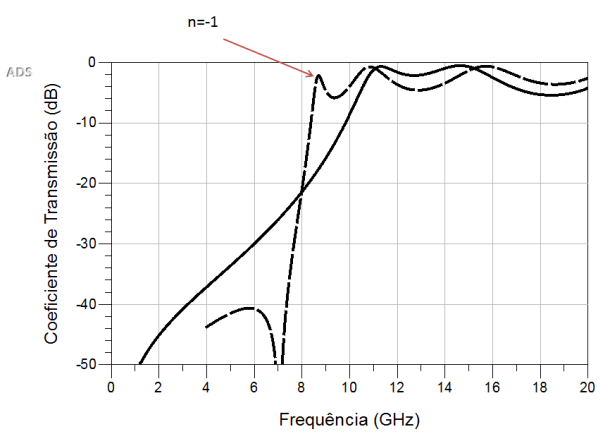

4.4(b):

Figura 4.4: Simulação GIS com fenda estendida em FR4: (a) layout e (b) Coeficiente de transmissão $S_{21}$, linha contínua para a GIS pura e tracejada para o caso com fenda estendida, ilustrando a ressonância de ordem -1.

Como posteriormente a deposição das estruturas baseadas em grafeno se dará no capacitor interdigital no centro da antena, algumas variações da 
capacitância interdigital são testadas de forma a aumentar a área de contato com o gás. O resultado da simulação de um destes testes é ilustrado na Figura 4.5. Conforme pode ser observado na linha tracejada, os novos graus de liberdade adicionados ao projeto da antena geram um comportamento anômalo na resposta da estrutura, fazendo com que alguns vales indesejados surjam no coeficiente de transmissão. Desta forma, optou-se por seguir com o projeto da Figura 4.4(a).

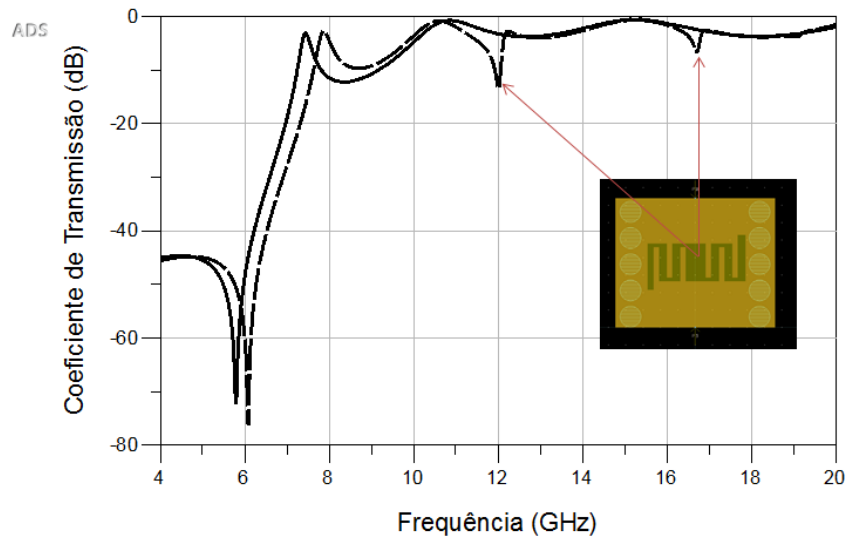

Figura 4.5: Simulação coeficiente de transmissão $S_{21}$ GIS com fenda modificada em FR4. Linha contínua: estrutura da Figura 4.4(a); linha tracejada: guia de onda com fenda modificada (margem do gráfico).

\section{2}

\section{Projeto das Antenas GIS Condição de Contorno Aberta}

Demonstrado o funcionamento das guias de onda como estrutura de duas portas, o próximo passo consiste em testar o funcionamento da estrutura como irradiadora, impondo as condições de contorno aberto e curto. Removendo a porta 2, impõe-se a condição de contorno de circuito aberto. Na Figura 4.6(a) é ilustrada a comparação do coeficiente de reflexão na entrada das estruturas de 1 e 2 portas. Conforme pode ser observado, os resultados são bastante próximos, validando assim o método de projeto utilizado para obtenção da resposta desejada. A Figura 4.6(b) ilustra a impedância de entrada da antena. Note que as ressonâncias $n=-1,0$ e 1 aparecem, conforme esperado pela teoria.

Observando a Figura 4.6(b) pode-se notar que a antena apresenta impedância de entrada próxima à $50 \Omega$ na frequência de interesse. Além disso, é conhecido que o plano de terra deve ser maior que as dimensões da antena de forma a não interferir na eficiência e no formato do diagrama de irradiação. Logo, adicionando à antena uma linha de microfita com impedância característica de $50 \Omega$ e aumentando as dimensões do plano de terra conforme ilustrado 


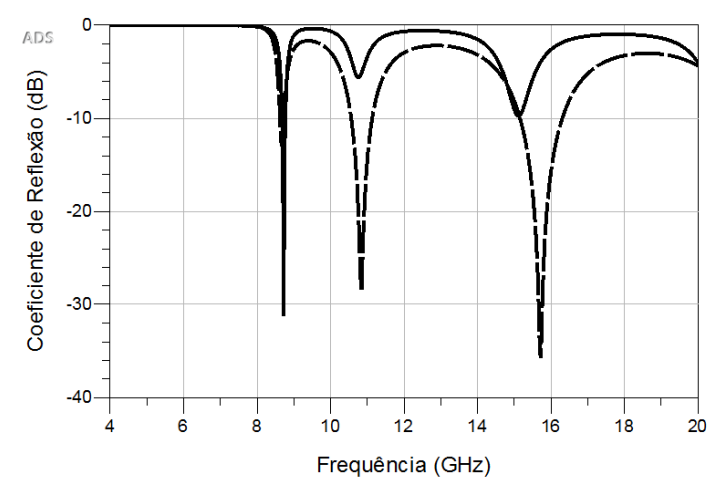

4.6(a):

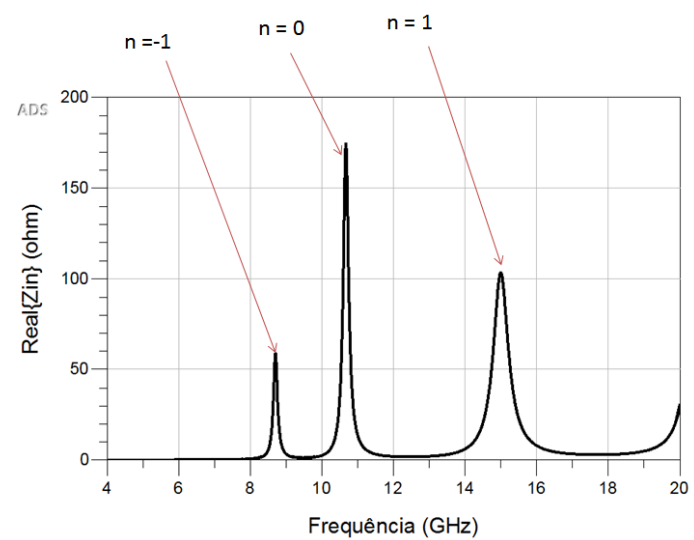

4.6(b):

Figura 4.6: Simulação antena GIS: (a) Comparação entre coeficiente de reflexão das estruturas de 1 e 2 portas; e (b) Parte real da impedância de entrada.

na Figura 4.7(a), a Figura 4.7(b) ilustra o resultado da simulação de ambas as estruturas. Conforme pode ser observado, há pouca variação na frequência de ressonância de ordem -1, mesmo havendo uma melhora no valor do coeficiente de reflexão, devido a uma pequena mudança no valor da impedância de entrada. A Figura 4.8 ilustra o diagrama de irradiação tridimensional e os cortes nos planos verticais. Como pode-se observar, o diagrama apresenta um máximo diferente de $\theta=0$ no plano $\phi=90^{\circ}$, o que também foi observado em [30] e nas antenas implementadas no Capítulo 3. Na frequência de ressonância $f_{-1}=8,794 \mathrm{GHz}$, o ganho e eficiência simulados são de $3 \mathrm{dBi}$ e 49,3\%, respectivamente.

\section{3}

\section{Antenas GIS com Condição de Contorno Curto-Circuito}

Uma metodologia similar à da Seção 4.2 será aplicada agora para o caso de condição de contorno de curto-circuito. Fechando também com vias a estrutura inicial de guia de onda apresentada na Figura 4.1(a), obtém-se uma 


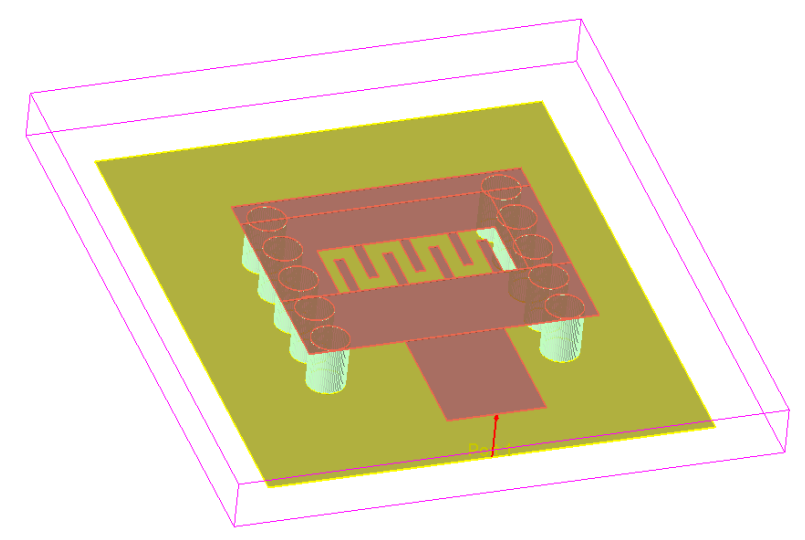

$4.7(\mathrm{a})$ :

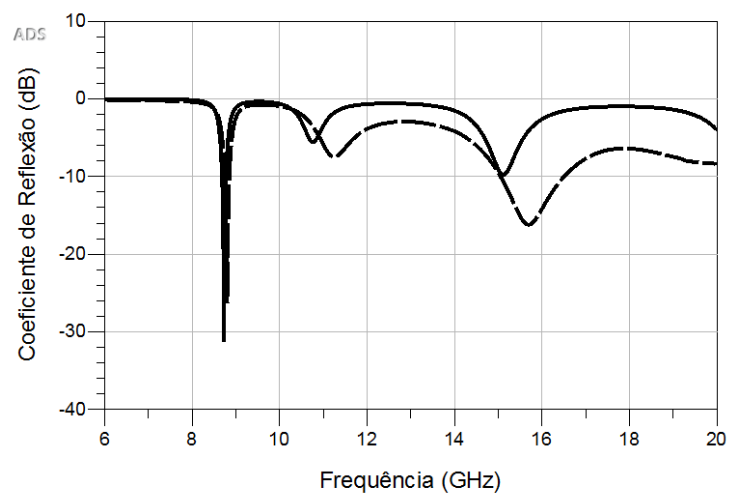

$4.7(b)$ :

Figura 4.7: Simulação antena GIS com alimentação microfita e plano de terra: (a) Layout e (b) Comparação entre coeficiente de reflexão das duas estruturas.

cavidade ressonante integrada em substrato, conforme ilustrado na Figura 4.9. $\mathrm{O}$ modo dominante agora é o $\mathrm{TE}_{110}$, cuja frequência de ressonância para as mesmas dimensões utilizadas para o caso aberto $(s=1,5 \mathrm{~mm}$ e $d=1,2 \mathrm{~mm})$ pode ser aproximada por:

$$
f_{110} \approx \frac{c}{2 \sqrt{\epsilon_{r}}}\left(\frac{1}{\ell^{2}}+\frac{1}{w_{\text {eff }}^{2}}\right)^{1 / 2} \approx 14,2 \mathrm{GHz},
$$

sendo que a largura eficaz $w_{\text {eff }}$ foi definida no Capítulo 2 , e $\ell$ é o comprimento da cavidade.

O resultado da simulação da cavidade ressonante da Figura 4.9 é ilustrado na Figura 4.10. Conforme pode-se observar, a ressonância ocorre na frequência de $12,32 \mathrm{GHz}\left(e_{\%} \approx 15 \%\right)$.

Assim como efetuado no projeto com condição de contorno aberta, 


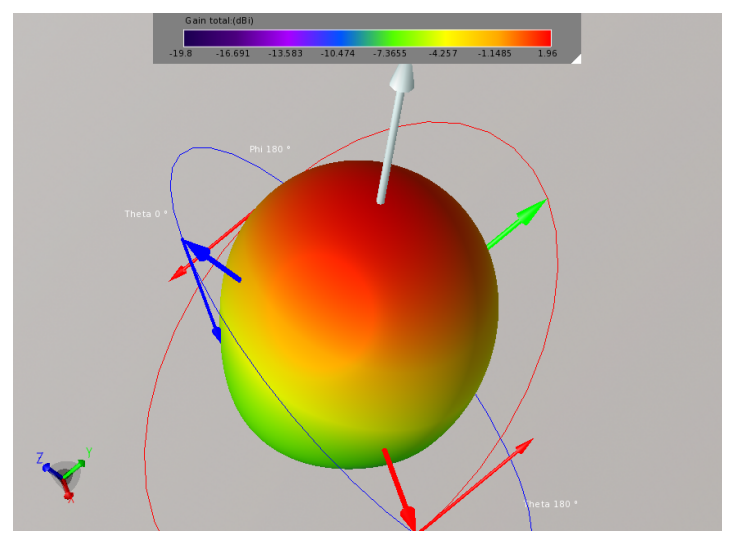

4.8(a):

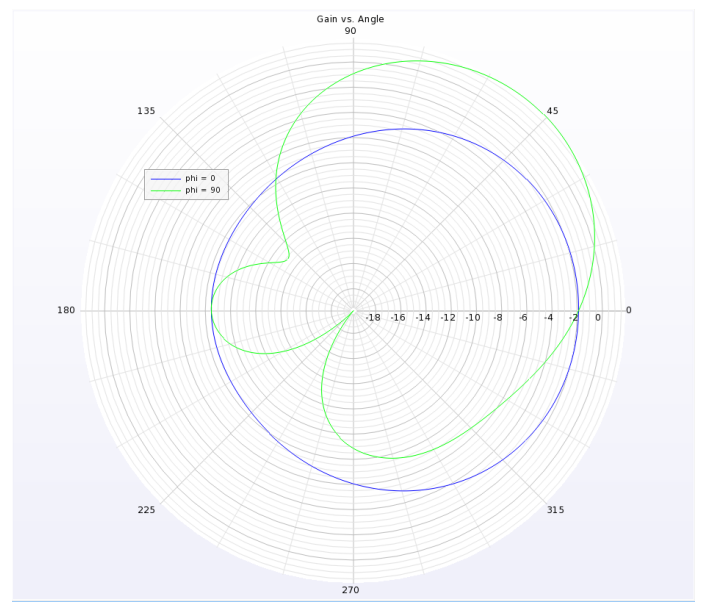

4.8(b):

Figura 4.8: Simulação diagrama de irradiação antena GIS com alimentação microfita e plano de terra: (a) 3D e (b) Corte planos $\phi=0$ e $\phi=\pi / 2$.

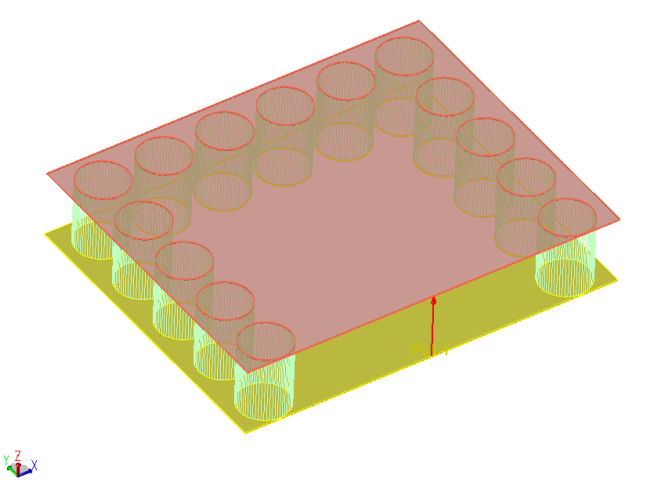

Figura 4.9: Layout da cavidade ressonante integrada em substrato utilizada para projeto da antena GIS com condição de contorno curto-circuitada.

adiciona-se à cavidade ressonante uma fenda em ziguezague no centro da estrutura, conforme ilustrado na Figura 4.11. Note que em contrapartida ao caso aberto, não é possível caracterizar o coeficiente de transmissão com duas portas em uma cavidade ressonante. Desta forma, partimos direto para caracterização 


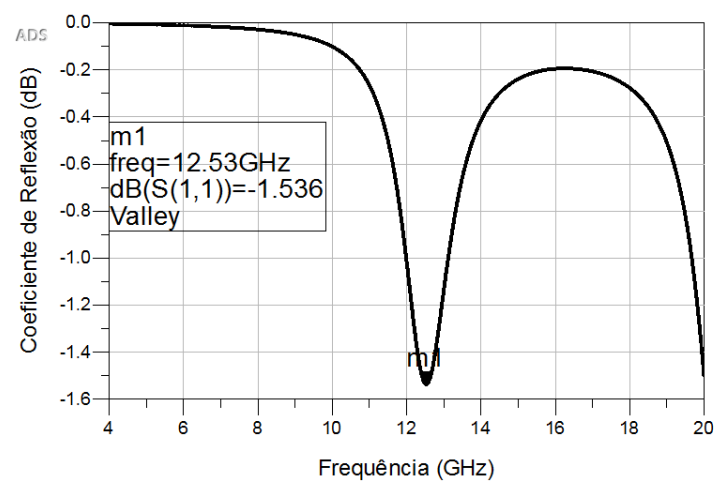

4.10(a):

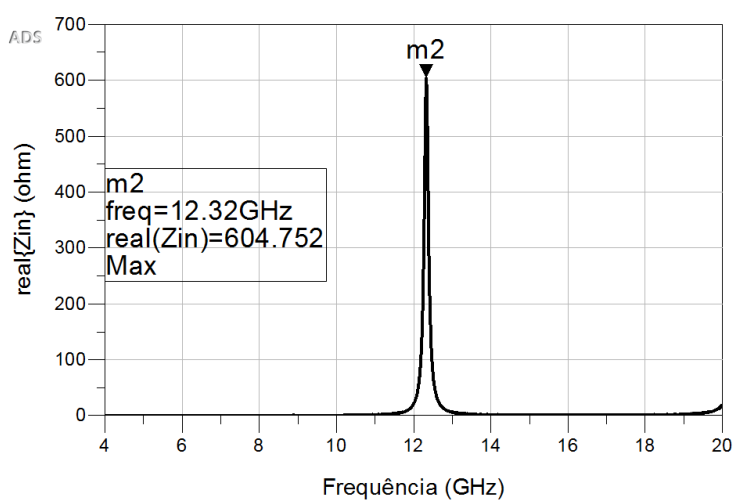

4.10(b):

Figura 4.10: Simulação cavidade ressonante integrada em substrato: (a) Coeficiente de Reflexão e (b) Parte real da impedância de entrada.

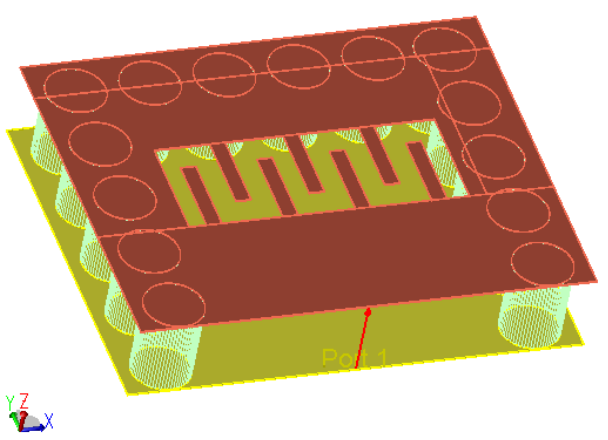

Figura 4.11: Layout da antena GIS com condição de contorno curto-circuitada.

da estrutura com uma porta, operando como antena. A simulação do coeficiente de reflexão na entrada é ilustrado na Figura 4.12(a), e a parte real da impedância de entrada em comparação com a antena de condição de contorno aberta é ilustrado na Figura 4.12(b). Note que o casamento de impedâncias é aceitável $(<-10 \mathrm{~dB})$ na frequência de interesse. Além disso, analisando a Figura 4.12(b) pode-se observar que conforme previsto pela teoria, a ressonância de 


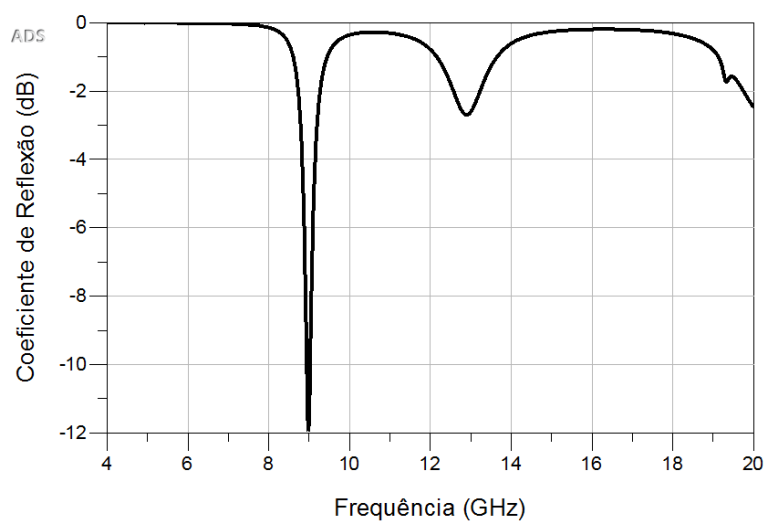

4.12(a):

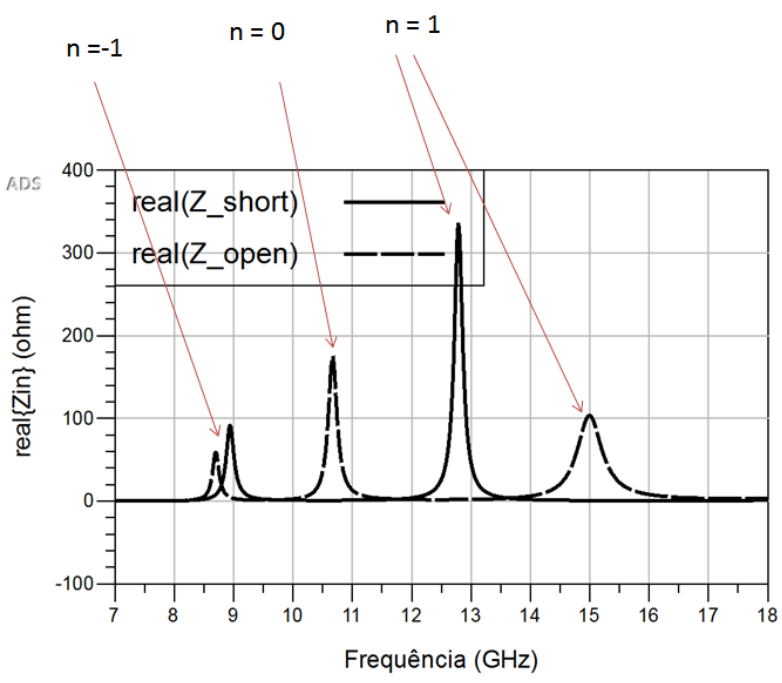

4.12(b):

Figura 4.12: Simulação antena GIS com condição de contorno curto-circuitada: (a) Coeficiente de Reflexão e (b) Parte real da impedância de entrada, comparação entre condição de contorno curto-circuito e circuito aberto (linha contínua: curto-circuito; linha tracejada: circuito aberto).

ordem zero desaparece para a condição de contorno de curto-circuito, devido à condição de campo elétrico uniforme ao longo do comprimento da estrutura.

Também como para o caso aberto, é importante aumentar as dimensões do plano de terra, além de adicionar uma linha de alimentação de $50 \Omega$ à antena $^{2}$. O layout da versão final da antena junto da simulação do coeficiente de reflexão é ilustrado na Figura 4.13. Observe que há uma pequena melhora no coeficiente de reflexão. Além disso, a simulação dos diagramas de irradiação tridimensional e os cortes nos planos verticais são ilustrados na Figura 4.14. Na frequência de ressonância $f_{-1}=9,237 \mathrm{GHz}$ o ganho simulado é $3.86 \mathrm{dBi}$, e

\footnotetext{
${ }^{2}$ Note que deveria-se adicionar um casamento de impedâncias se a impedância de entrada da antena já não fosse $\approx 50 \Omega$, o que aconteceu apenas por coincidência, em outras frequências ou substratos isso não necessariamente ocorreria.
} 


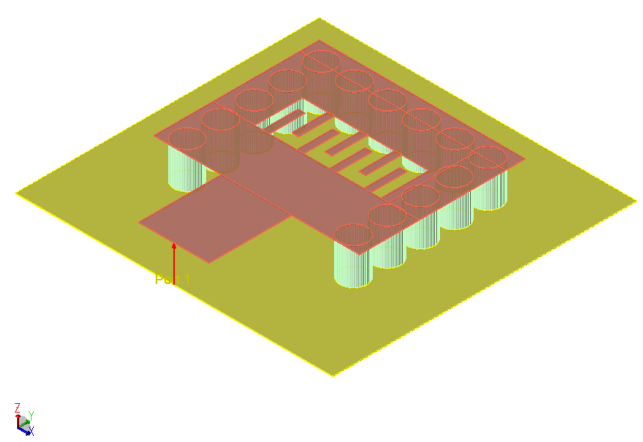

4.13(a):

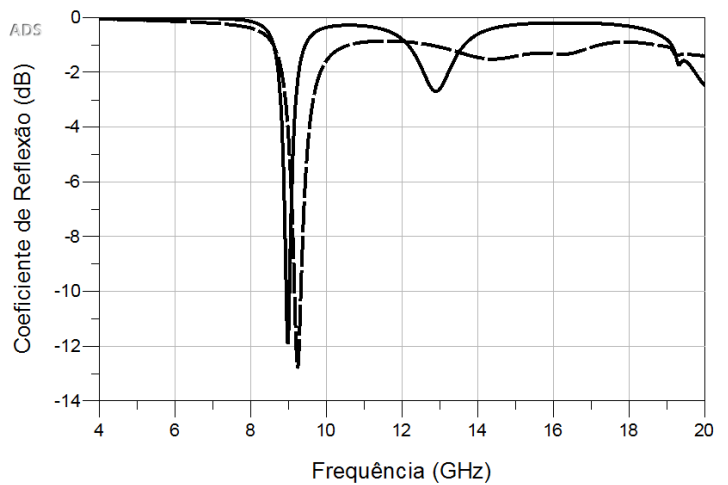

4.13(b):

Figura 4.13: Simulação antena GIS com condição de contorno curto-circuitada,

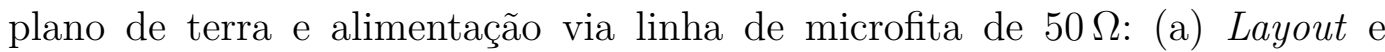
(b) Coeficiente de reflexão (linha contínua: antena da Figura 4.12(a); linha tracejada: esta topologia).

a eficiência $69,4 \%$.

\section{4}

Simulação e Caracterização Experimental das Estruturas como Sensor

Conforme realizado no Capítulo 3, optou-se por simular a resposta da antena carregada com um filme fino de espessura $17,5 \mu \mathrm{m}$ com resistividade na faixa semicondutiva, de forma a emular a resposta do OGr na fenda da antena. Os resultados da variação do coeficiente de reflexão da condição de contorno aberta são ilustrados na Figura 4.15. Conforme pode ser observado, há um deslocamento das curvas para diferentes tempos de redução. Na Figura 4.16, são ilustrados os resultados dos ganhos nos planos principais para diferentes valores de resistividade. Os gráficos referentes à condição de contorno curto-circuito são omitidos, pois o comportamento é análogo para os mesmos valores de resistividade. A variação da eficiência de irradiação com o valor da resistividade é ilustrado na Figura 4.17.

De forma a ilustrar o que foi mencionado no Capítulo 2 em relação 


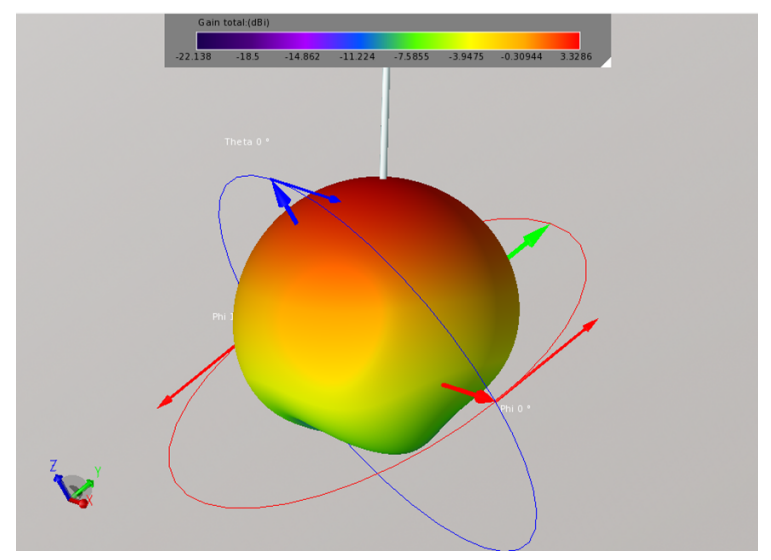

4.14(a):

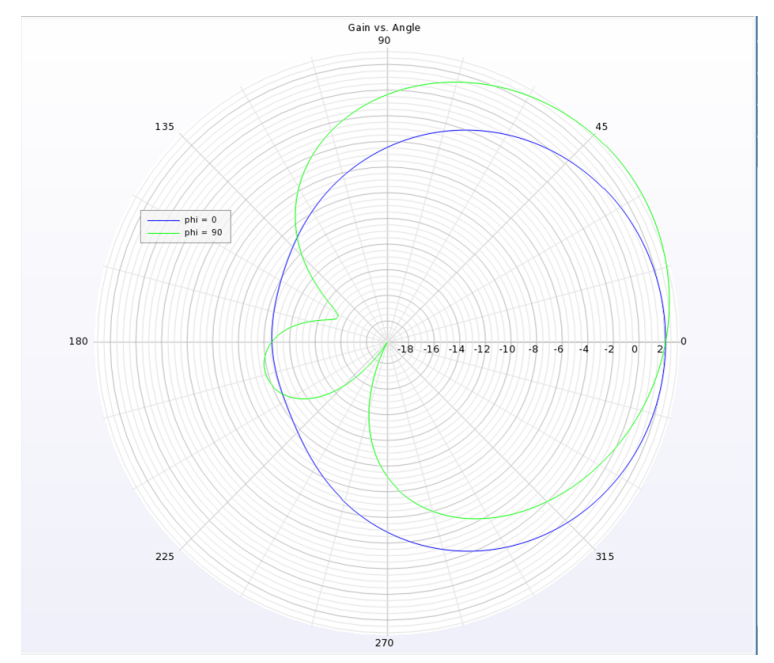

4.14(b):

Figura 4.14: Simulação diagrama de irradiação versão final antena GIS com condição de contorno curto-circuitada: (a) 3D e (b) Cortes nos planos $\phi=0$ e $\phi=\pi / 2$.

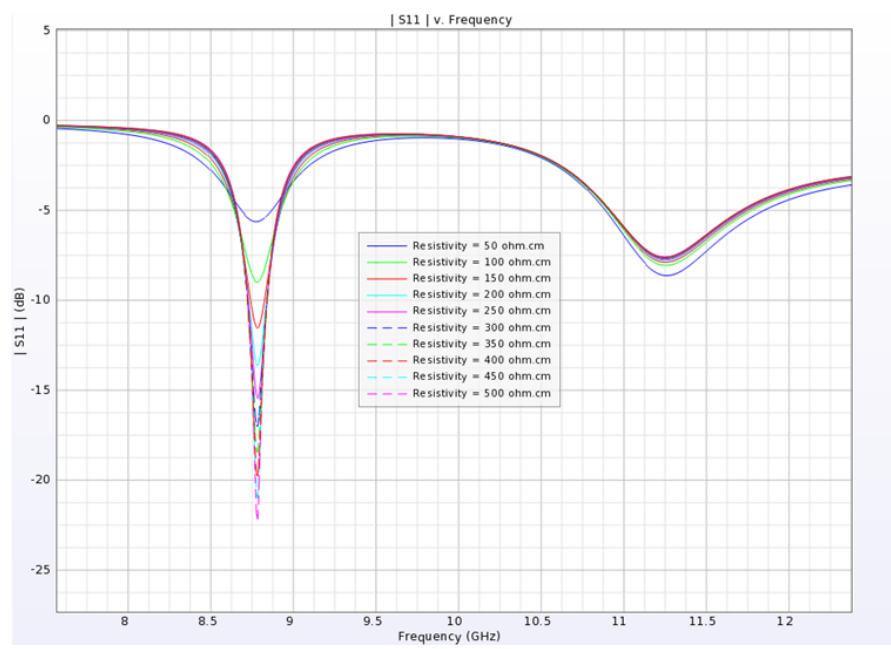

Figura 4.15: Simulação coeficiente de reflexão GIS condição de contorno aberta para diferentes valores de resistividade na faixa de interesse. 


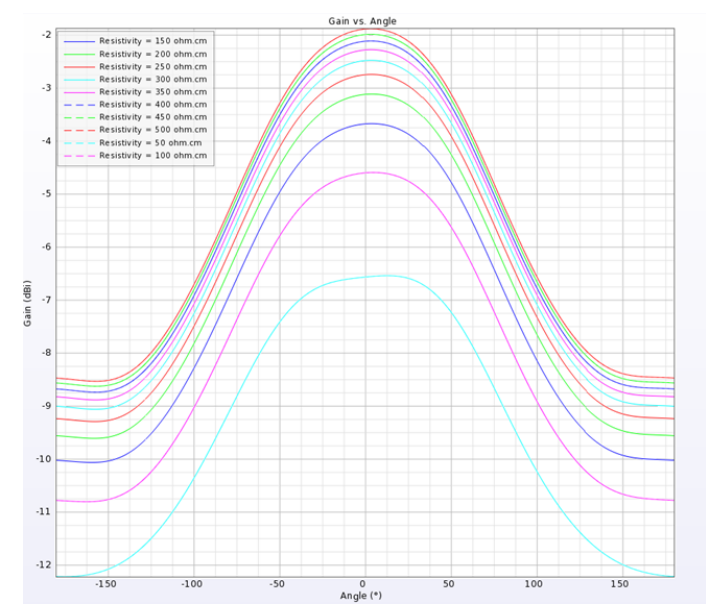

4.16(a):

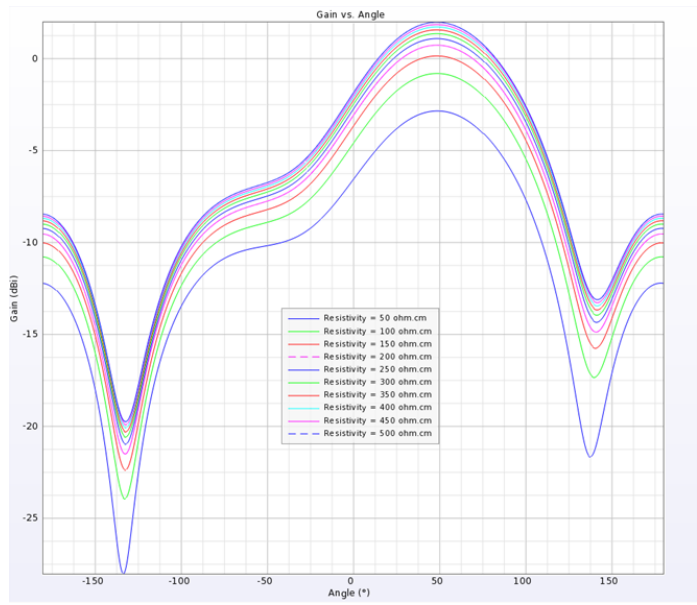

4.16(b):

Figura 4.16: Simulação diagrama de irradiação GIS condição de contorno aberta para diferentes valores de resistividade na faixa de interesse: (a) plano $\phi=0$ e (b) $\phi=\pi / 2$.

à diminuição dos grupos funcionais de oxigênio na redução de $O G$, optouse por efetuar também caracterização via espectroscopia de fotoelétrons por raio $\mathrm{x}$, ou XPS. Esta técnica é baseada no efeito fotoelétrico, e faz uso do fato que diferentes partículas possuem diferentes energias de ligação com o núcleo do átomo. Desta forma, as proporções químicas relativas do material são quantificadas através da irradiação de feixes de raios x sobre a amostra e medição da energia cinética dos elétrons arrancados [39]. Duas amostras de OG são depositadas sobre silício, conforme ilustrado na Figura 4.18. Uma é reduzida por 60 min e a outra mantida sem redução, servindo como referência. Os resultados são ilustrados na Figura 4.19. A Tabela 4.1 compara as percentagens das ligações nas amostras de OG e OGr 60 min. Conforme pode ser observado, há uma redução nas ligações C — O — C, de $47 \%$ para 30,4\%. Isto mostra que a quantidade de grupos funcionais no OG foram diminuídos, 


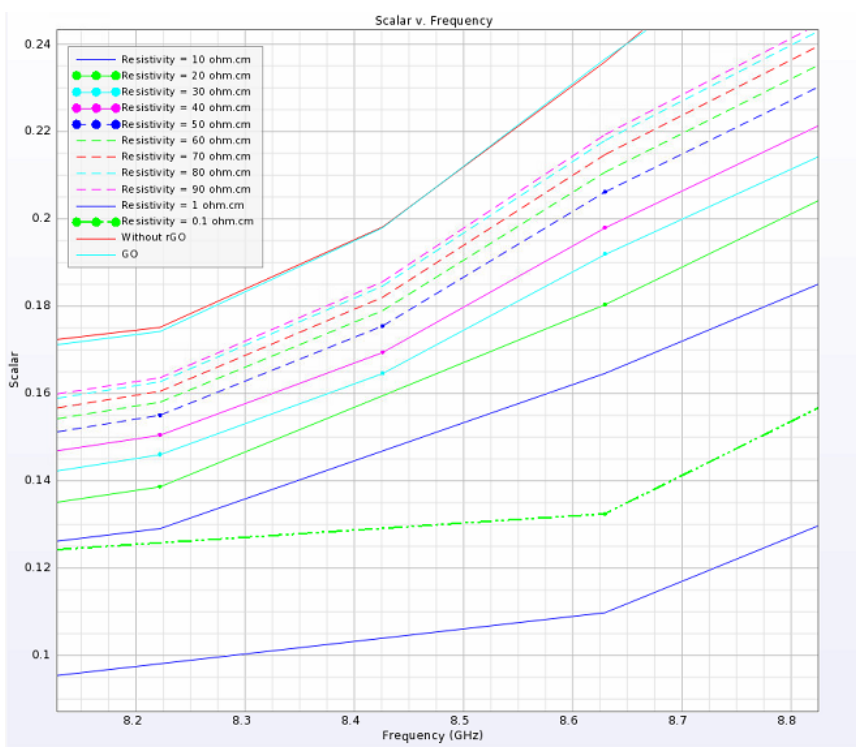

Figura 4.17: Simulação eficiência de irradiação GIS condição de contorno aberta para diferentes valores de resistividade na faixa de interesse.

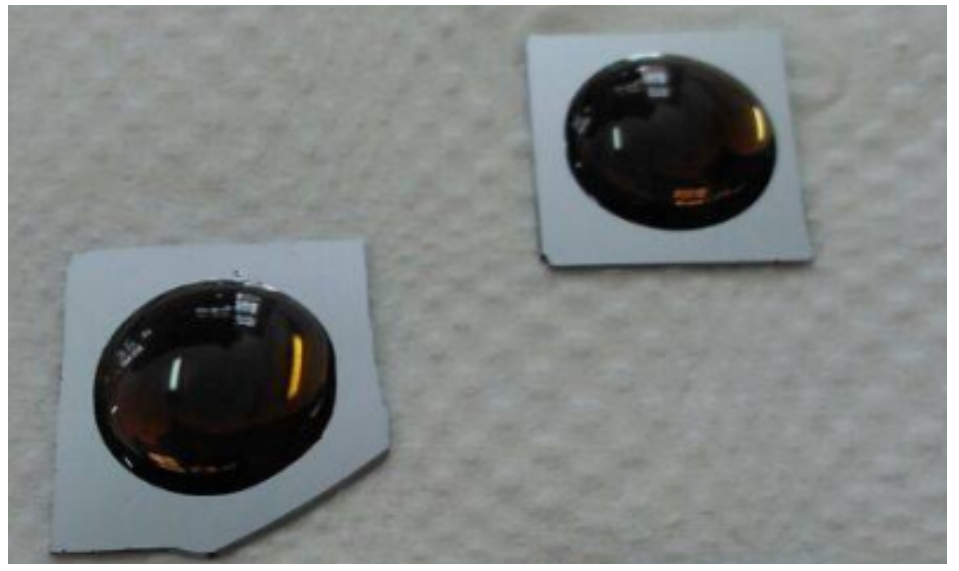

Figura 4.18: Amostras OG em silício para caracterização via XPS.

restaurando as ligações $\mathrm{sp}^{2} \mathrm{C}=\mathrm{C}$, com aumento da proporção relativa de $46,49 \%$ para $59,66 \%$. Isto está de acordo com o esperado pela teoria descrita na Seção 2.5.3. A redução no número de grupos funcionais é responsável pelo aumento da condutividade da amostra. Os grupos funcionais $\mathrm{C}-\mathrm{C}=\mathrm{O}$ são minoria no OG $(6,5 \%)$ e continuam proporcionalmente em pequeno número no OGr $(9,93 \%)$.

Finalizadas as medidas XPS, amostras de OG foram depositadas em FR4 como descrito no Capítulo 3 e reduzidas por 60, 75 e $90 \mathrm{~min}$, sendo que 60 e 90 min são os tempos de redução parcial de interesse, conforme observado nas simulações, e optou-se também por tomar um tempo intermediário de 75 min. Depois de estimadas as resistividades utilizando o método das duas pontas, descrito no Capítulo 3, os resultados aproximados são resumidos na Tabela 4.4. $10 \mu \mathrm{L}$ de $\mathrm{OG}$ são depositados nas antenas aberta e curto, e 


\begin{tabular}{c|c|c}
\multicolumn{3}{c}{ Tabela 4.1: Medidas XPS OG e OGr } \\
\hline \hline & OG & OGr 60 min \\
\hline \hline $\mathrm{C}-\mathrm{O}-\mathrm{C}$ & $47,00 \%$ & $30,40 \%$ \\
$\mathrm{C}=\mathrm{C}$ & $46,49 \%$ & $59,66 \%$ \\
$\mathrm{C}-\mathrm{C}=\mathrm{O}$ & $6,51 \%$ & $9,93 \%$ \\
\hline \hline
\end{tabular}

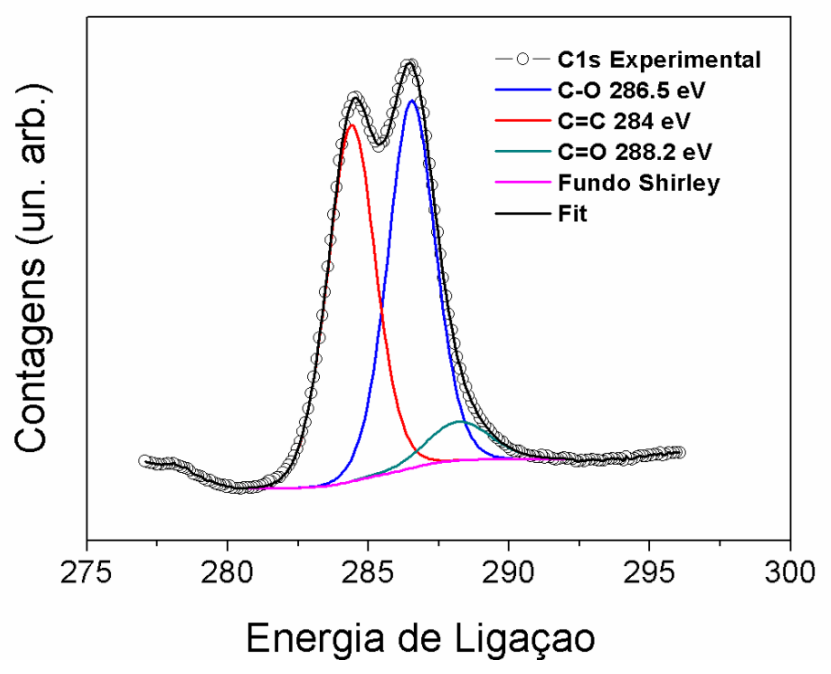

$4.19(\mathrm{a})$ :

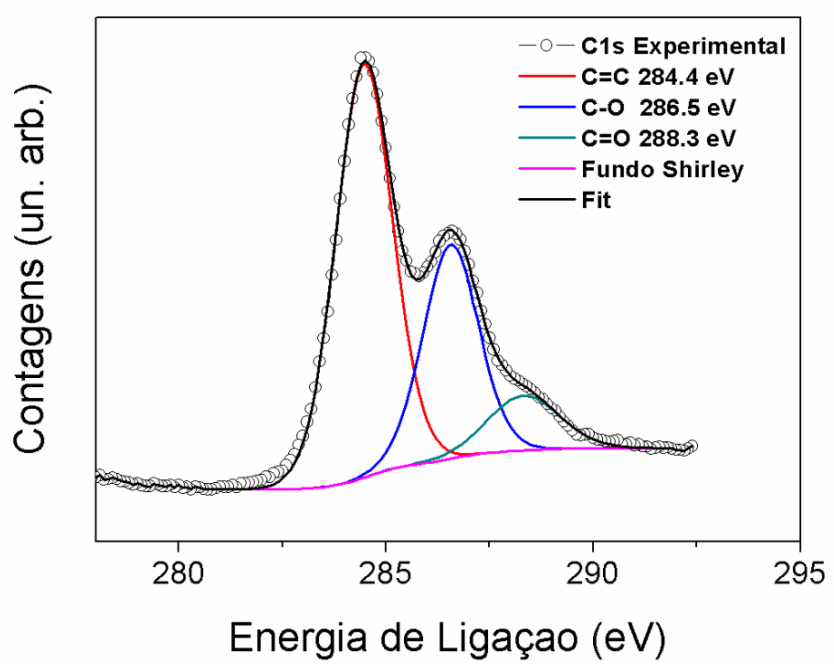

$4.19(\mathrm{~b})$ :

Figura 4.19: Caracterização via XPS para OG e OGr em silício (a) OG e (b) OGr $60 \mathrm{~min}$.

reduzidas nos três tempos citados. Os resultados da espectroscopia Raman na fenda da antena para os três diferentes tempos são ilustrados na Figura 4.20, mostrando que de fato as estruturas apresentam os picos D e G que seriam esperados para amostras de OG e OGr (ver Capítulo 2). 


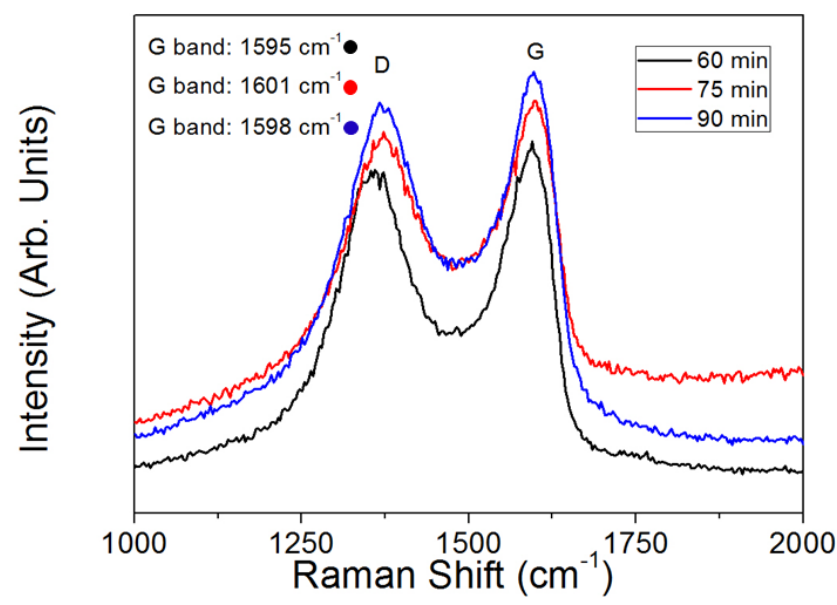

Figura 4.20: Espectroscopia Raman das três amostras preparadas para sensoriamento de vapor de álcool.

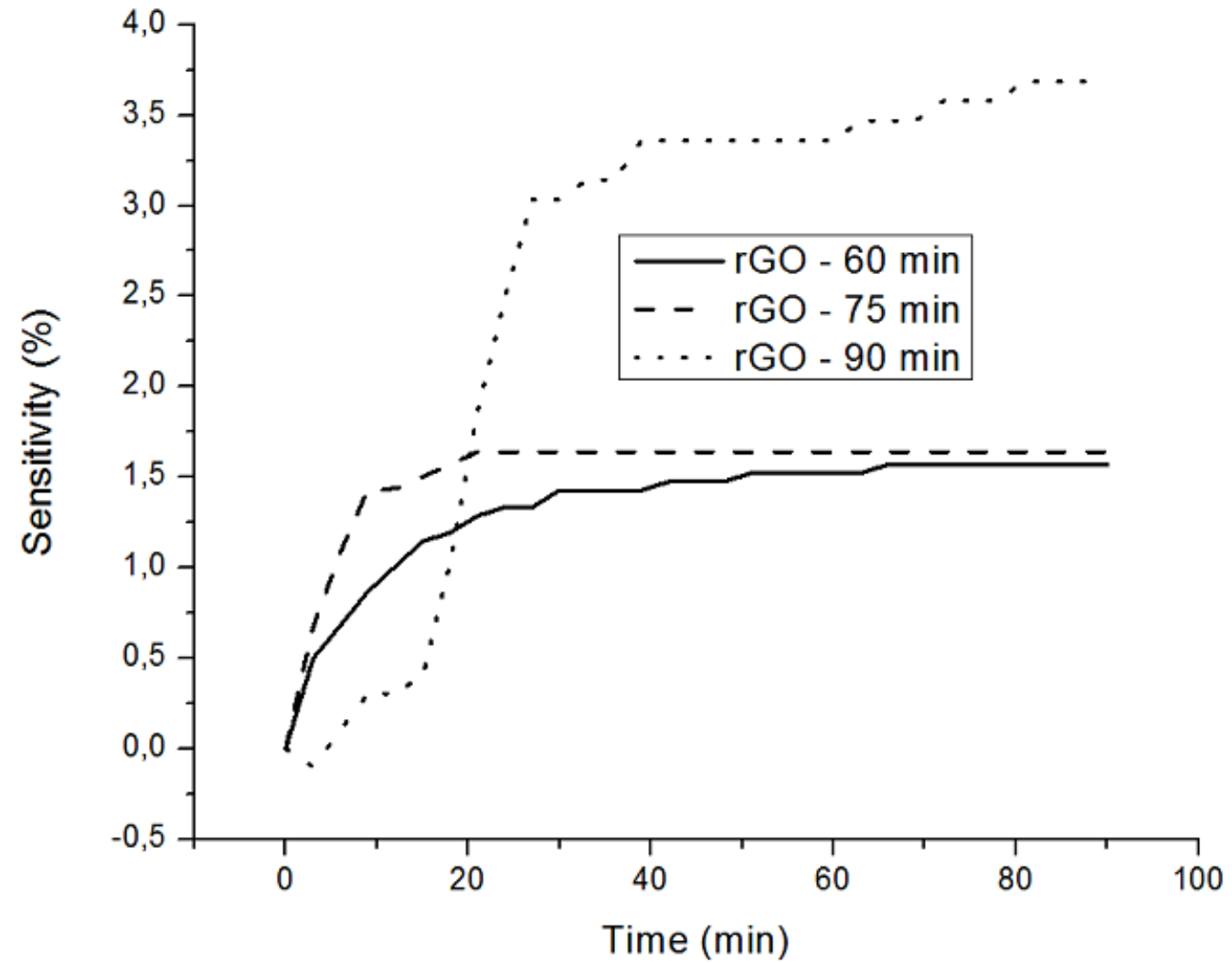

Figura 4.21: Medidas sensibilidade versus tempo dos sensores de condição de contorno aberta para álcool isopropílico.

\section{5}

\section{Caracterizações Sensor de Vapor}

O setup de caracterização do sensor sem fio é idêntico ao que foi utilizado no Capítulo 3, ilustrado na Figura 3.28. Optou-se pelas medições utilizando 


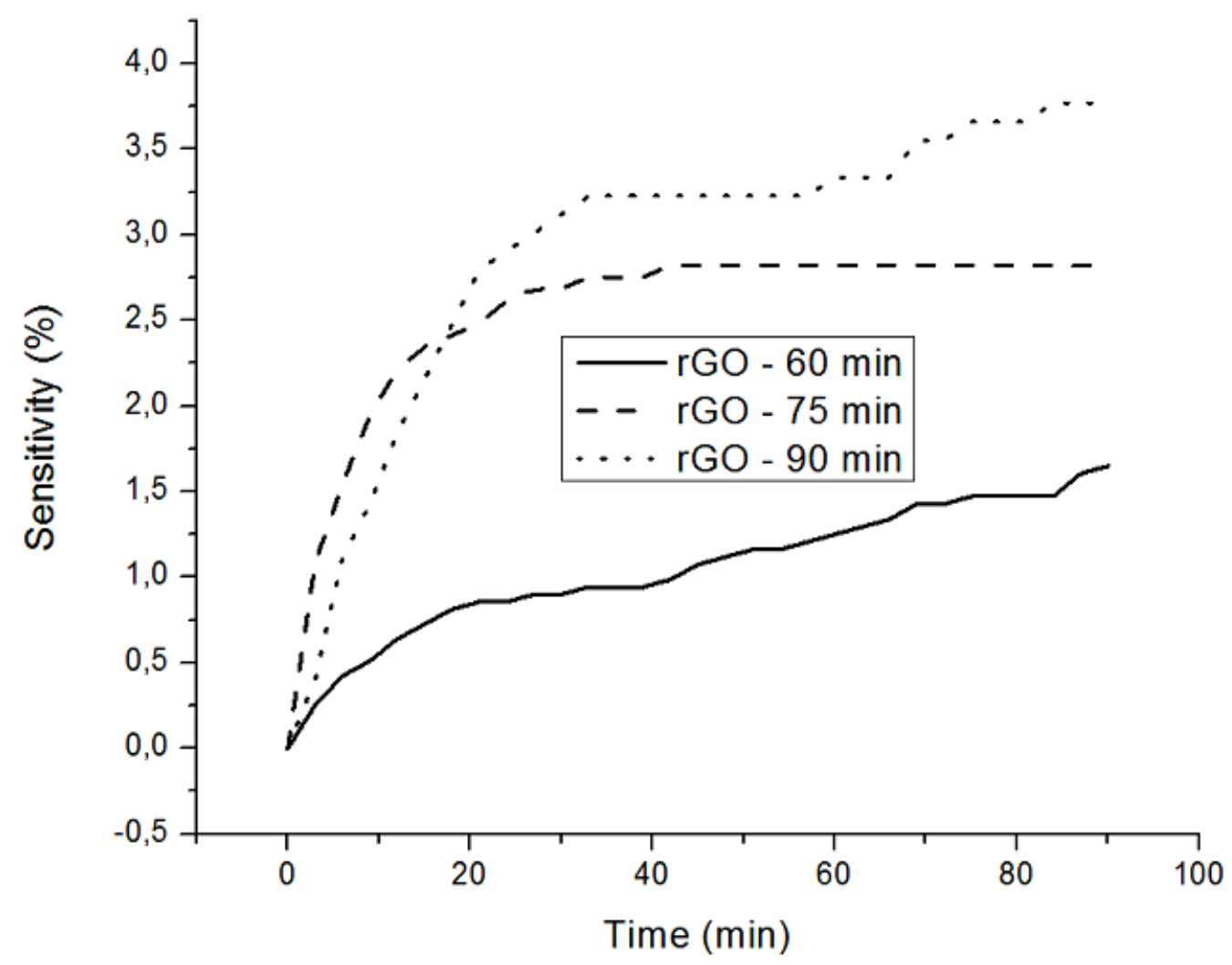

Figura 4.22: Medidas sensibilidade versus tempo dos sensores de condição de contorno aberta para etanol.

Tabela 4.2: Resultados Medidas GIS aberto

\begin{tabular}{c|ccc|ccc|}
\hline \hline & Isopropílico $60 \mathrm{~min}$ & $75 \mathrm{~min}$ & $90 \mathrm{~min}$ & Etanol $60 \mathrm{~min}$ & $75 \mathrm{~min}$ & $90 \mathrm{~min}$ \\
\hline Sensibilidade & $1,57 \%$ & $1,64 \%$ & $3,69 \%$ & $1,65 \%$ & $2,82 \%$ & $3,77 \%$ \\
\hline \hline
\end{tabular}

diferentes tipos de álcool - isopropílico e etanol -, de forma a obter uma prova de conceito inicial para o projeto desenvolvido. Novamente, a janela de tempo de medição foi de uma hora e trinta minutos. Para a condição de contorno aberta, os resultados para álcool isopropílico e etanol são ilustrados nas Figuras 4.21 e 4.22. Os valores finais de sensibilidade para esta condição de contorno são sumarizados na Tabela 4.2. Para as condições de contorno de curto-circuito em ambiente de isopropílico, as curvas são ilustradas nas Figuras 4.23 e 4.24, respectivamente. Além disso, os resultados são resumidos na Tabela 4.3. Conforme pode ser observado, o melhor resultado ocorre para a condição de contorno de curto circuito com OGr 90 min para álcool isopropílico, com sensibilidade de $11,41 \%$.

É importante salientar que embora as medidas sem fio não tenham sido efetuadas, devido a limitações na estrutura laboratorial, a discussão apresentada no Capítulo 2 sobre a relação entre as características de re- 


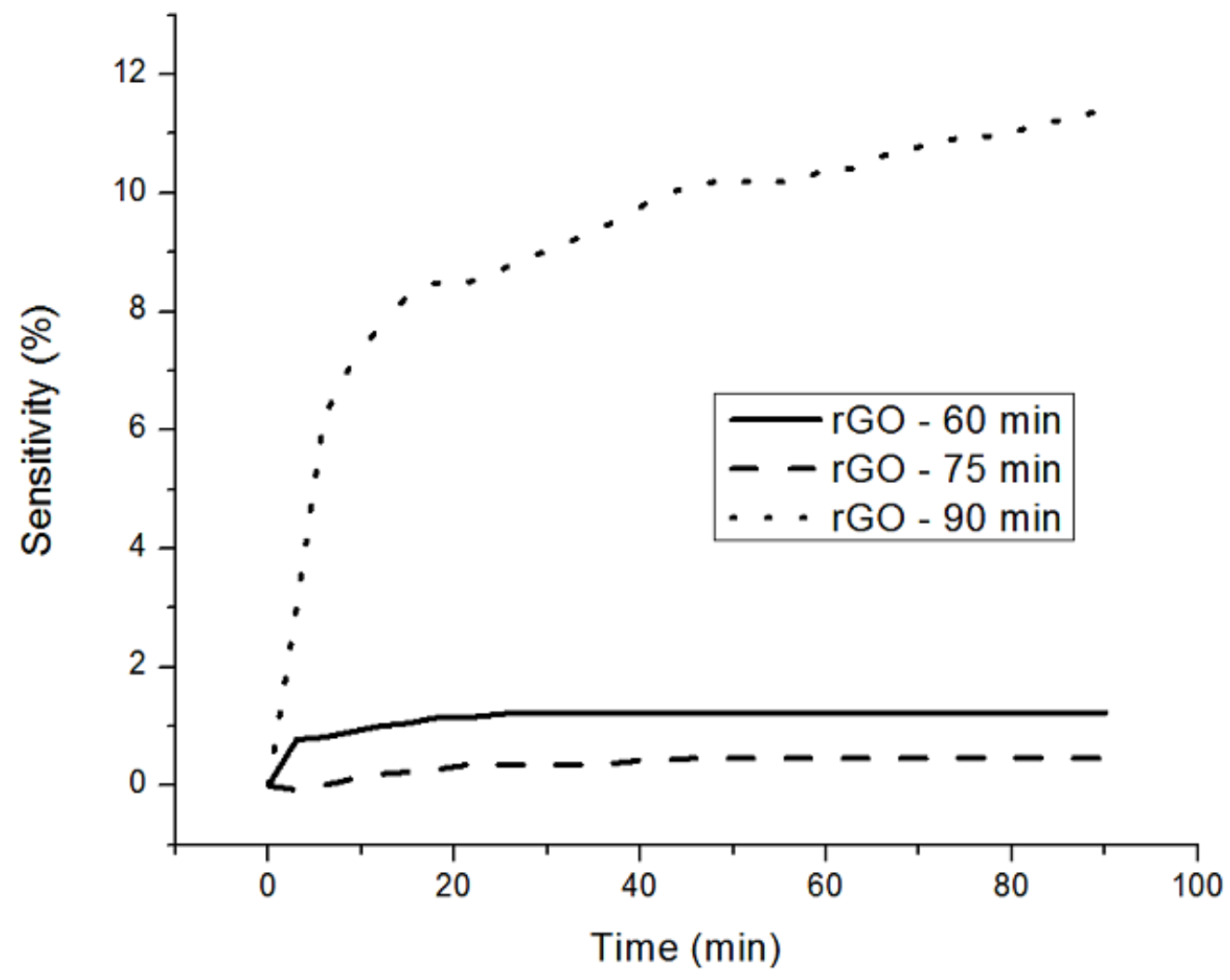

Figura 4.23: Medidas sensibilidade versus tempo dos sensores de condição de contorno curto-circuito para álcool isopropílico.

Tabela 4.3: Resultados Medidas GIS curto-circuito

\begin{tabular}{l|ccc|ccc|}
\hline \hline & Isopropílico $60 \mathrm{~min}$ & $75 \mathrm{~min}$ & $90 \mathrm{~min}$ & Etanol $60 \mathrm{~min}$ & $75 \mathrm{~min}$ & $90 \mathrm{~min}$ \\
\hline Sensibilidade & $1,23 \%$ & $0,46 \%$ & $11,41 \%$ & $1,65 \%$ & $0,80 \%$ & $10,85 \%$ \\
\hline
\end{tabular}

irradiação - ou seja, a RCS equivalente - e parâmetros da antena como ganho e coeficiente de reflexão tem como objetivo fundamentar o projeto realizado. Esta abordagem é comum na literatura, como por exemplo em [1]. 


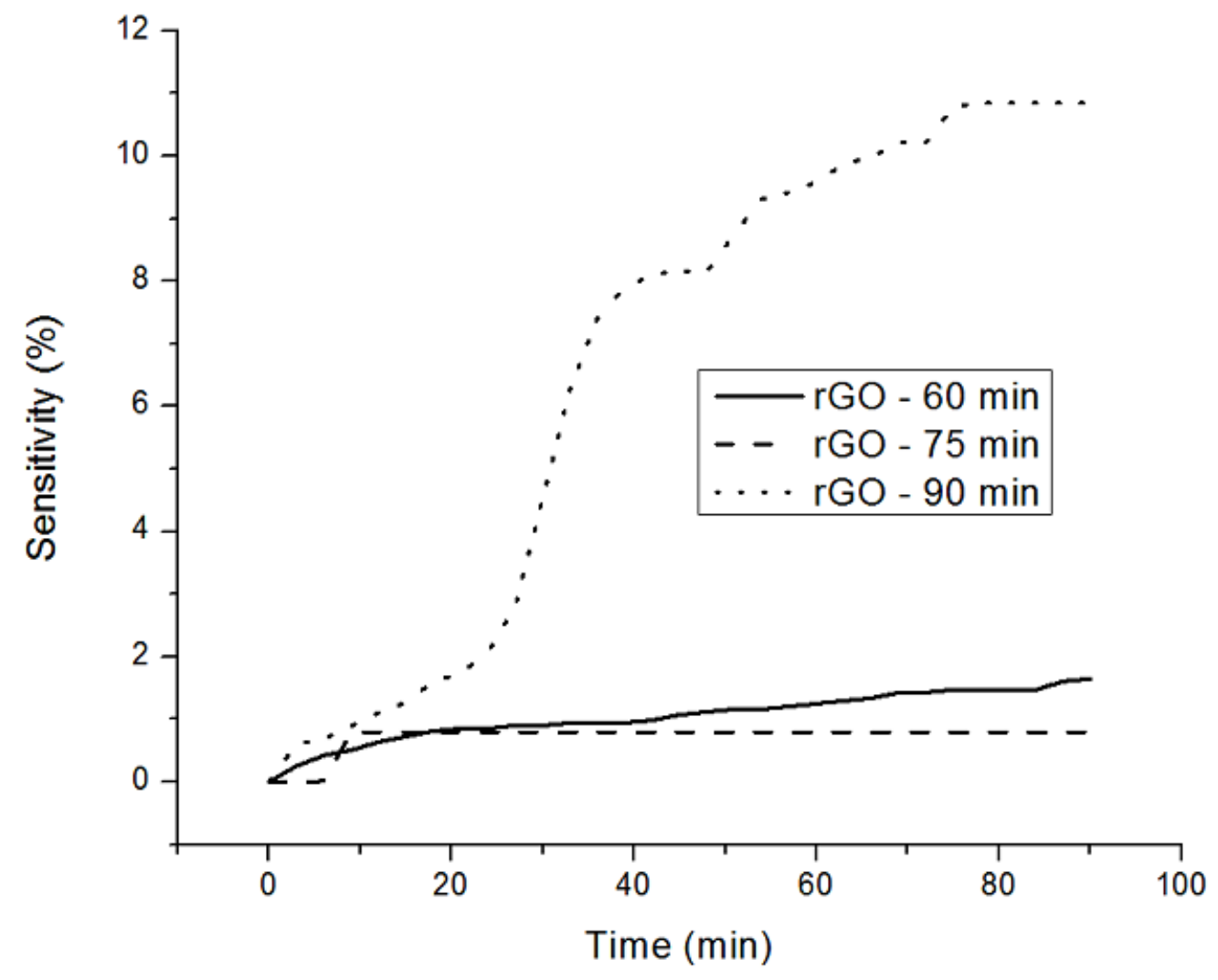

Figura 4.24: Medidas sensibilidade versus tempo dos sensores de condição de contorno curto para etanol.

Tabela 4.4: Medidas de resistividade OGr

\begin{tabular}{c|c|c|c}
\hline \hline & OGr 60 min & 75 min & $90 \mathrm{~min}$ \\
\hline \hline$\rho(\Omega . \mathrm{cm})$ & 140 & 40 & 29,5 \\
\hline \hline
\end{tabular}




\section{5}

\section{Conclusão e Trabalhos Futuros}

Neste trabalho foram propostas antenas-sensor utilizando estruturas baseadas em grafeno para detecção sem fio de vapor de álcool. A primeira parte do projeto - efetuado utilizando uma abordagem mais empírica que puramente teórica - demonstrou que ao contrário dos casos de sensores resistivos, que operam bem em diversas faixas de resistividade, a topologia empregada demanda um projeto mais diligente em relação à resistividade da folha de OGr, sendo que o sensor responde apenas para uma determinada faixa de valores de resistividade. Desta forma, o controle foi efetuado através de um estudo da resistividade em função do tempo e temperatura de redução das amostras de OG. Nesta primeira fase, provas de conceito de sensores com sensibilidades de até 8,96\% são obtidos para detecção de etanol.

Na segunda parte do trabalho foi proposta uma metodologia para projeto das antenas utilizadas como sensor. A teoria de MTMs ali aplicada foi detalhada através da teoria e simulações, e os passos efetuados no Capítulo 3 foram retomados para as novas estruturas. A caracterização das amostras de OG e OGr foi efetuada não apenas em termos de resistividade, mas também foram performadas espectroscopia Raman e de fotoelétrons por raio x (XPS), de forma a angariar maior intuição sobre o comportamento das estruturas. O espectro Raman prova que as amostras efetivamente apresentam características de OG e OGr. Os resultados XPS mostram que de fato há restauração das ligações $\mathrm{C}=\mathrm{C}$ em detrimento dos grupos funcionais do $\mathrm{OG}$, explicando o aumento da condutividade com o tempo de redução para uma mesma temperatura. Provas de conceito de sensores sem fio são efetuadas e sensibilidades de até $10,85 \%$ são obtidos para detecção de etanol de até 11,41\% para álcool isopropílico para as amostras reduzidas por 90 min à $200{ }^{\circ} \mathrm{C}$. Embora as medidas não tenham sido efetuadas sem fio, devido a limitações estruturais do laboratório, a teoria que relaciona as características de re-irradiação com parâmetros da antena foi amplamente discutida, de forma a fundamentar o que foi exposto.

Sugestões de trabalhos futuros:

- Através da funcionalização das estruturas de OG e OGr é possível melhorar características de sensoriamento como tempo de resposta, 
seletividade, sensibilidade entre outros [17]. Assim, sugere-se a utilização de nanopartículas de ouro para funcionalização de OGr, de forma a reduzir os tempos de resposta dos sensores implementados, considerados impráticos para diversas aplicações reais, embora válidos para a prova de conceito aqui proposta.

- Demonstrada a viabilidade do sensor sem fio baseado em OG/OGr, é importante estudar sua implementação em substratos orgânicos, flexíveis e de baixo custo, como por exemplo PET e outros polímeros, papel, entre outros, já que o custo pode ser reduzido ainda mais neste tipo de material. Além disso, aplicações orgânicas são facilmente conformáveis em objetos na qual a tag deve ser alocada, são biodegradáveis, compatíveis com eletrônica impressa, etc, todas características relevantes para a aplicação massiva e ubíqua deste tipo de sistema.

- Desenvolvimento de um setup seguro para detecção de gases nocivos ${ }^{1}$. Este tipo de estrutura pode encontrar diversas aplicações em segurança, como por exemplo para implementação de sistemas RFID sem chip para detecção de amônia em um conjunto de câmaras frigoríficas, controle da qualidade do ar à distância para aplicações médicas, entre muitas outras.

Em resumo, as possibilidades para sequência do trabalho são imensas. Entretanto, acredita-se ter dado um passo importante, em conjunto com professores, colegas e laboratórios parceiros, para iniciar no CETUC uma linha de pesquisa em sensores baseados em RFID sem chip e metamateriais, focando sempre nas demandas da sociedade para a implementação das novas tecnologias de comunicações sem fio.

\footnotetext{
${ }^{1}$ Usualmente, câmaras utilizadas neste tipo de medida são metálicas de forma a aumentar a robustez mecânica, porém esta abordagem não funciona bem para medidas eletromagnéticas, sendo que a câmara acaba operando como uma gaiola de Faraday.
} 


\section{Referências bibliográficas}

[1] MARROCCO, G.. The art of uhf rfid antenna design: Impedancematching and size-reduction techniques. IEEE antennas and propagation magazine, 50(1), 2008.

[2] VIRTANEN, J.; VIRKKI, J.; UKKONEN, L. ; SYD, L.. Inkjet-printed uhf rfid tags on renewable materials. 2012.

[3] PERRET, E.. Radio Frequency Identification and Sensors: From RFID to Chipless RFID. John Wiley \& Sons, 2014.

[4] IDTECHEX; HARROP, P. ; DAS, R.. RFID Forecasts, Players and Opportunities 2014-2024. IDTechEx, 2014.

[5] TEDJINI, S.; KARMAKAR, N.; PERRET, E.; VENA, A.; KOSWATTA, R.; RUBAYET, E. ; OTHERS. Hold the chips: Chipless technology, an alternative technique for rfid. IEEE Microwave Magazine, 14(5):56-65, 2013.

[6] AMIn, E. M.; KARMAKAR, N. C. ; WInTher-JEnSEN, B.. Polyvinylalcohol (pva)-based rf humidity sensor in microwave frequency. Progress In Electromagnetics Research B, 54:149-166, 2013.

[7] AMENDOLA, S.; LODATO, R.; MANZARI, S.; OCCHIUZZI, C. ; MARROCCO, G.. Rfid technology for iot-based personal healthcare in smart spaces. IEEE Internet of Things Journal, 1(2):144-152, 2014.

[8] DONG, Y.; ITOH, T.. Metamaterial-based antennas. Proceedings of the IEEE, 100(7):2271-2285, 2012.

[9] CHEN, T.; LI, S. ; SUN, H.. Metamaterials application in sensing. Sensors, 12(3):2742-2765, 2012.

[10] NETO, A. C.; GUINEA, F.; PERES, N. M.; NOVOSELOV, K. S. ; GEIM, A. K.. The electronic properties of graphene. Reviews of modern physics, 81(1):109, 2009.

[11] NOVOSELOV, K. S.; GEIM, A. K.; MOROZOV, S. V.; JIANG, D.; ZHANG, Y.; DUBONOS, S. V.; GRIGORIEVA, I. V. ; FIRSOV, A. A.. Electric field 
effect in atomically thin carbon films. science, 306(5696):666-669, 2004.

[12] SHAO, Y.; ZHANG, S.; ENGELHARD, M. H.; LI, G.; SHAO, G.; WANG, Y.; LIU, J.; AKSAY, I. A. ; LIN, Y.. Nitrogen-doped graphene and its electrochemical applications. Journal of Materials Chemistry, 20(35):74917496, 2010.

[13] HUANG, B.; LI, Z.; LIU, Z.; ZHOU, G.; HAO, S.; WU, J.; GU, B.-L. ; DUAN, W.. Adsorption of gas molecules on graphene nanoribbons and its implication for nanoscale molecule sensor. The Journal of Physical Chemistry C, 112(35):13442-13446, 2008.

[14] LeEnAerTS, O.; PARTOENS, B. ; PEETERS, F.. Adsorption of h2o, nh3, co, no2, and no on graphene: A first-principles study. Physical Review B, 77(12):125416, 2008.

[15] KPMG. Second report of the 13th five-year plan report series, 2016. [Disponível online; acessado em 3 de fevereiro de 2017].

[16] ZHAO, J.; LIU, L. ; LI, F.. Graphene oxide: physics and applications. Springer, 2015.

[17] WANG, T.; HUANG, D.; YANG, Z.; XU, S.; HE, G.; LI, X.; HU, N.; YIN, G.; HE, D. ; ZHANG, L.. A review on graphene-based gas/vapor sensors with unique properties and potential applications. NanoMicro Letters, 8(2):95-119, 2016.

[18] BALANIS, C. A.. Antenna theory: analysis and design. John Wiley \& Sons, 2016.

[19] STUTZMAN, W. L.; DAVIS, W. A.. Antenna theory. Wiley Encyclopedia of Electrical and Electronics Engineering, 1998.

[20] KNOTT, E. F.. Radar cross section measurements. Springer Science \& Business Media, 2012.

[21] BALANIS, C. A.. Advanced engineering electromagnetics. John Wiley \& Sons, 2012.

[22] NIKITIN, P. V.; RAO, K. S.. Theory and measurement of backscattering from rfid tags. IEEE Antennas and Propagation Magazine, 48(6):212-218, 2006. 
[23] WANG, W.; GONG, S.; WANG, X.; GUAN, Y. ; JIANG, W.. Differential evolution algorithm and method of moments for the design of low-rcs antenna. IEEE Antennas and Wireless Propagation Letters, 9:295298, 2010.

[24] CALOZ, C.; ITOH, T.. Electromagnetic metamaterials: transmission line theory and microwave applications. John Wiley \& Sons, 2005.

[25] VESELAGO, V. G.. The electrodynamics of substances with simultaneously negative values of and $\mu$. Soviet physics uspekhi, 10(4):509, 1968.

[26] UDDIN, M. J.; ULLAH, M. H.. The effective periodic homogeneous metamaterials for infinite complementary dielectric slab characteristics. International Journal of Applied Electromagnetics and Mechanics, 50(2):255-262, 2016.

[27] DONG, Y.. Substrate integrated waveguide based metamaterial components and novel miniaturized planar antennas. 2012.

[28] DINESH, R.; VINOD, V.; DEEPAK, U.; VINESH, P. ; MOHANAN, P.. Cpwfed zeroth-order resonator antenna using shorted crlh transmission line. Microwave and Optical Technology Letters, 55(12):2844-2847, 2013.

[29] BOZZI, M.; GEORGIADIS, A. ; WU, K.. Review of substrateintegrated waveguide circuits and antennas. IET Microwaves, Antennas \& Propagation, 5(8):909-920, 2011.

[30] DONG, Y.; ITOH, T.. Miniaturized substrate integrated waveguide slot antennas based on negative order resonance. IEEE transactions on antennas and propagation, 58(12):3856-3864, 2010.

[31] RAY, S.. Applications of graphene and graphene-oxide based nanomaterials. William Andrew, 2015.

[34] CHEN, J.; YAO, B.; LI, C. ; SHI, G.. An improved hummers method for eco-friendly synthesis of graphene oxide. Carbon, 64:225-229, 2013.

[35] FERRARI, A. C.. Raman spectroscopy of graphene and graphite: disorder, electron-phonon coupling, doping and nonadiabatic effects. Solid state communications, 143(1):47-57, 2007. 
[36] PATIL, G. P.; BAGAL, V. S.; MAHAJAN, C. R.; CHAUDHARI, V. R.; SURYAWANSHI, S. R.; MORE, M. A. ; CHAVAN, P. G.. Observation of low turn-on field emission from nanocomposites of go/tio 2 and rgo/tio 2. Vacuum, 123:167-174, 2016.

[37] DOBKIN, D. M.. The rf in RFID: uhf RFID in practice. Newnes, 2012.

[38] VAN DER PAUW, L.. A method of measuring specific resistivity and hall effect of discs of arbitrary shape. Philips Res. Rep, 13:1-9, 1958.

[39] BRIGGS, D.; SEAH, M. ; BUBERT, H.. Practical surface analysis. vol. 1: Auger and x-ray photoelectron spectroscopy. Angewandte Chemie-German Edition, 107(11):1367-1367, 1995. 